\title{
Icing Analysis of a Swept NACA 0012 Wing Using LEWICE3D Version 3.48
}

\author{
Colin S. Bidwell ${ }^{1}$ \\ NASA Glenn Research Center, Cleveland, OH, 44135
}

\begin{abstract}
Icing calculations were performed for a NACA 0012 swept wing tip using LEWICE3D Version 3.48 coupled with the ANSYS CFX flow solver. The calculated ice shapes were compared to experimental data generated in the NASA Glenn Icing Research Tunnel (IRT). The IRT tests were designed to test the performance of the LEWICE3D ice void density model which was developed to improve the prediction of swept wing ice shapes. Icing tests were performed for a range of temperatures at two different droplet inertia parameters and two different sweep angles. The predicted mass agreed well with the experiment with an average difference of $12 \%$. The LEWICE3D ice void density model under-predicted void density by an average of $30 \%$ for the large inertia parameter cases and by $63 \%$ for the small inertia parameter cases. This under-prediction in void density resulted in an over-prediction of ice area by an average of $115 \%$. The LEWICE3D ice void density model produced a larger average area difference with experiment than the standard LEWICE density model, which doesn't account for the voids in the swept wing ice shape, $(115 \%$ and $75 \%$ respectively) but it produced ice shapes which were deemed more appropriate because they were conservative (larger than experiment). Major contributors to the overly conservative ice shape predictions were deficiencies in the leading edge heat transfer and the sensitivity of the void ice density model to the particle inertia parameter. The scallop features present on the ice shapes were thought to generate interstitial flow and horse shoe vortices which enhance the leading edge heat transfer. A set of changes to improve the leading edge heat transfer and the void density model were tested. The changes improved the ice shape predictions considerably. More work needs to be done to evaluate the performance of these modifications for a wider range of geometries and icing conditions.
\end{abstract}

\section{Nomenclature}

$\begin{array}{ll}\text { AOA } & =\text { angle-of-attack } \\ \mathrm{C} & =\text { chord length, } \mathrm{m} \\ d & =\text { particle diameter, } \mathrm{m} \\ \mathrm{ds} & =\text { surface wrap distance, } \mathrm{m} \\ \mathrm{LWC} & =\text { liquid water content, } \mathrm{g} / \mathrm{m}^{3} \\ \mathrm{MVD} & =\text { median volume diameter, } \mu \mathrm{m} \\ \mathrm{K} & =\text { inertia parameter, }\left(\rho_{p} V_{\infty} d^{2} /(18 \mu C)\right) \\ \mathrm{K}_{\mathrm{r}} & =\text { Roughness size, } \mathrm{m} \\ \mathrm{R}_{\mathrm{C}} & =\text { surface radius of curvature, } \mathrm{m} \\ \mathrm{S} & =\text { surface wrap distance from highlight, } \mathrm{m} \\ \mathrm{SLD} & =\text { super cooled large drop }\end{array}$

${ }^{1}$ Aerospace Engineer, Icing Branch, 21000 Brookpark Rd, Cleveland, OH 44135, MS 11-2, AIAA Member 


$\begin{array}{ll}u_{*} & =\text { friction velocity, } \mathrm{m} / \mathrm{s} \\ V_{\infty} & =\text { free stream airspeed, } \mathrm{m} / \mathrm{s} \\ \mathrm{XKR} & =\text { roughness ratio, } \mathrm{K}_{\mathrm{r}} / \mathrm{R}_{\mathrm{c}} \\ \mathrm{y} & =\text { wall normal distance, } \mathrm{m} \\ \mathrm{y}^{+} & =\text {non-dimensional wall distance, }\left(u_{*} y / v\right)\end{array}$

\section{Greek Letters}

$\begin{array}{ll}\beta & =\text { collection Efficiency } \\ \mu & =\text { air viscosity, } \mathrm{kg} /(\mathrm{ms}) \\ \rho_{i} & =\text { standard LEWICE ice density, } \mathrm{kg} / \mathrm{m}^{3} \\ \rho_{p} & =\text { particle density, } \mathrm{kg} / \mathrm{m}^{3} \\ \rho_{V} & =\text { void ice density, } \mathrm{kg} / \mathrm{m}^{3} \\ v & =\text { kinematic viscosity, } \mathrm{m}^{2} / \mathrm{s} \\ \theta & =\text { particle impact angle, degrees }\end{array}$

\section{Introduction}

Swept wing ice accretions are particularly challenging to the modeling community. Standard ice density models which use densities varying from $800-1000 \mathrm{~kg} / \mathrm{m}^{3}$ are inadequate for swept wing icing analysis and can result in under predictions of the ice shape area by as much as $92 \%$. The "scallop" or "lobster-tail" type ice accretions have large voids and complex features. The capability to resolve and compute these features on large scale geometries does not exist. For this reason a computationally efficient void density model was developed at NASA Glenn to better predict the outer mold lines of an ice shape which are thought to best represent the aerodynamic characteristics of the ice shape. The void density is the ice density that is required to generate the outer mold lines of the scallop ice shape from the predicted ice mass. The void density model allows the prediction of a representative ice shape without the computational burden of resolving and computing the complex features of the scallop ice shape.

The work entailed in this paper is an attempt to evaluate the LEWICE3D ${ }^{1}$ swept wing ice density model for a set of limiting conditions. The LEWICE3D swept wing ice density model is based on particle impact angle, surface roughness and freezing fraction ${ }^{2}$. The void fractions are known to increase with sweep. It is also known that the void fractions reach a maximum somewhere in the mixed to glaze icing regime. At rime temperatures and high glaze conditions the large voids disappear and the ice structures mimic those seen in un-swept conditions. The experiment employed a temperature sweep to determine the maximum void fraction for a large and a small droplet inertia parameter setting while maintaining the same water catch. The droplet size, airspeed and liquid water content (LWC) were chosen to generate the maximum change in inertia parameter and hence particle impact angle while still maintaining a similar size.

\section{Experiment}

\section{A. Experimental Apparatus}

The ice accretion tests were carried out in the NASA Glenn IRT. The test equipment included the IRT, the NASA Glenn ESCORT data system ${ }^{3}$, and the NACA 0012 swept wing tip (Fig. 1).

The IRT facility ${ }^{3}$ can provide a range of airspeeds, angles-of-attack, temperatures, LWC, and drop sizes. The IRT has a $2.47 \mathrm{~m}$ x $1.82 \mathrm{~m}$ test section with a maximum airspeed of $134 \mathrm{~m} / \mathrm{s}$ with an empty tunnel. Angle-of-attack is controlled by a movable turntable to which the models are mounted. A refrigeration system allows year-round testing at temperatures from $-29^{\circ} \mathrm{C}$ to $10^{\circ} \mathrm{C}$. The spray system located upstream of the test section can provide a cloud with a range of LWC of $0.25-3.0 \mathrm{~g} / \mathrm{m}^{3}$ and a median volumetric droplet diameter (MVD) size range of 12$200 \mu \mathrm{m}$.

The IRT swept wing model was a partial span wing tip based on a NACA 0012 section profile (Fig. 1). The model had a removable inboard section which allowed the wing to be set at $0^{\circ}, 30^{\circ}$ and $45^{\circ}$ degree sweep. The $45^{\circ}$ swept wing model had a chord of 0.9228 meters and a span of 1.03 meters. The $30^{\circ}$ swept wing model had a chord of 0.9228 meters and a span of 1.14 meters. 


\section{B. Experimental Testing}

The data taken during the icing tests included surface pressure, tunnel flow and spray conditions, ice shape photographs, tracings, wax molds and in some cases castings.

The ESCORT system was used to record surface pressure measurements and tunnel flow and spray conditions. The surface pressure measurements were used to set a zero angle-of-attack for the model and to provide validation data for flow solvers.

The photographs and ice shape tracings were used along with the wax molds and castings to document the ice shapes.

A typical test point involved several steps. The operators first adjusted the tunnel fan and heat exchanger settings to produce a stable test point. The IRT spray system was then adjusted to produce the requested drop size and LWC. The spray system was then activated for the requested time after which the tunnel was brought down to zero speed so the personnel could enter the test section to make the appropriate measurements. Photographs and ice shape tracings normal to the leading edge were taken at two span-wise locations $20 \mathrm{~cm}$ apart. The leading edge was then removed to aid in the wax mold and casting processes (Fig. 2). The wing leading edge was then mounted on a horizontal table at which point steam was channeled through a hole bored in the leading edge to aid in removing the ice. After the ice shape was removed from the leading edge it was carried down to the wax bath where it was dipped multiple times at various angles to fully encase and seal the ice shape in wax (Fig. 2). The wax encased ice shapes were then weighed as part of the ice density measurements. The personnel then returned to the control room and prepared for the next test point.

The ice shape density measurements involved measuring the mass and length of ice contained in the wax molds and the area of the ice shape tracings (Fig. 3). The results for ice shape void density and ice mass are documented in Tables 1 and 2. The mass of ice was generated by either weighing the ice shape directly or by subtracting the weight of the empty molds from the weight of the wax molds with the trapped water from the ice shape. The ice removal process resulted in some mass loss because feathers and any ice that was not part of the main ice shape were lost during the heating process used to remove the ice shape from the wing leading edge. An attempt was made to measure the mass loss for case AF2146 (Table 2). For this case the ice shape mass was $289.0 \mathrm{~g}$ and the feather mass was $29.5 \mathrm{~g}$ yielding a 10\% mass loss. The wax mold length (Fig. 3a) and ice shape tracing area (Fig. 3d) were used to calculate the volume of the ice shape used in the void density calculation. The ice shape tracings were trimmed to better reflect the region of the ice shape which was contained in the mold (Fig. 3c). The larger of the ice shape areas of the two ice shape tracings taken for each test point was used in the density calculation (Fig. 3d). The larger ice shape area was chosen to better represent the bounding or maximum ice shape although there was no guarantee that this was the best representation.

To generate a more consistent comparison of experimental and analytical ice mass the experimental ice mass was corrected to account for the missing mass in the feathers (Fig. 3c). This was accomplished by multiplying the experimental mass by the ratio of the ice shape tracing area to the ice shape tracing area without the feathers. The results of the corrected and uncorrected mass are shown in Tables 1 and 2. The average correction was 9\% while the maximum was $28 \%$. The largest correction occurred for case AF1789 which was a small rime shape with a large number of feathers aft of the main ice shape.

\section{Analytical Method}

The ANSYS 13 Mesh tool and CFX flow solver ${ }^{4}$ were used to generate the 3D unstructured grid based flow solutions and the LEWICE3D software was used to generate the ice shapes.

\section{A. ANSYS Mesh}

The ANSYS 13 package contains several meshing methods to handle various configurations. The meshing methods include patch conforming and patch independent tetrahedral, sweep, multi-zone, hex dominant, automatic and cut cell. The automatic method which combines the sweep method and the tetrahedral patch conforming methods was used to generate the mixed element grids used in this study.

\section{B. ANSYS CFX}

The ANSYS CFX flow solver is a 3D compressible, unstructured, Reynolds Averaged Navier-Stokes flow solver $^{5-6}$. The solver is a mixed element, vertex based, finite volume based flow solver. The parallel solver, which can solve steady or unsteady cases, employs local time stepping to aid in convergence. 


\section{LEWICE3D Version 3.48}

The LEWICE3D grid based code incorporates droplet trajectory, heat transfer and ice shape calculation into a single computer program ${ }^{1}$. The code can handle generic multi-block structured grid based flow solutions, unstructured grid based flow solutions, simple cartesian grids with surface patches, and adaptive grids with surface patches. The latter two methods allow the use of generic panel code input which, when combined with LEWICE3D, is a computationally efficient method for generating ice shapes. The code can handle overlapping and internal grids and can handle multiple planes of symmetry. Calculations of arbitrary streamlines and trajectories are possible. The code has the capability to calculate tangent trajectories and impingement efficiencies for single droplets or droplet distributions using a standard area-based collection efficiency method or a parcel based method. Ice accretions can be calculated at arbitrary regions of interest in either a surface normal or tangent droplet trajectory direction. The program can run on a variety of single processor and parallel computers, including Unix, Linux and Windows.

Version 3.48 of the LEWICE3D software, which incorporates several new features, was used for the analysis. These features include a new particle splash and bounce algorithm, a new geometry handling scheme which allows complex mirroring, transformation and relative motion of input grid blocks and a new algorithm which calculates block to block collection efficiencies. The code also incorporates a new injection plane scheme which allows the insertion of water based particles at multiple locations and states in the flow. These new additions enable users to analyze super-cooled large drop (SLD) conditions ${ }^{7}$ and to calculate collection efficiency with particle splash and bounce effects through turbo-machinery.

The LEWICE3D void density model used to predict ice density for scallop ice shapes is based on the concept that the roughness elements generate shadowing by particles impacting the surface at shallow angles which results in voids (Fig. 4, Eq. (1)). A geometric analysis of the relative voids and ice regions as depicted in Fig. 4 result in the equation for void density (Eq. (1)). To generate a void density at a given location the model uses a weighting of the minimum void density and the standard LEWICE3D density based on freezing fraction (Fig. 5). The weighting factor is set by a correlation which was generated to match a set of experimental data. In summary, the minimum density for a void density curve is set by a math model and the functional relationship with freezing fraction is set by a correlation based on experimental data. Additionally the local values are mass averaged to generate a single void density for the ice shape.

$$
\rho_{V}=\frac{\rho_{i}}{\left(\frac{d s}{K_{r}}+1\right)}
$$

There are seven basic steps involved in generating a strip based ice shape using the LEWICE3D software. First, a grid and flow solution is generated for the body. As the LEWICE3D software does not incorporate a grid or flow solver these must be provided. Second, collection efficiency is calculated for the region-of-interest using a Lagrangian based particle trajectory method. Third, a surface streamline or cut is generated at the region-of-interest. Fourth, collection efficiencies are interpolated onto the surface streamline or cut. In the fifth step an integral boundary layer method which incorporates roughness and transition effects is used to determine the heat transfer coefficients along the surface streamline or cut. In the sixth step a Messenger based control volume approach is used to calculate the ice thickness along the surface streamline or cut. The method employs a quasi-steady control volume based marching scheme which starts at the stagnation line or point and moves aft. Any water that has not frozen at a control volume is assumed to move aft into the next control volume. The ice mass generated at a control volume is determined from the available water and convective heat transfer using mass and energy balances. Evaporation is considered as part of this step. The ice thickness for the control volume is calculated from the ice mass, ice density and the length of the control volume. In the seventh and final step the ice shape coordinates are generated by adding the ice thickness to the surface coordinates in the surface normal direction.

\section{Configuration}

The swept NACA 0012 flow solutions were generated using the CFX flow solver. The isolated wing models employed a plane of symmetry at the wing root. The viscous, compressible flow solutions were generated at an aircraft-angle-of-attack of $0^{\circ}$. A normal wall spacing of $3.8 \times 10^{-6} \mathrm{~m}$ was used for the viscous grids which corresponds to a $\mathrm{y}^{+}=1$ spacing at a Reynolds number of 7.2 million and a reference length of $1 \mathrm{~m}$. The volume grid for the $45^{\circ}$ swept model contained 5,640,314 volume elements and 1,520,916 nodes. The grid and surface models for the $45^{\circ}$ swept flow model are shown in Fig. 6. The volume grid for the $30^{\circ}$ swept model contained 6,093,024 volume elements and 1,653,950 nodes. The grid and surface models for the $30^{\circ}$ swept flow model are shown in Fig. 7. 


\section{Analysis}

The results from the calculated collection efficiency, heat transfer and the ice shape comparisons will be discussed for the Swept NACA 0012 wing.

Figures 8-9 show the calculated collection efficiency distributions for the swept wing. In the figure the distributions have been plotted as a function of wrap distance, $\mathrm{s}$, from the highlight (minimum $\mathrm{x}$ location on the wing cut) of the wing. From the figure we can see that the larger inertia parameter (0.378) conditions generated a greater amount and extent of impingement than the smaller inertia parameter (0.036) conditions. The inertia parameter which increases with drop size and speed is a non-dimensional measure of the relaxation time of a particle. That is the time it takes a particle velocity to relax to the flow velocity. A particle with a smaller inertia parameter adapts to the flow more quickly than a particle with a larger inertia parameter. Particles which are more resistant to changes in velocity are less apt to avoid obstacles in their path and hence generate higher collection efficiencies. The calculations also show that as sweep angle increases the collection efficiency decreases for the same particle size and free stream speed.

The predicted heat transfer coefficient distributions for the wing are shown in Fig. 10-11. The comparisons show that the heat transfer coefficients increase with speed for both models. The calculations also show that the heat transfer coefficients decrease with increased sweep angle at the same speed. This sweep effect is caused by a reduction in the chord-wise velocity with increased sweep angle.

The ice shape comparisons for the swept wing are shown in Fig. 12-15. Figures 12-15 depict a temperature progression from cold to warm which spans the rime to glaze regimes.

The mass accretion results for the ice accretions are shown in Tables 1 and 2. The experimental results for the temperature sweeps show that that the mass does not vary a large amount from the average $(<15 \%)$ except for run AF1792 (30\%). We can see from Table 1 and Fig. 12e that run AF1792 produced the largest ice shape for the $45^{\circ}$ swept, small inertia parameter temperature sweep and that it was a scallop ice shape. The large difference from the mean accretion mass for case AF1792 indicates that the collection efficiency and heat transfer varied significantly throughout the icing event due to the magnitude of the shape change. The LEWICE3D predictions show very little variation in accreted mass for the temperature sweep data $(<5 \%)$. The average difference between the experimental and predicted ice mass was $12 \%$ while the maximum difference was $33 \%$. There was no clear trend in the mass accretion comparisons. In some cases the mass was over-predicted and in others it was under-predicted. The large scallop shapes produced the largest differences in ice mass and for these cases there was an under-prediction of mass. The poor performance in the prediction of ice mass for these cases is probably due to the single time step approach used in LEWICE3D which assumes constant collection efficiency and heat transfer throughout the accretion. The LEWICE3D software does have a mass correction to improve performance for the single time step predictions which is based on a correlation with multi-time stepping LEWICE for a set of 2D ice accretions ${ }^{2}$ but apparently this correction was not sufficient for the largest scallop shapes.

Table 1-2 and Fig. 16-17 summarize the results for the void density comparisons. From Fig. 16-17 one can see that on average the void density decreases with increased sweep angle. In all cases, the experimental void density for the swept ice shapes is significantly less than the ice density predicted using the standard LEWICE density model. This can be seen in the ice shape comparisons where the standard LEWICE density model produces a severe underprediction in ice shape size. The experimental results in Fig. 16-17 show a depression in the void density data at 263 $\mathrm{K}$ for the large inertia parameter cases and at approximately $265 \mathrm{~K}$ for the small inertia parameter cases. This depression occurs where the scallop ice shapes have the largest iced area. The LEWICE3D void density model was designed to mimic this behavior. From Fig. 16-17 we can see that the LEWICE3D void density model underpredicts void density for all cases. The average under-prediction was $46 \%$ while the maximum under-prediction was $67 \%$. From a conservative standpoint (i.e. analytical ice shape larger than experimental ice shape) this is much better than the standard LEWICE density model for which there was an average over-prediction of $129 \%$ and a maximum over-prediction of 224\%. The analytical model fared better for the large inertia parameter cases than for the small inertia parameter cases with average differences of $30 \%$ and $63 \%$ respectively. The analytical model showed a larger change in void density with inertia parameter than the experimental data. The experimental data also showed a cross over in the void density curves for the small and large inertia parameter data at lower and higher temperatures which is not produced in the analytical model. This could be due to the sparse nature of the experimental data, experimental measurement error or a modeling deficiency. The inertia parameter affects the analytical void density model through the droplet impact angle. The void density increases with impact angle in the LEWICE3D void density model (Fig. 5). An increase in sweep angle or a decrease in inertia parameter increases the impact angle and 
decreases the void density. From the comparisons it can be seen that the depression in the void density occurs at a higher temperature than for the experimental data. The LEWICE3D model predicts the minimum void density for a given impact angle, roughness size and surface radius of curvature using a simple math model. The model was tuned to a limited set of data for which there were very few points towards the rime end of the regime. The data set used to develop the void density correlation consisted of ice shape tracings. The data set included no ice mass or density information making it difficult to develop an accurate model.

It should also be noted that the local freezing fraction, which is used in the void density model, is based on the local heat transfer coefficient. If the heat transfer coefficient prediction was not accurate in either the development of the original correlation or in the subsequent use of the correlation then the void density depression will occur at the wrong location. The heat transfer coefficient used in LEWICE3D is based on an integral boundary layer method which uses a roughness parameter to incorporate the effect of roughness on transition and enhancement of heat transfer. The roughness parameter correlation used in the LEWICE3D is dependent upon temperature, LWC, radius of curvature and velocity. The correlation was developed for 2D ice accretion codes to improve agreement between predicted and measured ice shapes for a range of $2 \mathrm{D}$ wings and icing conditions ${ }^{8}$. It is obvious from the ice shape images that the swept accretions have 3D structures that do not exist in the 2D ice shapes or that are represented in the roughness model.

An example of the effect of inaccurate heat transfer prediction on the void density prediction can be inferred from the temperature series for the small inertia parameter, $45^{\circ}$ swept wing (Fig. 12a-c). The LEWICE3D model predicts a freezing fraction at the leading edge which is much less than one (0.8) for the lowest temperature tested ( $257 \mathrm{~K}$ ) indicating a mixed shape or glaze shape. From the pictures of the ice shape in Fig. 12a it is obvious that this shape is a rime shape. The ice shape is feathery and opaque at the leading edge. It is also noteworthy that there is very little change between the experimental shapes for the $257 \mathrm{~K}$ and $259 \mathrm{~K}$ test points (Fig. 12a and 12b respectively) which is another indication that the ice shape has converged at the lower temperatures to a rime shape. Figure 16 shows a plot of the measured and predicted void fractions as a function of temperature for the $45^{\circ}$ swept wing. From this figure it can be inferred that at the colder temperatures the LEWICE3D density model would give a reasonable value for void density for the small drop case $\left(\sim 370 \mathrm{~g} / \mathrm{m}^{3}\right)$. That is, it would produce a more reasonable void density if the predicted heat transfer were sufficiently increased to produce a freezing fraction of one.

The ice area results for the ice shapes are presented in Tables 1 and 2. The temperature sweep results for the experimental ice area show a peak in the iced area in the temperature range of 262-267 K. From the ice shape images in 12e, 13c, 14c, 15i it can be seen that these are classic scallop ice shapes. The shapes are typified by large void regions and a span-wise distribution of irregular scallop shaped glaze feathers. The scallop shapes occur in the mixed to glaze regime. From Tables 1 and 2 we can see that the predicted leading edge freezing fraction of the largest scallop shapes is in the range of 0.30-0.43.

From the experimental ice shape area results for the temperature series in Tables 1 and 2 one can see that the largest scallop shapes produced a $28-38 \%$ increase in area over the smallest shapes. These large increases in area were produced in a temperature band of approximately $5^{\circ} \mathrm{C}$ for the same icing conditions.

The predicted iced area results are shown in Tables 1 and 2. The results show that the iced area was over predicted for all cases. This is due to an under-prediction in void density. The average difference was $116 \%$ while the maximum difference was 308\%. As for the void density results the predicted ice areas for the large inertia parameter cases were better than for the smaller inertia parameter cases (average difference of 60\% and 163\% respectively). The differences in ice shape area between experiment and prediction were smaller for the standard LEWICE density model than for the LEWICE3D void ice density model (76\% versus 116\% respectively) but the LEWICE3D void density model generated results which were conservative (larger than experiment) while the standard LEWICE density generated ice shapes which were not conservative (smaller than experiment). We can also see that the analytical results do not reach a maximum in iced area the same point as the experimental data. The analytical iced area continues to rise in the neighborhood of the maximum experimental iced area. From Fig. 16-17 we can see that this is because the minimum point in the void density curve for the analytical model occurs at a higher temperature than for the experimental data.

Figure 18 shows a compilation of ice shapes as a function of time for the $30^{\circ}$ swept, large inertia cases. The time series included one for a rime condition, a glaze condition and a large scallop condition. From Table 2 one can deduce that the mass buildup rates are approximately linear for the cases where measurements were made. The accumulated mass at 12 minutes was $60-62 \%$ of the 20 minute ice shape mass for all three conditions. The ice shape area results show an approximate linear increase with time for the rime ice shape (23\%, and $63 \%$ for the $25 \%$ and $60 \%$ time steps respectively) and the short icing times ( $\leq 5$ minutes) for the scallop and glaze condition. The 12 minute scallop and glaze conditions showed a reduction over the linear result for the final ice shape (53\% and $45 \%$ respectively). This indicates that the ice shapes for the scallop and glaze condition become less dense with time 
which is also evident from the void densities in Table 2. The reduction in density with time is due to the development of the scallops and their associated voids. We can see from the images in Fig. 15e-15h that in the early stages of development (2 minutes) the ice shape does not appear to have any indication of scalloping (Fig. 15e). At the 5 minute mark (Fig. 15f) the ice shape still appears quite solid but small scallops are visible at the leading edge. At the 12 minute point (Fig. 15g) the scallops appear fully formed but the ice shape is still rather compact. From Fig. 15h we can see that the final scallop ice shape is fully developed with large individual scallops and large voids along the span of the leading edge.

In general the ice shape predictions based on the void density model were conservative if not overly so. The ice shape areas and icing limits were over-predicted for all cases. The main aerodynamic features of horn height and horn angle were also over-predicted for all cases. From a design optimization and software developer standpoint it would be advantageous to increase the fidelity of the model to reduce the conservatism and allow a more optimal design.

From looking at the comparison data for the large and small inertia parameter cases it appears that the greatest improvement in ice shape prediction could be attained by an increase in the stagnation line heat transfer. The comparison of the ice shape predictions to experiment using the experimentally determined void ice density illustrates this point. For all of the non-rime cases the leading edge ice thickness is under-predicted and the icing limit is over-predicted when the experimental void ice density is used in the analytical ice shape prediction. An increase in heat transfer at the stagnation line would increase the mass of ice accreted at the stagnation line and reduce the amount of mass available downstream. LEWICE3D uses an infinite swept wing approach to develop the heat transfer. This methodology involves removing the span-wise component of velocity when calculating the heat transfer coefficient. The span-wise gradients in temperature and pressure are zero for the smooth infinite swept wing which infers that the span-wise velocity does not contribute to the downstream convection of heat. The subtraction of the span-wise component of velocity yields a heat transfer distribution that has a large depression at the stagnation line due to the low velocity and the existence of a small laminar region near the stagnation line. One can increase the roughness parameter to increase heat transfer at the leading edge and this will increase the overall heat transfer and move the transition point further forward but it will not remove the laminar sub-region and the resulting depression in heat transfer at the stagnation line. It is obvious that some mechanism related to the surface roughness or scallop features is enhancing heat transfer at the stagnation line. It must be remembered that the span-wise component of flow is not small for swept wings. The leading edge span-wise component of flow for the $30^{\circ}$ and $45^{\circ}$ swept wing are $50 \%$ and $71 \%$ respectively of the free stream velocity. One explanation for the enhanced leading edge heat transfer could be that horse shoe vortices generated by the span-wise flow over the leading edge roughness elements increases the chord-wise convection of heat. Another reason for the discrepancy in leading edge heat transfer is that the scallop ice shape features become very large and very three dimensional as the ice shape progresses. These features protrude from the surface and in most cases probably create local flow disturbances which enhance heat transfer. It is evident to the author from the ice shape image in Fig. 13b and 19 that there is interstitial scallop flow. The scallops are cupped which results in a stagnation point at the centerline and ice growth much like a 2D glaze ice shape with horns. Typically heat transfer increases with decreased chord which implies that these features, which are much smaller than the airfoil, would result in an enhancement to heat transfer.

A simple method for enhancing the leading edge heat transfer was devised to improve the ice shape predictions for the non-rime conditions. The method involved generating a new value of heat transfer coefficient based on a weighting of the old predicted value with a value derived from an interpolation of the peak heat transfer coefficients on either side of the stagnation line. The heat transfer coefficient distribution between the peak values on either side of the stagnation line was replaced with this new distribution. After several trials a weighting of $80 \%$ on the interpolated peak heat transfer coefficient and $20 \%$ on the old value of heat transfer coefficient was chosen as the best candidate. The comparisons between the proposed enhancement and the original value of heat transfer coefficient are shown in Fig. 20-21 for the swept models.

A more accurate prediction of void density would also improve the ice shape predictions. The results are especially poor for the small inertia parameter cases. One improvement would be to use an impingement based mass averaging instead of one based on free stream mass averaging to generate the average particle impact angle for the droplet distribution. The use of impingement based mass averaging to calculate an impact angle would result in an increase in the average angle because the larger particles impinge in larger quantities than the smaller particles and the larger particles have larger impingement angles. The mass weighting would produce a smaller affect for the larger MVD's than for the smaller MVDs because the change in impact angle with drop sizes decreases with increased drop size. The void densities based on an impingement based mass weighting for the average impact angles are shown in Fig. 16-17. The results show that the void densities changed very little from the old model while those for the small inertia parameter cases increased significantly. 
Ice shapes were generated using the heat transfer coefficient enhancement and the void density model improvement discussed above for several cases. These ice shape comparisons are shown in Fig. 22-25. The predictions are vastly improved. The ice shapes have a better agreement in area, shape and the leading edge ice thickness. The enhanced heat transfer modification also increases the leading edge freezing fraction. The comparisons of void fraction as a function of leading edge freezing fraction are shown in Fig. 26-27. The experimental void fractions versus the LEWICE3D based leading edge fractions and versus the leading edge freezing fractions based on the enhanced leading edge heat transfer model are shown in the figure. The enhanced leading edge heat transfer model generates a shift to the right in the experimental void fraction data due to the higher leading edge freezing fraction it generates. We can see that the shifted data agrees better with the LEWICE3D void fraction model especially at higher freezing fraction and modified inertia parameter. The agreement at lower freezing fraction is still not good but it must be noted that the original data set from which the correlation was developed had very little data in this regime making it difficult to generate an accurate correlation. The better agreement of the shifted void fraction data with the previous void fraction data supports the hypothesis that the leading edge heat transfer is being enhanced by the scallop features. The heat transfer enhancement may be dependent on the model scale as the void fraction correlation was based on LEWICE3D heat transfer distributions without the enhancement. The wing chords used in the development of the original void fraction correlation were two times larger than the swept wings used in this study. From the heat transfer distributions in Fig. 20-21 we can see that the region between the stagnation line and the peak heat transfer is relatively small $(<2 \mathrm{~cm})$. The heat transfer enhancement due to the span-wise flow over the scallop features is probably related to the feature size and to the chord-wise velocity gradient. The increased chord-wise velocity gradients for the smaller chord wing probably generate a higher level of entrainment of higher energy flow than for the larger wings resulting in more heat transfer enhancement than for a larger wing. More testing of the models would be required to evaluate their suitability for a larger range of airfoil sizes, types and icing conditions but the proposed improvements appear to address the observed deficiencies and produce the desired results.

\section{Conclusion}

Ice shape, ice density and iced area comparisons were made between experiment and prediction for a series of icing conditions for a swept NACA 0012 wing tip model to evaluate the LEWICE3D void density model which was developed to predict more accurate ice shapes for swept wings. The tests involved a temperature sweep at two different inertia parameter settings for a $45^{\circ}$ and $30^{\circ}$ swept model to explore the rime through glaze icing regime.

The predicted ice mass agreed well with experiment with an average difference of $12 \%$. The maximum difference of $32 \%$ occurred for a large scallop shape where it appears the multi-time step mass correction in LEWICE3D is inadequate to handle the nonlinearity in the accretion rate.

The LEWICE3D void density model under-predicted the void density by an average of $46 \%$ and by a maximum of $67 \%$. The void density model fared better for the larger inertia parameter cases than for the smaller inertia parameter cases (30\% and 63\% average difference respectively). The LEWICE3D void density model more closely predicted the experimental void density and predicted values which were more conservative than the standard LEWICE density model which generated an average under-prediction of $129 \%$ and a maximum under-prediction of $224 \%$.

The ice shape area was over-predicted in all cases due to the under-prediction of void density. The average difference between experiment and prediction was $115 \%$ with a maximum difference of $308 \%$. The standard LEWICE density model produced a smaller average difference with experiment ( $76 \%$ versus $115 \%$ respectively) but the ice shapes produced using the LEWICE3D void density model were conservative while those produced using the standard LEWICE model were not.

The ice shape comparisons inferred that there was a deficiency in the predicted leading edge heat transfer. It was postulated that this could be due to interstitial flow over the large scallop features or to the existence of horse shoe vortices generated by the leading edge span flow over the scallop features. Both of these phenomena would enhance leading edge heat transfer and neither were modeled in the LEWICE3D heat transfer scheme.

Modifications were made to the void density model and to the heat transfer model to improve the predictions. A void ice density model which used impingement mass averaging instead of free stream mass averaging to generate the particle impact angle from the droplet distribution was implemented to reduce the sensitivity of the void density to inertia parameter. A simple modification was made to the heat transfer distribution at the leading edge which incorporated a weighting of the peak heat transfer with the stagnation line heat transfer. The ice shape predictions 
resulting from these changes showed a marked improvement in area and shape over the current predictions. More work would be required to verify these models for a larger range of model types and conditions.

The NASA Glenn ice void density model was developed to improve swept wing ice shape predictions over the standard LEWICE density model which does not account for the large voids in the swept wing ice shapes. The void density model, in general, over-predicted the ice shape size while the standard LEWICE density model underpredicted the ice shape size. The void density model was deemed more appropriate for swept wing analysis because it generates ice shapes which are conservative (larger than experiment). Further work would be required to reduce the conservatism.

\section{References}

${ }^{1}$ Bidwell, C.S., and Potapczuk, M.G., "Users Manual for the NASA Lewis Three-Dimensional Ice Accretion Code (LEWICE3D)," NASA TM 105974, 1993.

${ }^{2}$ Bidwell, C., "Icing Analysis of the NASA S3 Icing Research Aircraft Using LEWICE3D Version 2," SAE 07ICE-137, 2007.

${ }^{3}$ Irvine, T. B., Oldenburg, J. R., Sheldon, D. W., "New Icing Cloud Simulation System at the NASA Glenn Research Center", NASA TM-1999-208891.

${ }^{4}$ ANSYS, Inc., “ANSYS CFX Reference Guide, Release 13”, November 2010.

${ }^{5}$ Raw, M.J., "Robustness of Coupled Algebraic Multigrid for the Navier-Stokes Calculations," AIAA Paper 2001-2414, June 2001.

${ }^{6}$ Schneider, G. E., and Raw, M. J., "Control Volume Finite-Element Method for Heat Transfer and Fluid Flow Using Collocated Variables," Computational Procedure, Numerical Heat Transfer, Vol. 11, No. 4, 1987, pp. 363-390.

${ }^{7}$ Mazzawy R.S., Strapp J.W.; “Appendix D - An Interim Icing Envelope; SAE 2007-01-3311; SAE 2007 Aircraft and Engine Icing International Conference; Seville, Spain, November 2007.

${ }^{8}$ Ruff, G.A., Berkowitz, B.M., "Users Manual for the NASA Lewis Ice Accretion Prediction Code (LEWICE)," NASA CR185129, May 1990. 
Table 1. Experimental and analytical ice shape characteristics for $45^{\circ}$ swept NACA 0012 wing.

\begin{tabular}{|c|c|c|c|c|c|c|c|c|c|c|c|c|c|}
\hline Run\# & $\begin{array}{c}\text { Airspeed } \\
\mathrm{m} / \mathrm{s} \\
\end{array}$ & $\begin{array}{c}\text { Drop } \\
\text { Size } \\
\text { microns }\end{array}$ & $\begin{array}{l}\mathrm{LWC} \\
\mathrm{g} / \mathrm{m}^{3}\end{array}$ & \begin{tabular}{|c|} 
Static \\
Temperature \\
$\mathrm{K}$
\end{tabular} & $\begin{array}{c}\text { Experimental Ice } \\
\text { Mass per Unit Length } \\
\mathrm{g} / \mathrm{m} \\
\end{array}$ & $\begin{array}{c}\text { Corrected Experimental } \\
\text { Ice Mass per Unit Length } \\
\mathrm{g} / \mathrm{m} \\
\end{array}$ & $\begin{array}{c}\text { LEWICE3D Ice Mass } \\
\text { per Unit Length } \\
\mathrm{g} / \mathrm{m}\end{array}$ & \begin{tabular}{|c|} 
Experimental \\
Void Density \\
$\mathrm{Kg} / \mathrm{m}^{3}$
\end{tabular} & $\begin{array}{l}\text { LEWICE3D } \\
\text { Void Density } \\
\mathrm{Kg} / \mathrm{m}^{3}\end{array}$ & \begin{tabular}{|c|}
$\begin{array}{c}\text { Experimental } \\
\text { Ice Shape Area } \\
\mathrm{cm}^{3}\end{array}$ \\
\end{tabular} & $\begin{array}{c}\text { LEWICE3D } \\
\text { Ice Shape Area } \\
\mathrm{cm}^{3} \\
\end{array}$ & $\begin{array}{c}\text { LEWICE3D Ice Shape } \\
\text { Area }\left(\rho_{\text {ice }}=917 \mathrm{~g} / \mathrm{m}^{3}\right) \\
\mathrm{cm}^{3}\end{array}$ & \begin{tabular}{|c} 
Leading Edge \\
Freezing \\
Fraction \\
\end{tabular} \\
\hline AF1790 & 45 & 15 & 1.50 & 257 & 380 & 454 & 536 & 325 & 106 & \begin{tabular}{|l|}
12.3 \\
\end{tabular} & \begin{tabular}{|l|}
50.4 \\
\end{tabular} & 5.6 & 0.80 \\
\hline AF1789 & 45 & 15 & 1.50 & 259 & 376 & 483 & 546 & 323 & 139 & 13.8 & 39.2 & 5.6 & 0.71 \\
\hline AF1793 & 45 & 15 & 1.50 & 262 & 416 & 491 & 560 & 407 & 138 & 11.5 & 40.5 & 5.6 & 0.56 \\
\hline AF1788 & 45 & 15 & 1.50 & 265 & 536 & 557 & 581 & 380 & 136 & 14.5 & 42.7 & 5.4 & 0.41 \\
\hline AF1794 & 45 & 15 & 1.50 & 265 & 526 & 594 & 581 & 351 & 136 & 14.5 & 42.7 & 5.4 & 0.41 \\
\hline AF1792 & 45 & 15 & 1.50 & 267 & 702 & 706 & 582 & 374 & 132 & 18.6 & 44.2 & 5.6 & 0.31 \\
\hline AF1791 & 45 & 15 & 1.50 & 269 & 534 & 538 & 579 & 380 & 127 & 12.6 & 45.4 & 5.5 & 0.20 \\
\hline AF1799 & 103 & 32 & 0.45 & 257 & 1476 & 1582 & 1440 & 437 & 298 & 34.4 & 48.3 & 15.3 & 0.74 \\
\hline AF1798 & 103 & 32 & 0.45 & 261 & 1467 & 1576 & 1475 & 328 & 275 & 45.7 & 53.5 & 15.4 & 0.53 \\
\hline AF1797 & 103 & 32 & 0.45 & 263 & 1339 & 1432 & 1497 & 283 & 265 & 47.8 & 56.6 & 15.5 & 0.43 \\
\hline AF1796 & 103 & 32 & 0.45 & 265 & 1340 & 1438 & 1539 & 367 & 244 & 38.3 & 63.0 & 15.7 & 0.31 \\
\hline AF1795 & 103 & 32 & 0.45 & 266 & 1449 & 1599 & 1548 & 402 & 230 & 36.9 & 67.2 & 15.7 & 0.25 \\
\hline
\end{tabular}

Table 2. Experimental and analytical ice shape characteristics for $30^{\circ}$ swept NACA 0012 wing.

\begin{tabular}{|c|c|c|c|c|c|c|c|c|c|c|c|c|c|c|}
\hline Run \# & $\begin{array}{c}\text { Airspeed } \\
\mathrm{m} / \mathrm{s}\end{array}$ & $\begin{array}{c}\text { Drop } \\
\text { Size } \\
\text { microns }\end{array}$ & $\begin{array}{l}\text { LWC } \\
\mathrm{g} / \mathrm{m}^{3}\end{array}$ & $\begin{array}{c}\text { Static } \\
\text { Temperature } \\
\mathrm{K}\end{array}$ & $\begin{array}{l}\text { Icing } \\
\text { Time } \\
\text { min. }\end{array}$ & $\begin{array}{c}\text { Experimental Ice } \\
\text { Mass per Unit Length } \\
\mathrm{g} / \mathrm{m}\end{array}$ & $\begin{array}{l}\text { Corrected Experimental } \\
\text { Ice Mass per Unit Length } \\
\mathrm{g} / \mathrm{m}\end{array}$ & $\begin{array}{l}\text { LEWICE3D Ice Mass } \\
\text { per Unit Length } \\
\mathrm{g} / \mathrm{m}\end{array}$ & $\begin{array}{c}\text { Experimental } \\
\text { Void Density } \\
\mathrm{Kg} / \mathrm{m}^{3}\end{array}$ & $\begin{array}{c}\text { LEWICE3D } \\
\text { Void Density } \\
\mathrm{Kg} / \mathrm{m}^{3}\end{array}$ & $\begin{array}{c}\text { Experimental } \\
\text { Ice Shape Area } \\
\mathrm{cm}^{3}\end{array}$ & $\begin{array}{c}\text { LEWICE3D } \\
\text { Ice Shape Area } \\
\mathrm{cm}^{3}\end{array}$ & $\begin{array}{c}\text { LEWICE3D Ice Shape } \\
\text { Area }\left(\rho_{\text {ice }}=917 \mathrm{~g} / \mathrm{m}^{3}\right) \\
\mathrm{cm}^{3}\end{array}$ & \begin{tabular}{|c|} 
Leading Edge \\
Freezing \\
Fraction
\end{tabular} \\
\hline AF2155 & 45 & 15 & 1.50 & 255 & 20 & 787 & 943 & 752 & 505 & 219 & 17.6 & 34.4 & 8.0 & 0.76 \\
\hline AF2140 & 45 & 15 & 1.50 & 264 & 20 & 906 & 906 & 799 & 494 & 186 & 17.0 & 43.0 & 8.1 & 0.39 \\
\hline AF2138 & 45 & 15 & 1.50 & 266 & 20 & 1170 & 1178 & 802 & 446 & 172 & 24.9 & 46.7 & 8.0 & 0.30 \\
\hline AF2139 & 45 & 15 & 1.50 & 266 & 20 & 1191 & 1191 & 802 & 435 & 172 & 26.5 & 46.7 & 8.0 & 0.30 \\
\hline AF2141 & 45 & 15 & 1.50 & 268 & 20 & 1113 & 1113 & 806 & 475 & 161 & 22.4 & 50.1 & 8.0 & 0.22 \\
\hline AF2153 & 103 & 32 & 0.47 & 257 & 5 & NA & NA & 467 & NA & 331 & 7.8 & 14.4 & 21.2 & 0.63 \\
\hline AF2154 & 103 & 32 & 0.47 & 257 & 12 & 827 & 1145 & 1176 & 484 & 331 & 21.0 & 35.5 & 5.1 & 0.63 \\
\hline AF2144 & 103 & 32 & 0.47 & 262 & 20 & 1774 & 2002 & 2037 & 417 & 308 & 44.7 & 66.2 & 21.5 & 0.40 \\
\hline AF2148 & 103 & 32 & 0.47 & 263 & 2 & NA & NA & 183 & NA & 301 & 4.9 & 6.1 & 21.6 & 0.35 \\
\hline AF2149 & 103 & 32 & 0.47 & 263 & 5 & NA & NA & 475 & NA & 301 & 11.8 & 15.8 & 2.0 & 0.35 \\
\hline AF2150 & 103 & 32 & 0.47 & 263 & 12 & 893 & 1160 & 1196 & 491 & 301 & 25.7 & 39.7 & 5.0 & 0.35 \\
\hline AF2143 & 103 & 32 & 0.47 & 263 & 20 & 1830 & 1938 & 2054 & 355 & 301 & 48.9 & 68.2 & 12.6 & 0.35 \\
\hline AF2142 & 103 & 32 & 0.47 & 264 & 20 & 1814 & 2060 & 2079 & 365 & 291 & 49.6 & $\begin{array}{ll}71.4 \\
\end{array}$ & 21.7 & 0.31 \\
\hline AF2151 & 103 & 32 & 0.47 & 266 & 5 & NA & NA & 477 & NA & 261 & 9.3 & 18.3 & 22.0 & 0.22 \\
\hline AF2152 & 103 & 32 & 0.47 & 266 & 12 & 779 & 1012 & 1222 & 557 & 261 & 15.4 & 46.8 & 5.0 & 0.22 \\
\hline AF2145 & 103 & 32 & 0.47 & 266 & 20 & 1429 & 1618 & 2119 & 459 & 261 & 34.0 & 81.1 & 12.7 & 0.22 \\
\hline
\end{tabular}




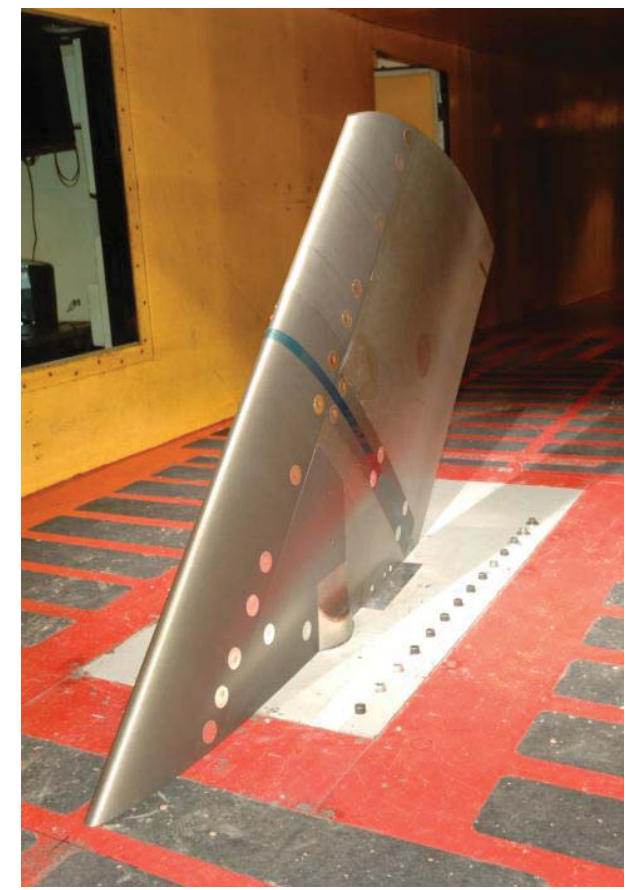

a) $45^{\circ}$ sweep

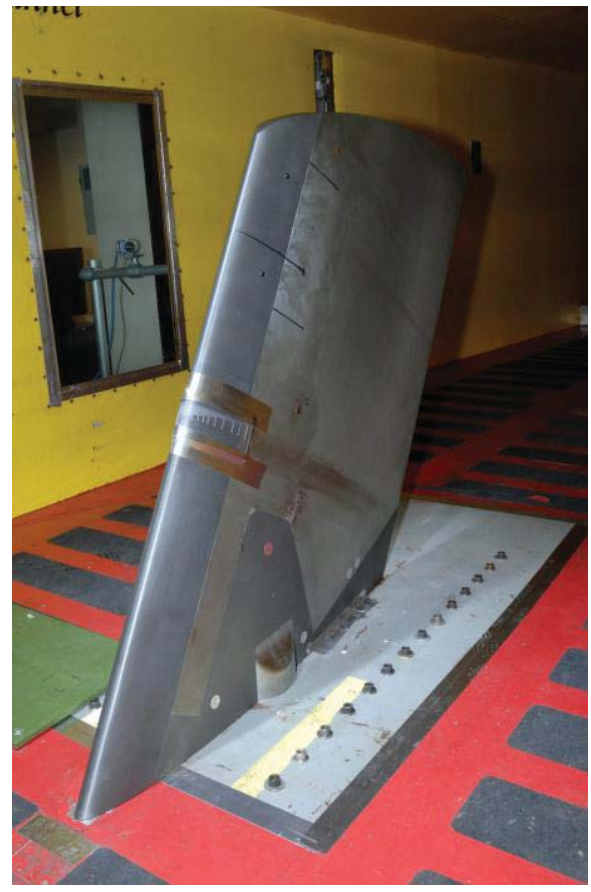

b) $30^{\circ}$ sweep

Figure 1. Swept NACA 0012 wing models installed in IRT test section.

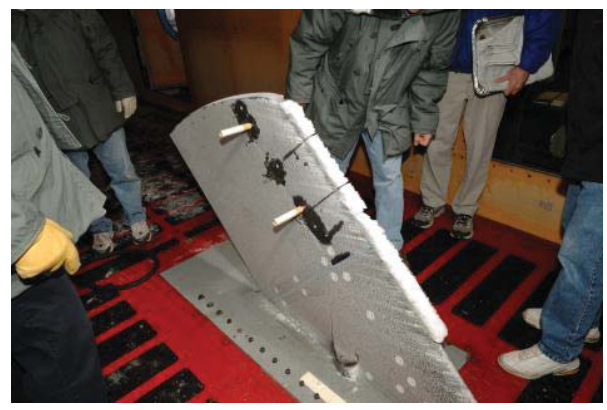

a) ice shape tracings

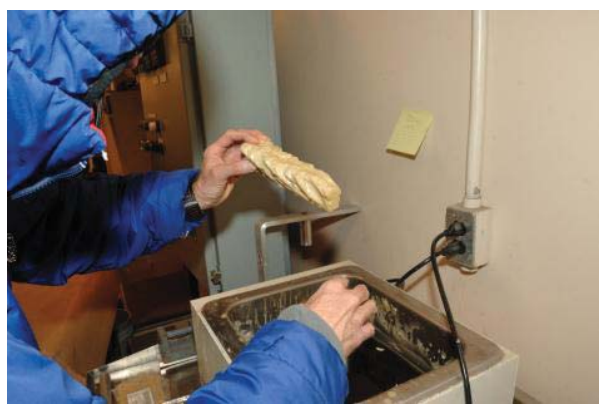

c) dipping ice shape in wax bath

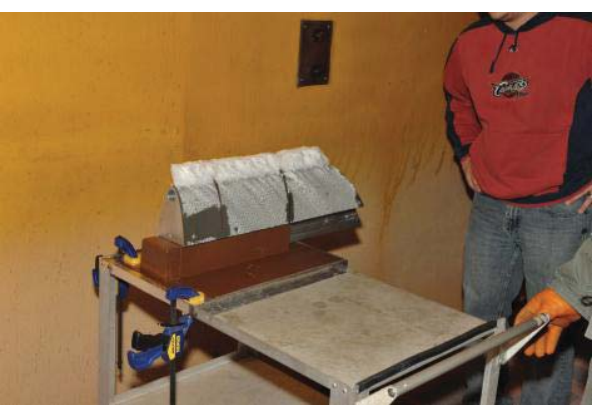

b) leading edge removed

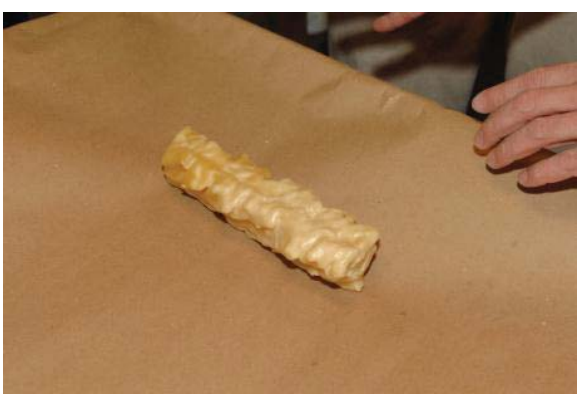

d) final wax mold

Figure 2. Ice shape wax mold process for $45^{\circ}$ swept wing. 


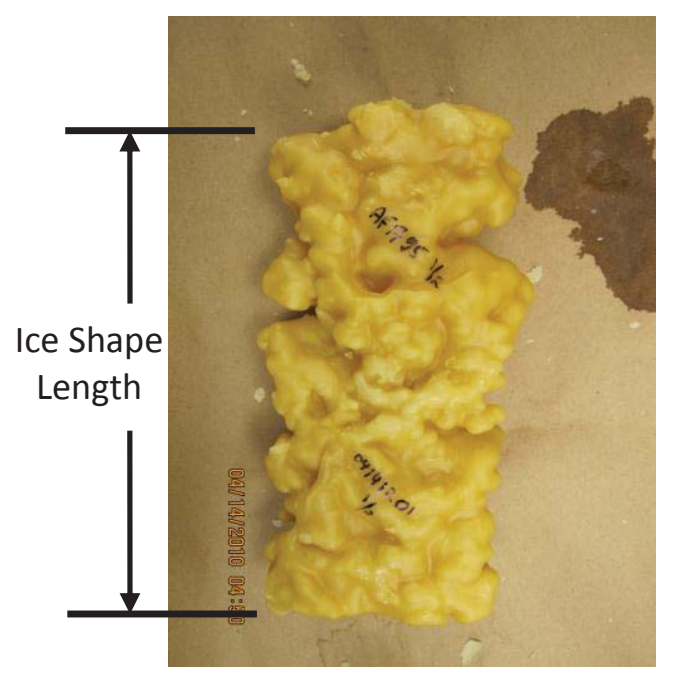

a) ice shape wax mold for $45^{\circ}$ swept wing

- Tracing

— Tracing Without Feathers

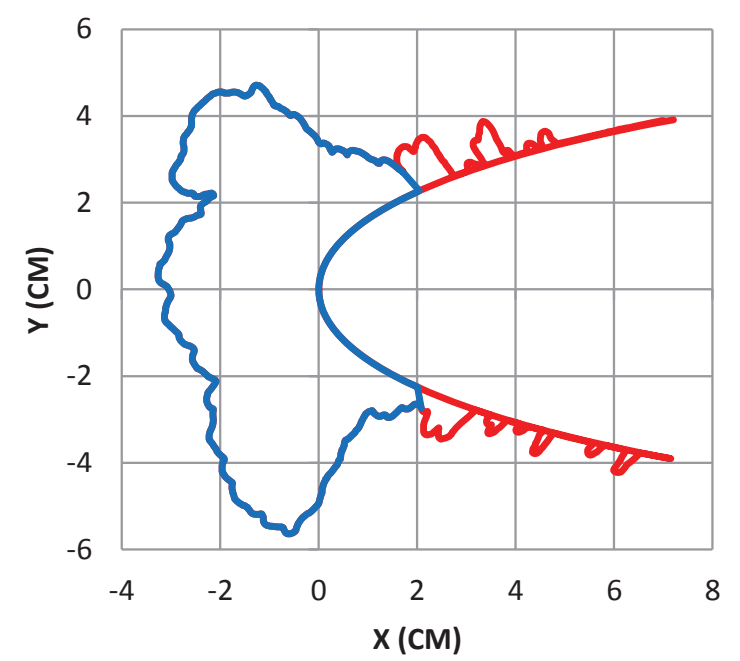

c) removal of ice feathers from tracing

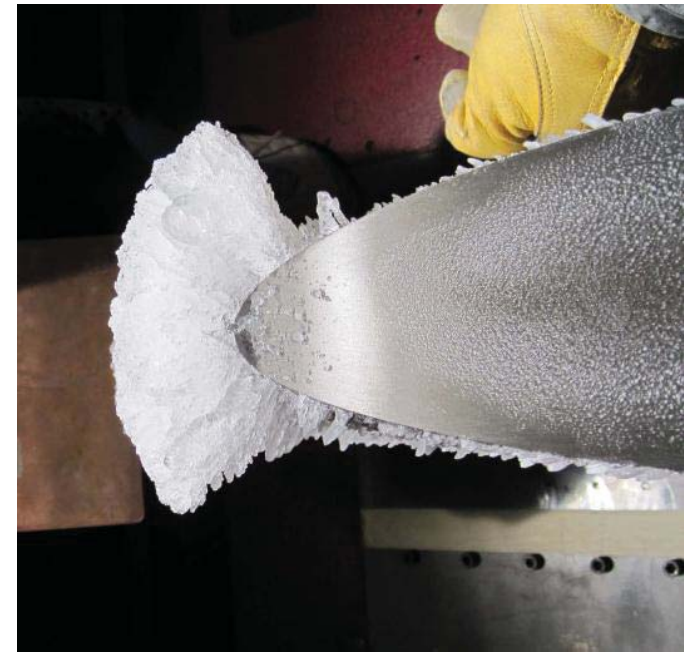

b) ice shape with feathers for $45^{\circ}$ swept wing
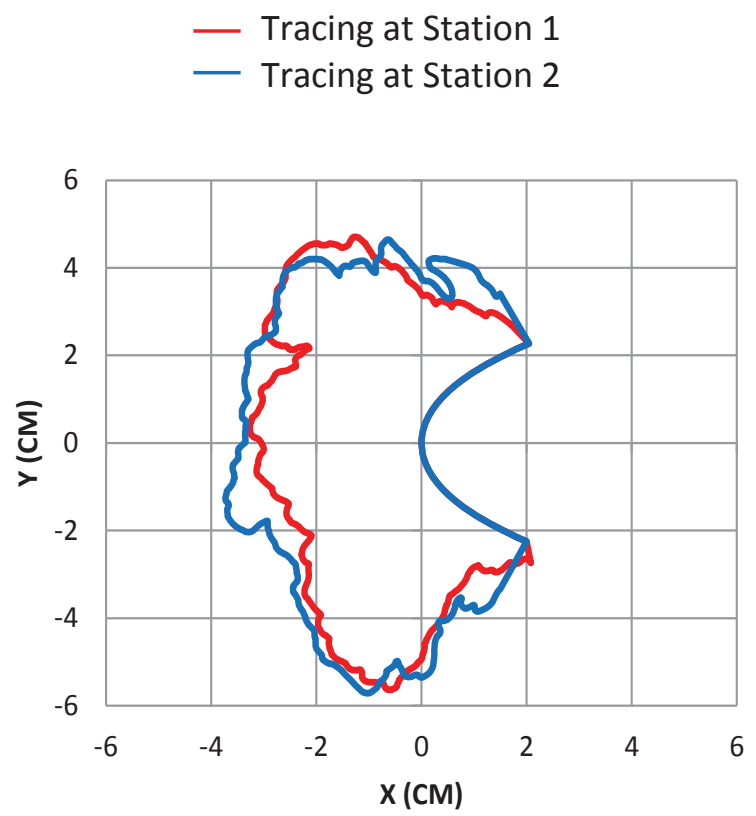

d) comparison of tracings at station 1 and 2

Figure 3. Ice shape void density calculation for $45^{\circ}$ swept wing. 


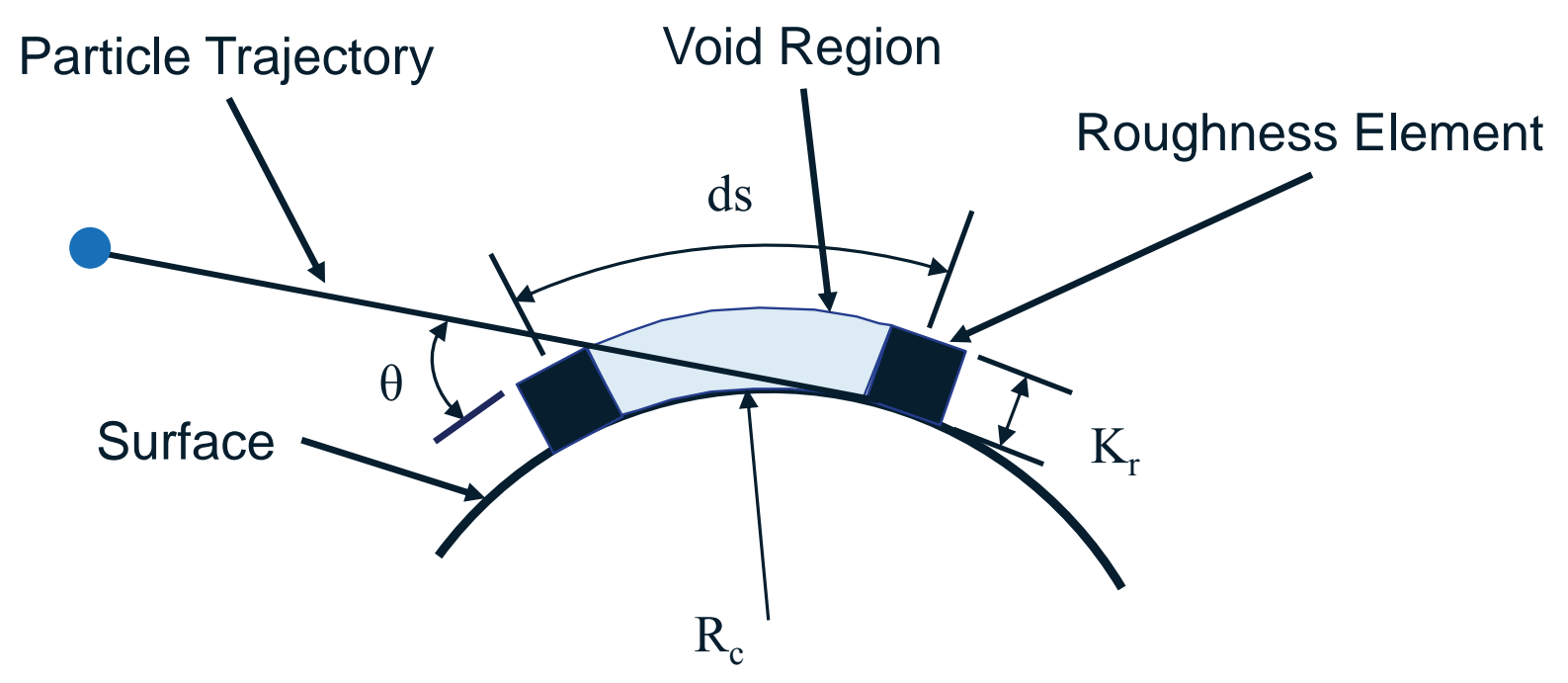

Figure 4. Schematic of math model for ice shape void density model.

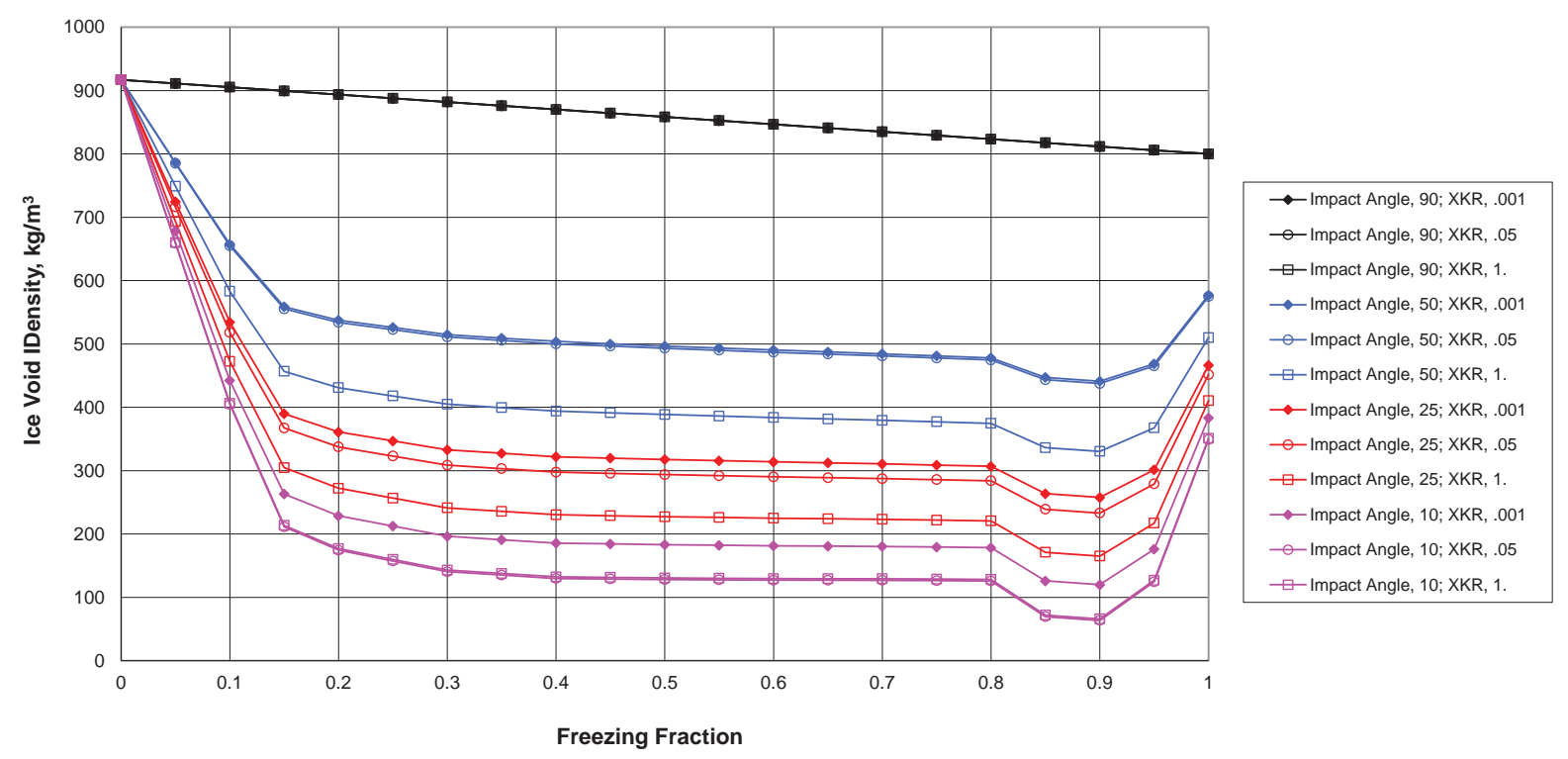

Figure 5. LEWICE3D void density as a function of freezing fraction, particle impact angle and roughness ratio. 

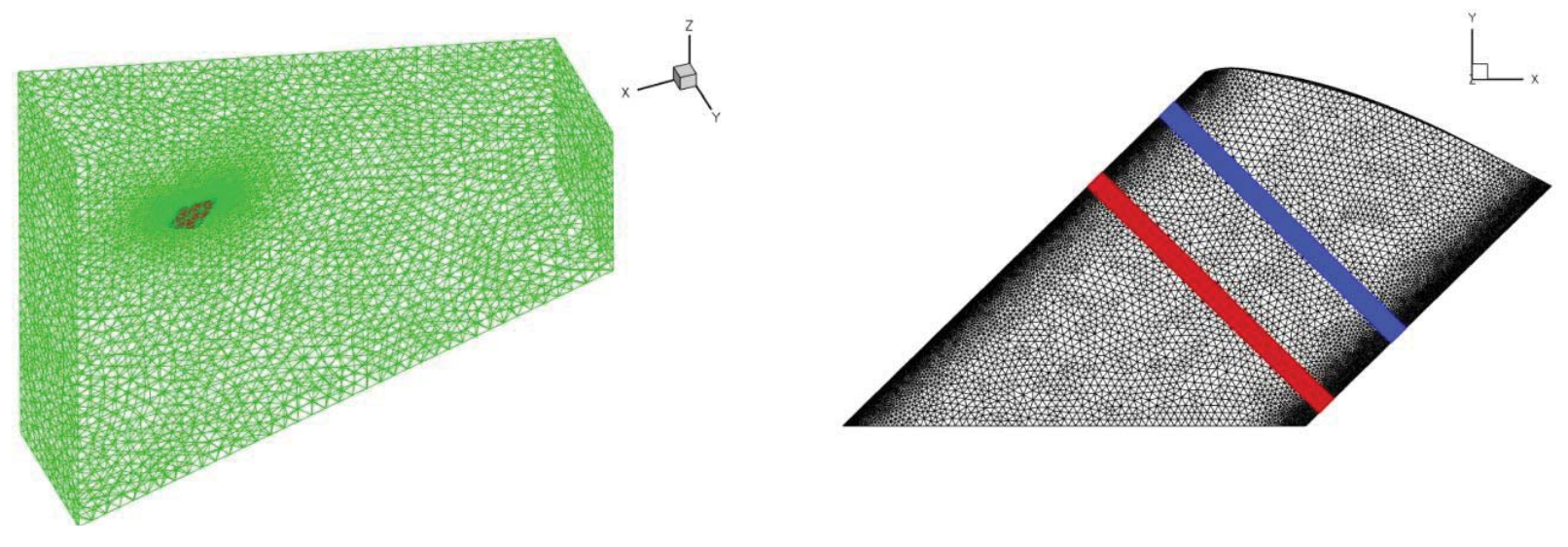

Figure 6. CFX volume grid and surface model showing ice tracing locations for $45^{\circ}$ swept wing.
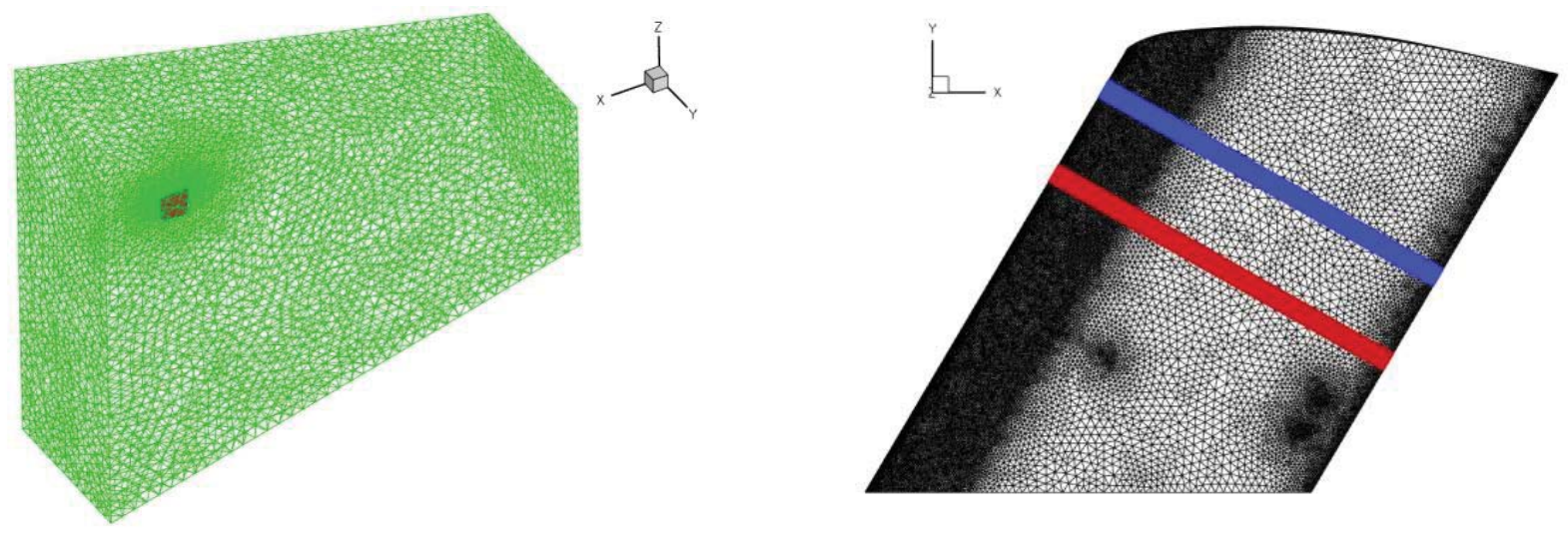

Figure 7. CFX volume grid and surface model showing ice tracing locations for $30^{\circ}$ swept wing. 


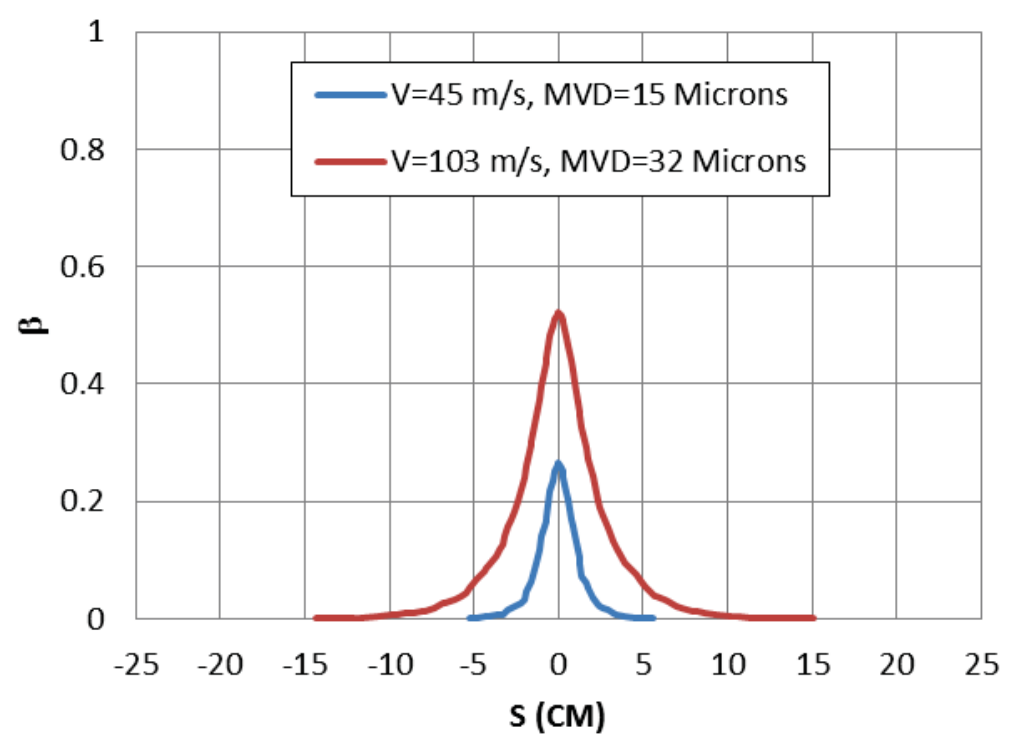

Figure 8. Collection efficiency distributions for $45^{\circ}$ swept wing.

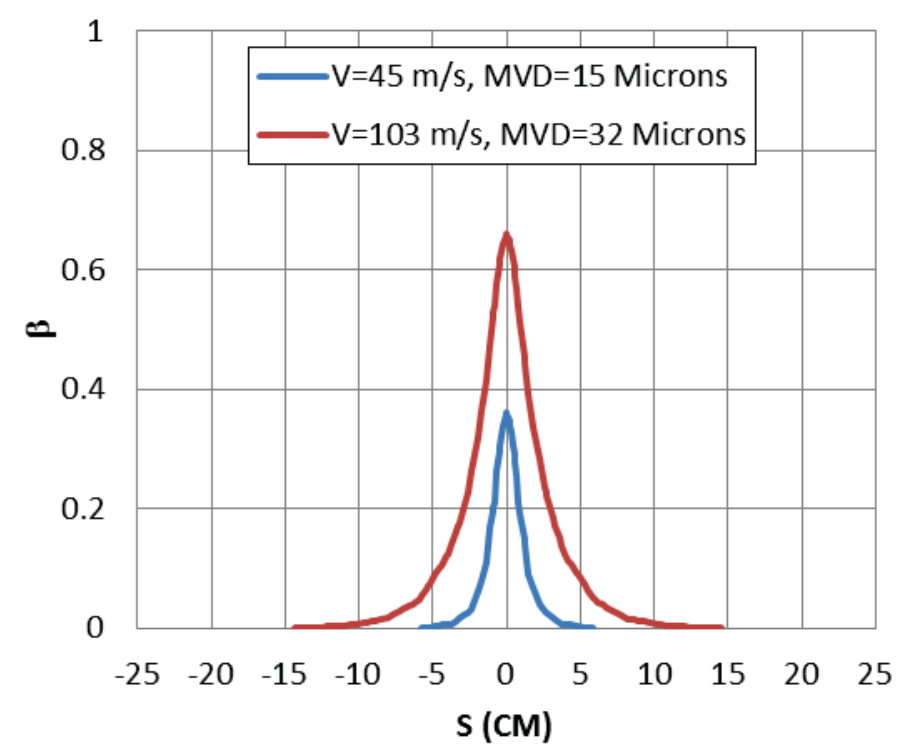

Figure 9. Collection efficiency distributions for $30^{\circ}$ swept wing. 


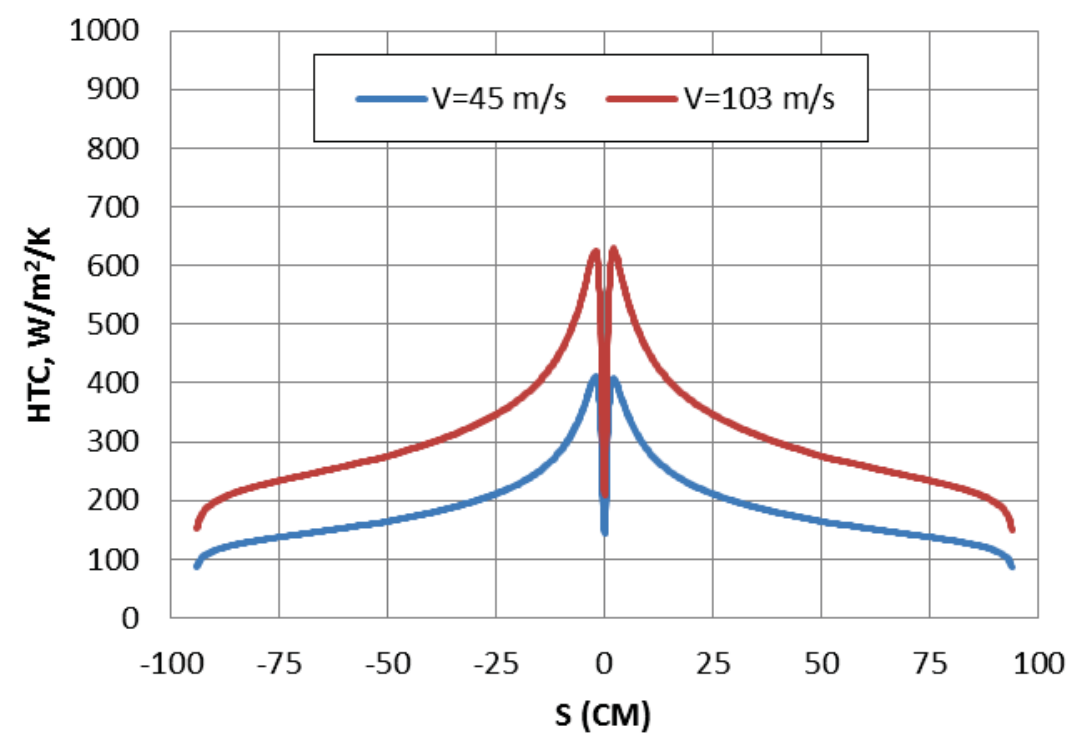

Figure 10. Heat transfer coefficient distributions for $45^{\circ}$ swept wing.

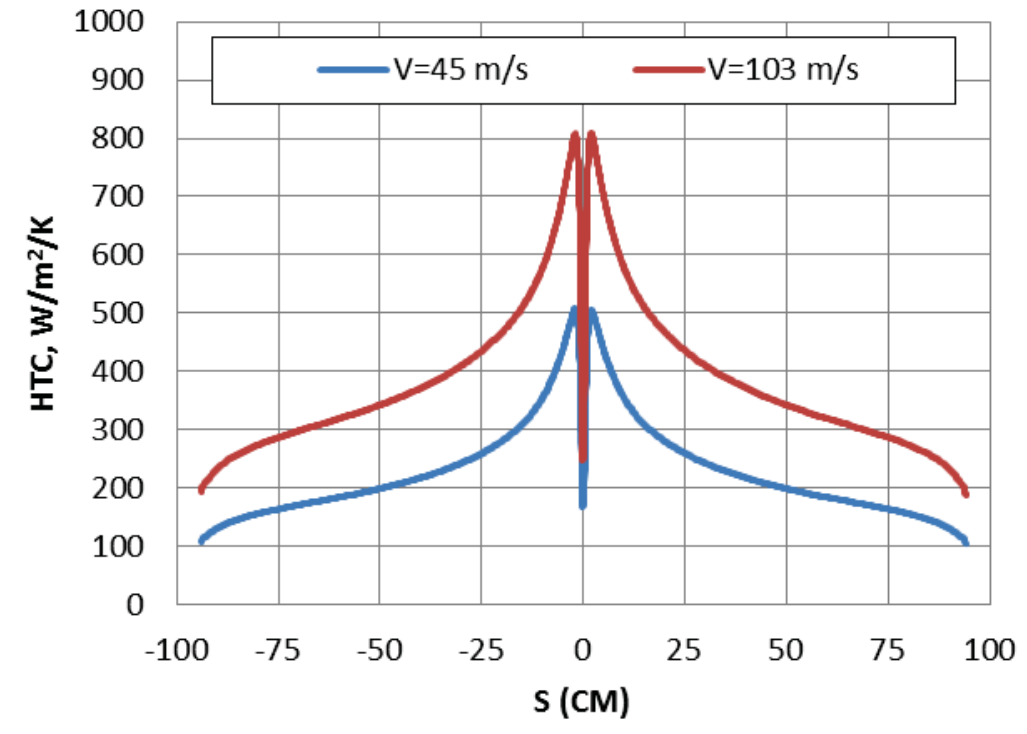

Figure 11. Heat transfer coefficient distributions for $30^{\circ}$ swept wing. 

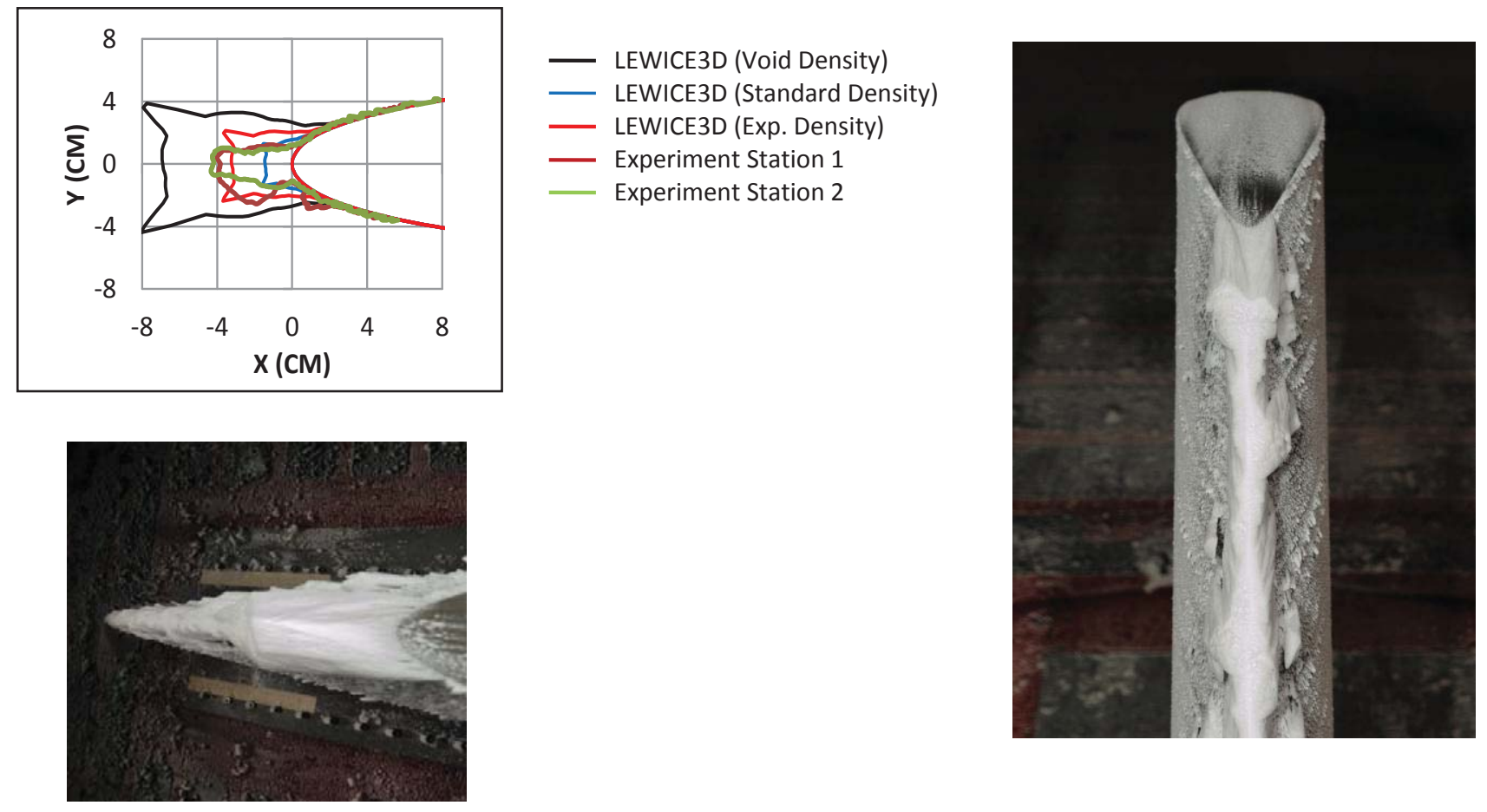

a) static temperature, $257 \mathrm{~K}$
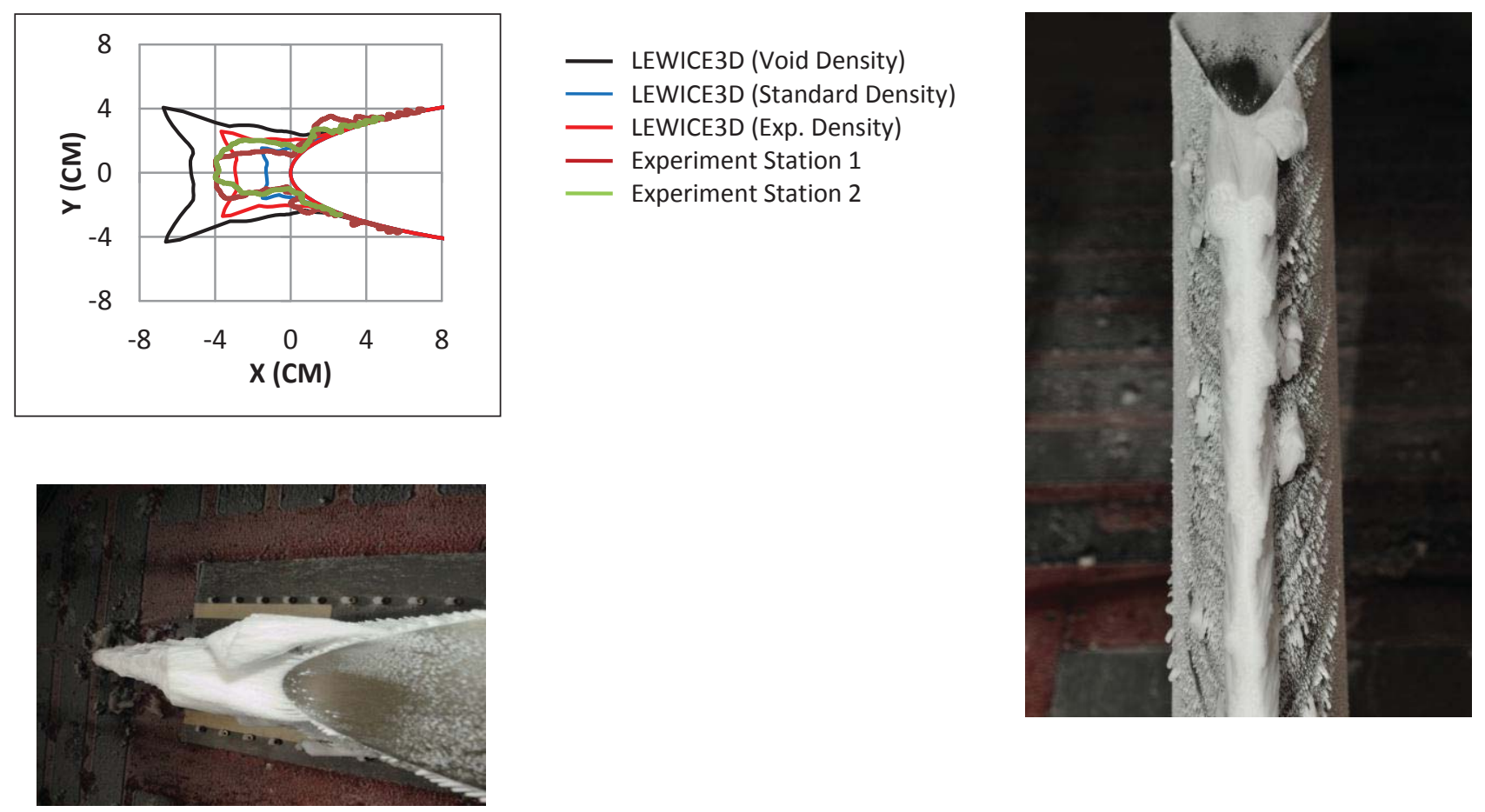

b) static temperature, $259 \mathrm{~K}$

Figure 12. Ice shape comparisons for $45^{\circ}$ swept wing. Icing conditions: airspeed $45 \mathrm{~m} / \mathrm{s}$; icing time 20 minutes; liquid water content, $1.5 \mathrm{~g} / \mathrm{m}^{3}$; static pressure, $99981 \mathrm{~Pa}$; MVD, $15 \mu \mathrm{m}$. 

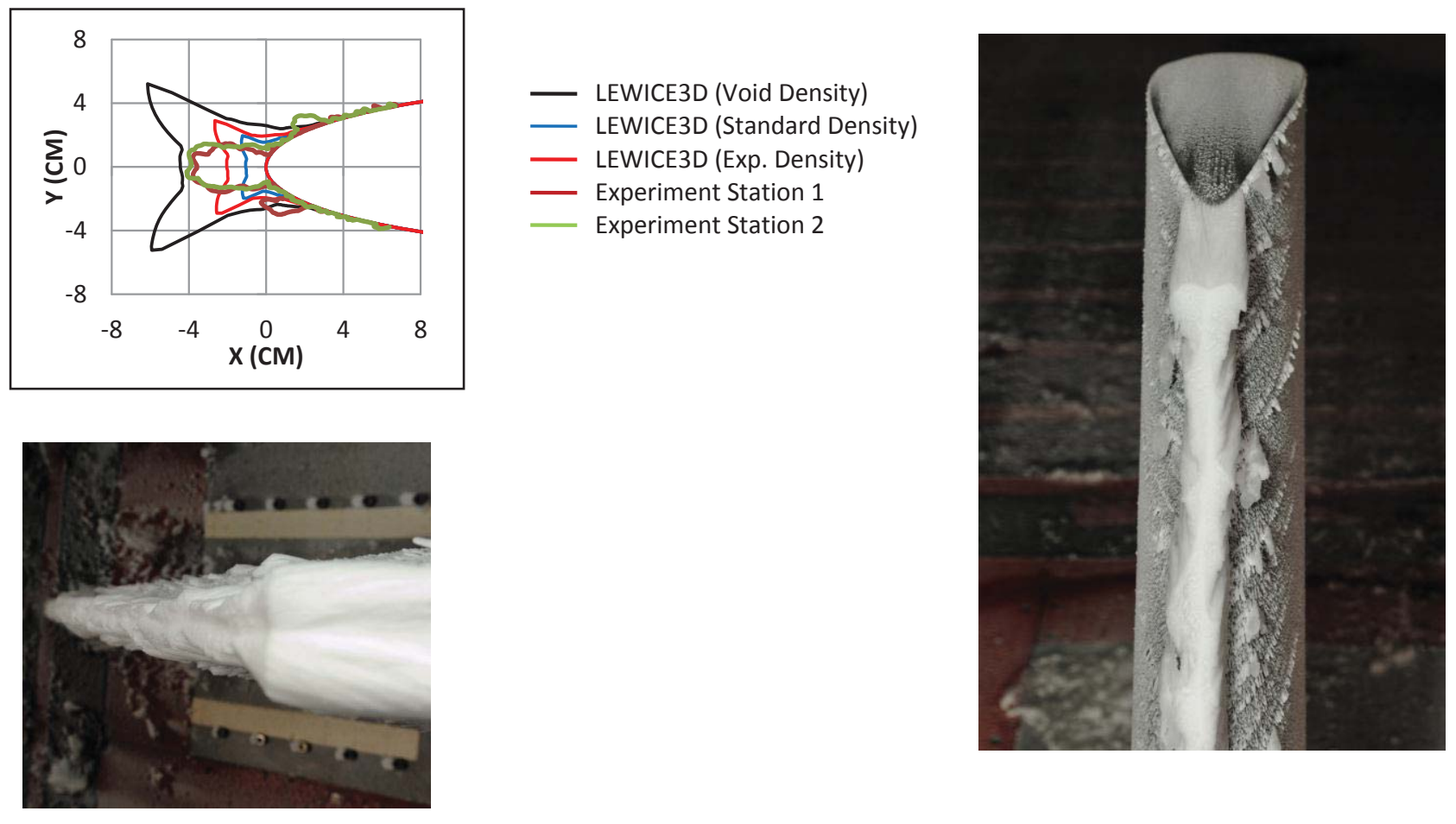

c) static temperature, $262 \mathrm{~K}$
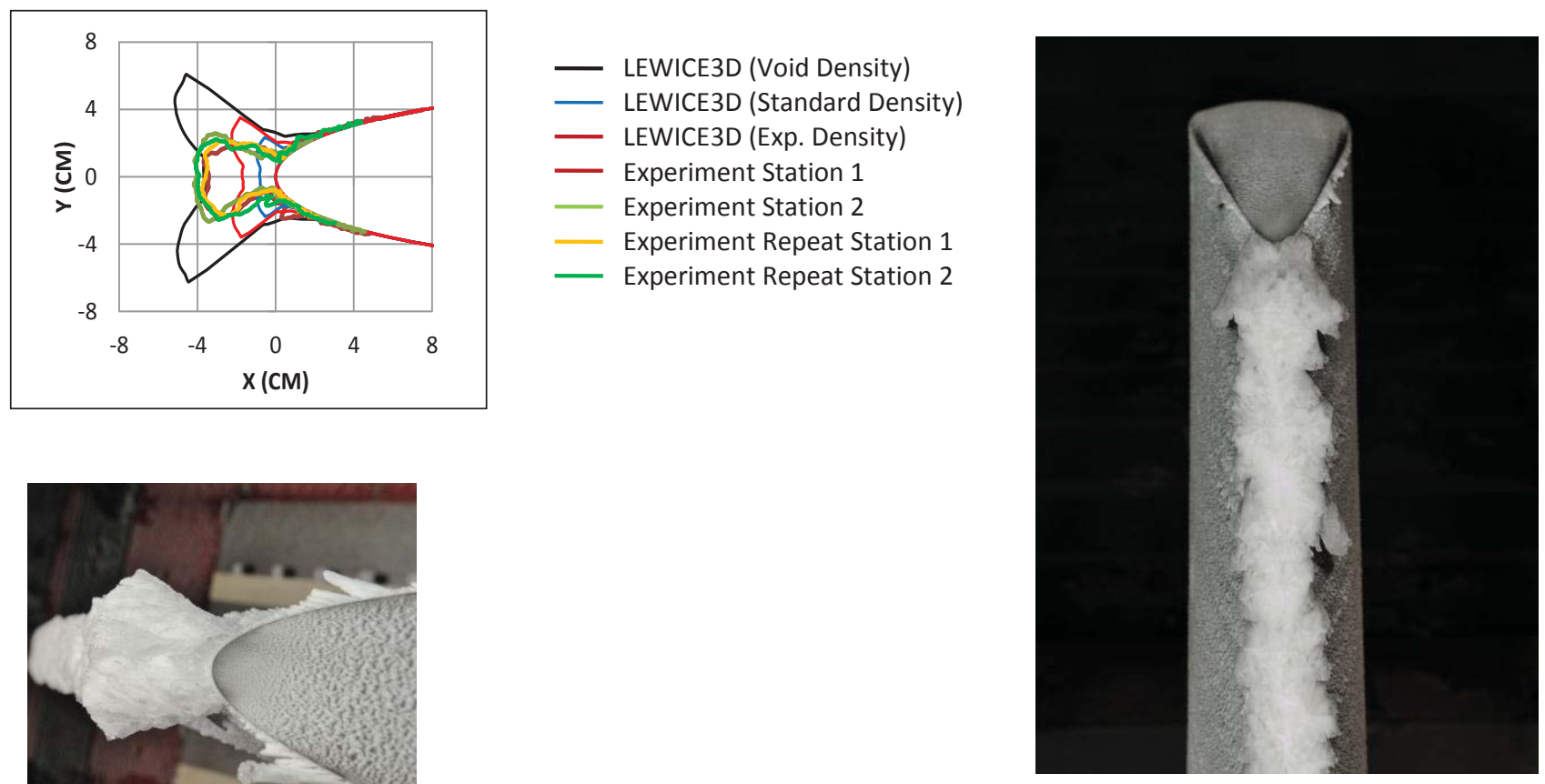

d) static temperature, $265 \mathrm{~K}$

Figure 12. - Continued. Ice shape comparisons for $45^{\circ}$ swept wing. Icing conditions: airspeed $45 \mathrm{~m} / \mathrm{s}$; icing time 20 minutes; liquid water content, $1.5 \mathrm{~g} / \mathrm{m}^{3}$; static pressure, $99981 \mathrm{~Pa}$; MVD, $15 \mu \mathrm{m}$. 

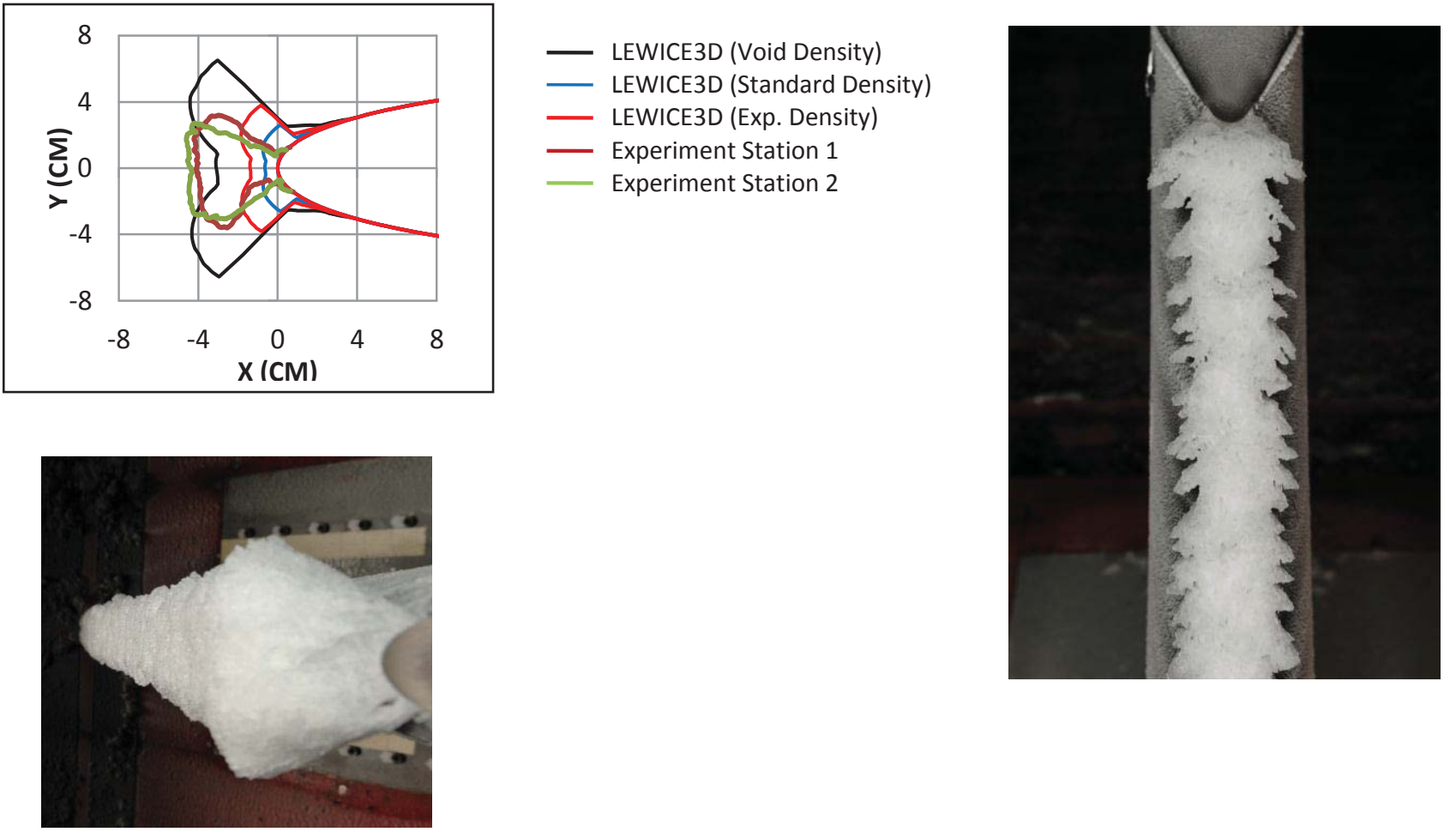

e) static temperature, $267 \mathrm{~K}$
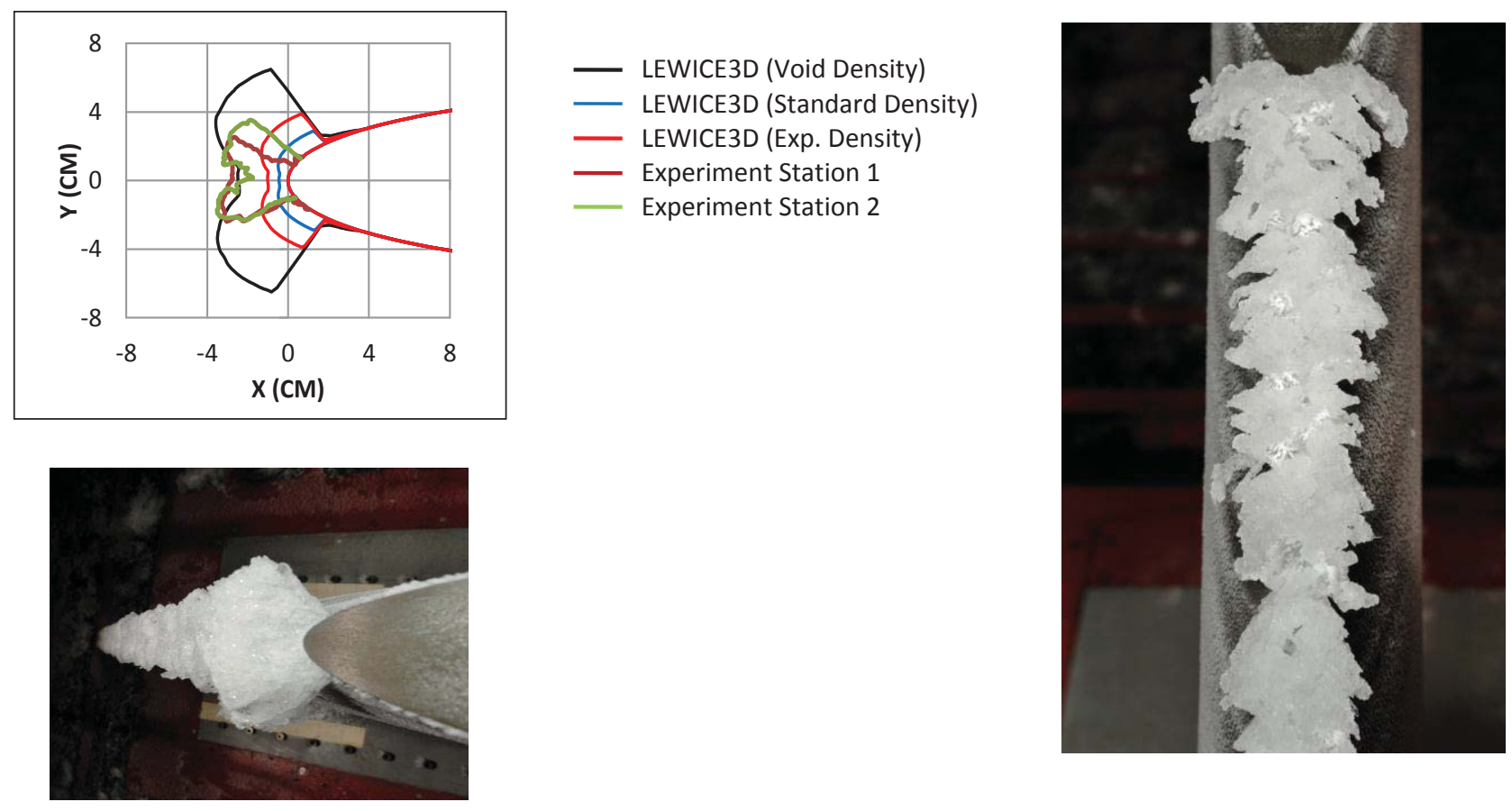

f) static temperature, $269 \mathrm{~K}$

Figure 12. - Concluded. Ice shape comparisons for $45^{\circ}$ swept wing. Icing conditions: airspeed $45 \mathrm{~m} / \mathrm{s}$; icing time 20 minutes; liquid water content, $1.5 \mathrm{~g} / \mathrm{m}^{3}$; static pressure, $99981 \mathrm{~Pa}$; MVD, $15 \mu \mathrm{m}$. 

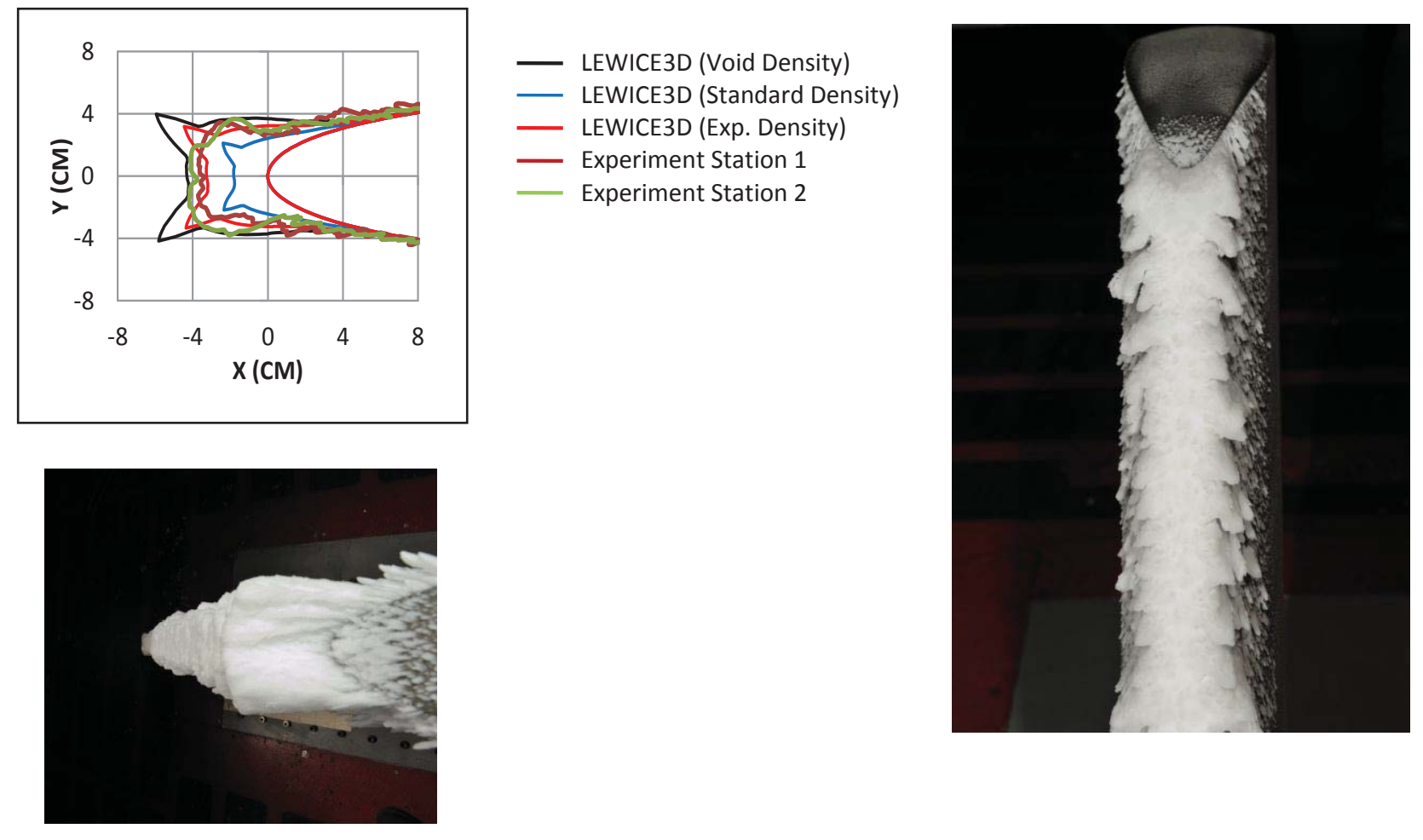

a) static temperature, $257 \mathrm{~K}$
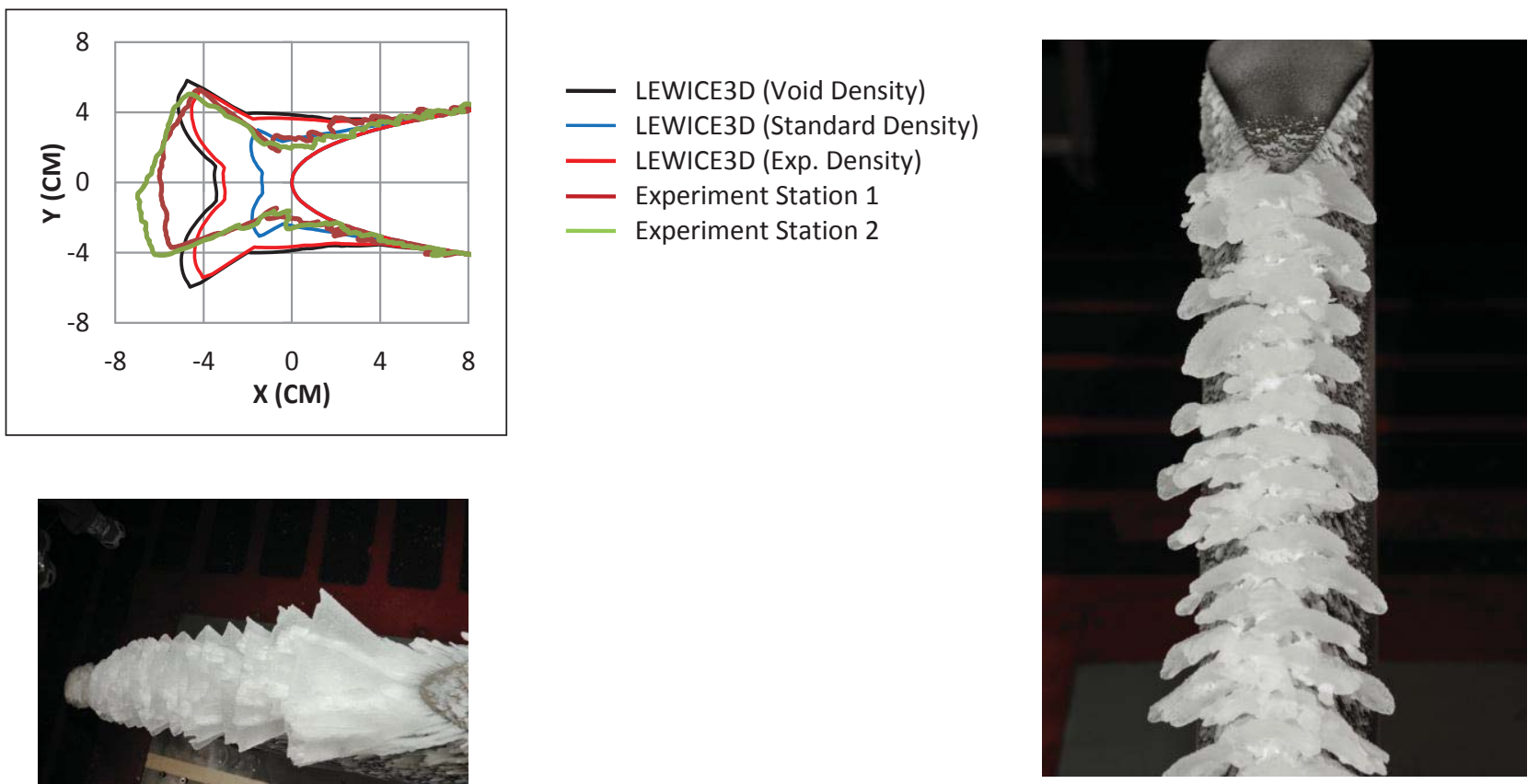

b) static temperature, $261 \mathrm{~K}$

Figure 13. Ice shape comparisons for $45^{\circ}$ swept wing. Icing conditions: airspeed $103 \mathrm{~m} / \mathrm{s}$; icing time 20 minutes; liquid water content, $0.45 \mathrm{~g} / \mathrm{m}^{3}$; static pressure, $94463 \mathrm{~Pa}$; MVD, $32 \mu \mathrm{m}$. 

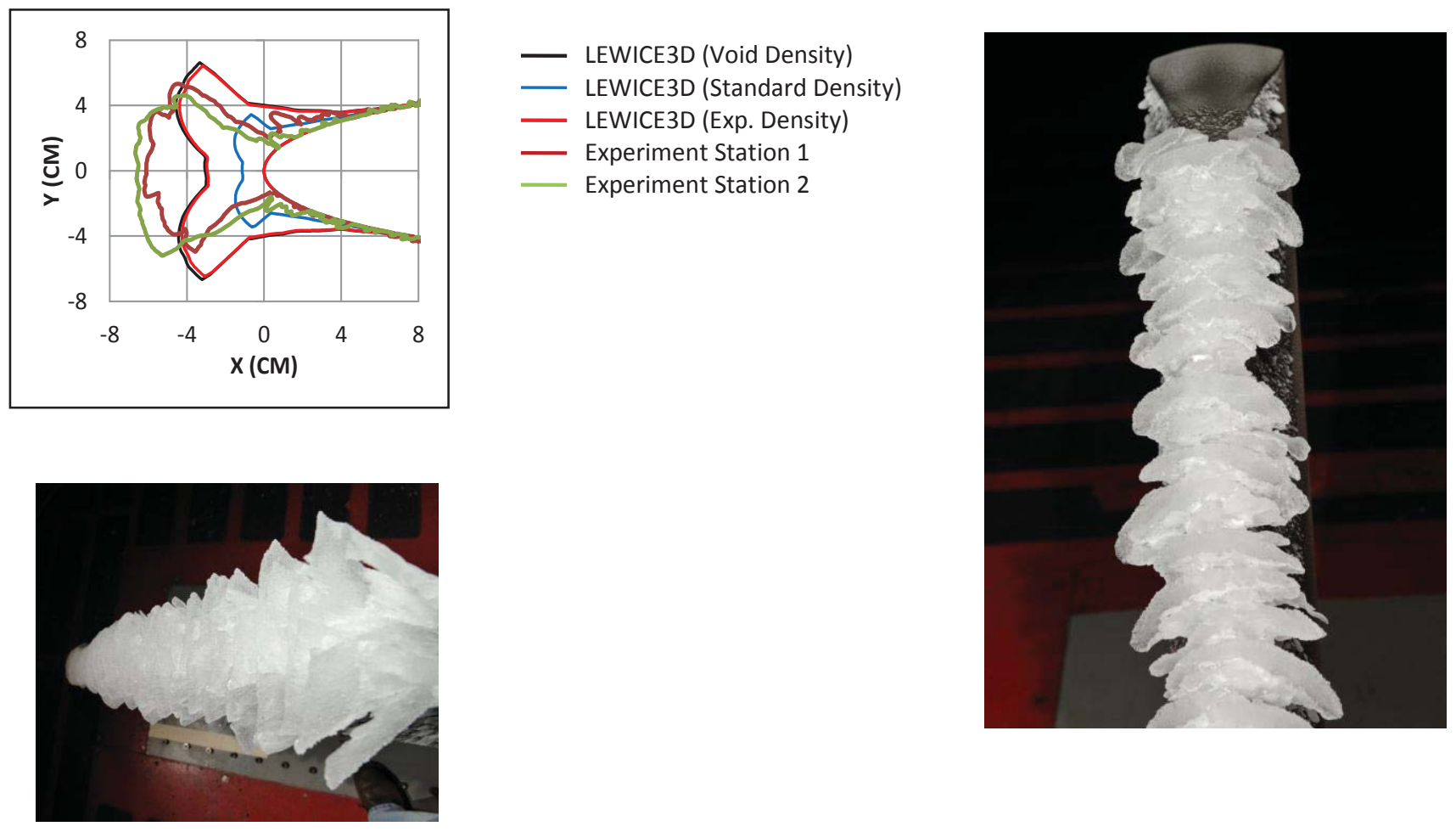

c) static temperature, $263 \mathrm{~K}$
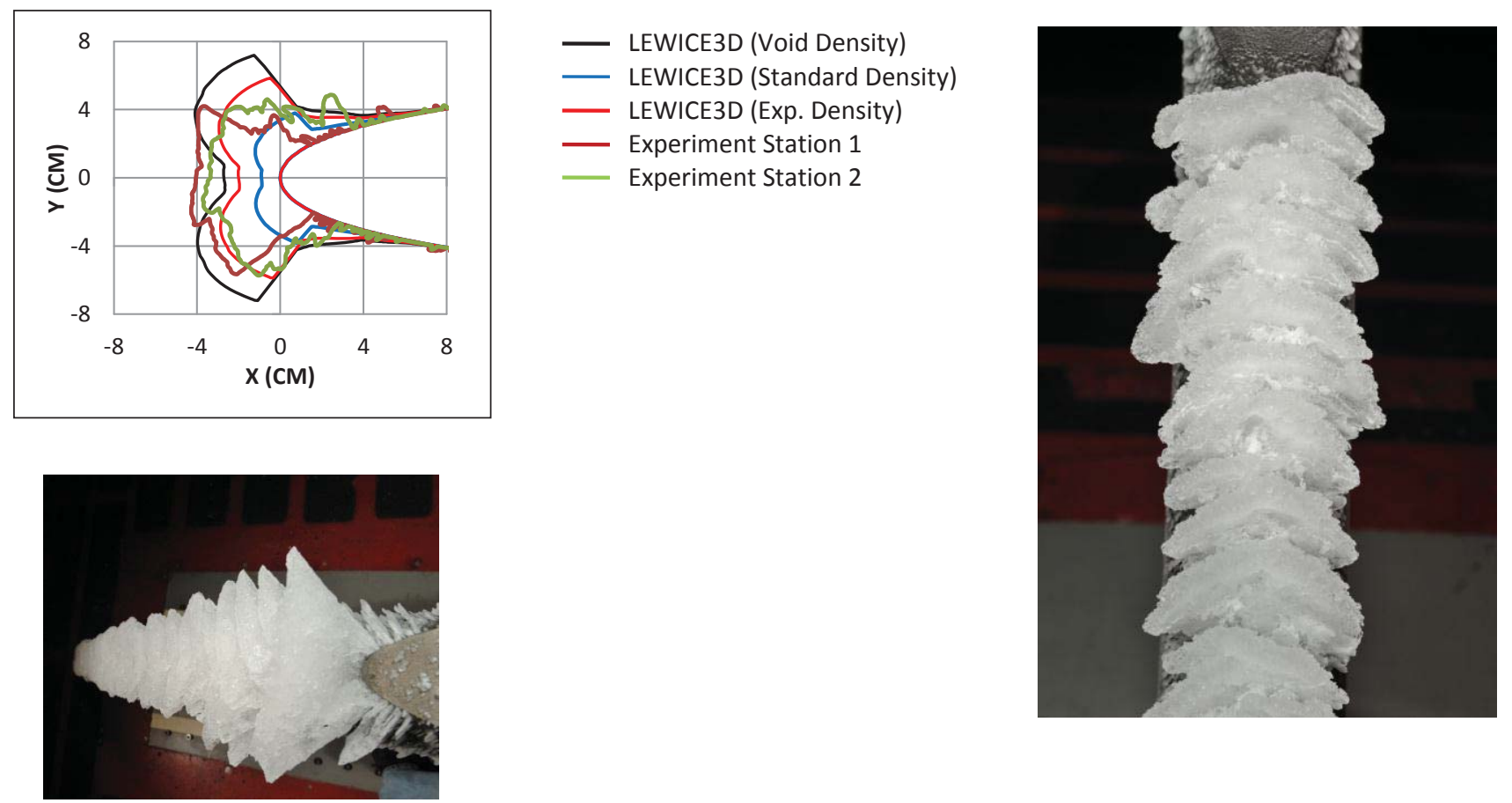

d) static temperature, $265 \mathrm{~K}$

Figure 13. - Continued. Ice shape comparisons for $45^{\circ}$ swept wing. Icing conditions: airspeed $103 \mathrm{~m} / \mathrm{s}$; icing time 20 minutes; liquid water content, $0.45 \mathrm{~g} / \mathrm{m}^{3}$; static pressure, $94463 \mathrm{~Pa}$; MVD, $32 \mu \mathrm{m}$. 

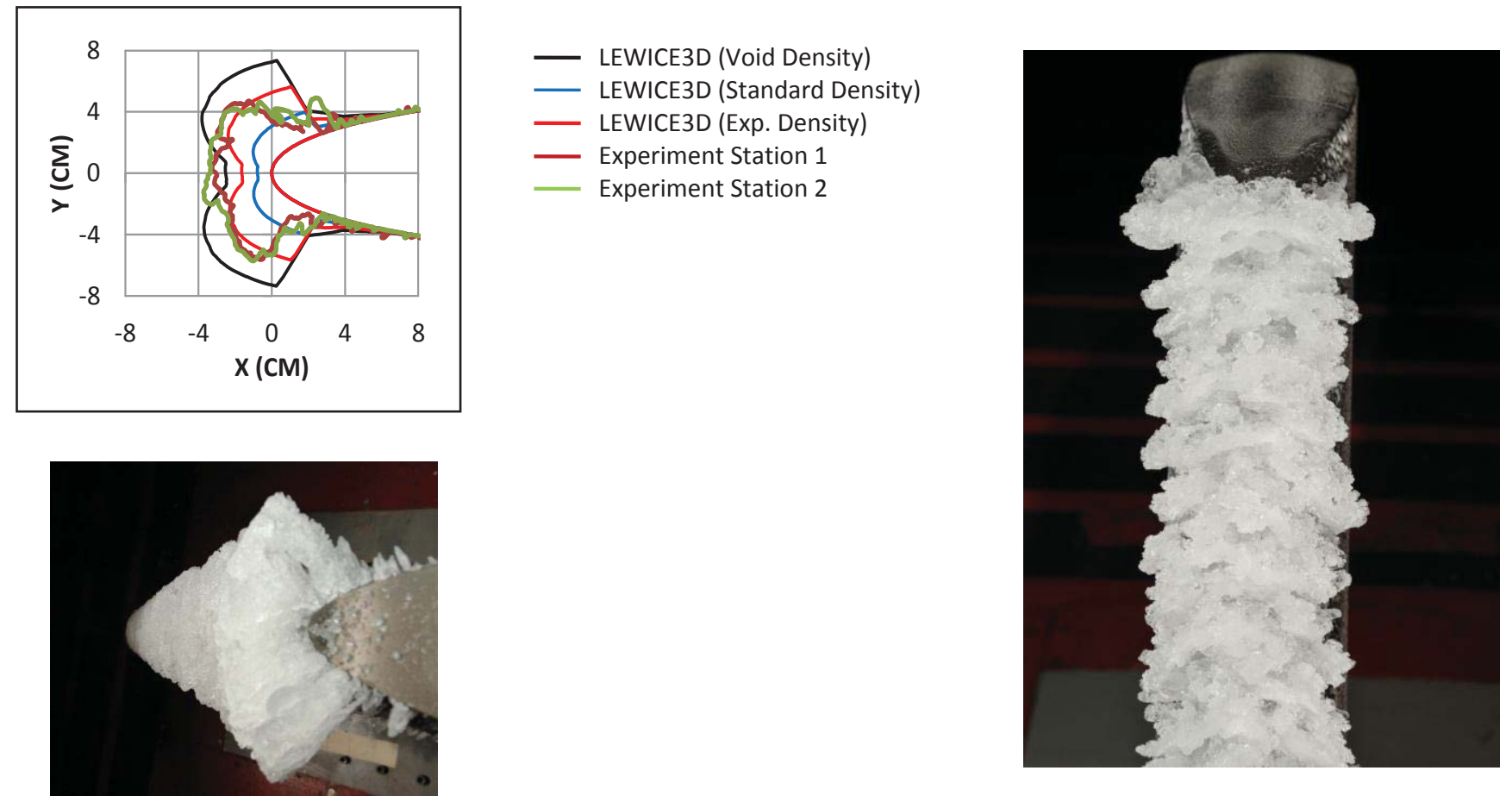

e) static temperature, $266 \mathrm{~K}$

Figure 13. - Concluded. Ice shape comparisons for $45^{\circ}$ swept wing. Icing conditions: airspeed $103 \mathrm{~m} / \mathrm{s}$; icing time 20 minutes; liquid water content, $0.45 \mathrm{~g} / \mathrm{m}^{3}$; static pressure, $94463 \mathrm{~Pa}$; MVD, $32 \mu \mathrm{m}$. 


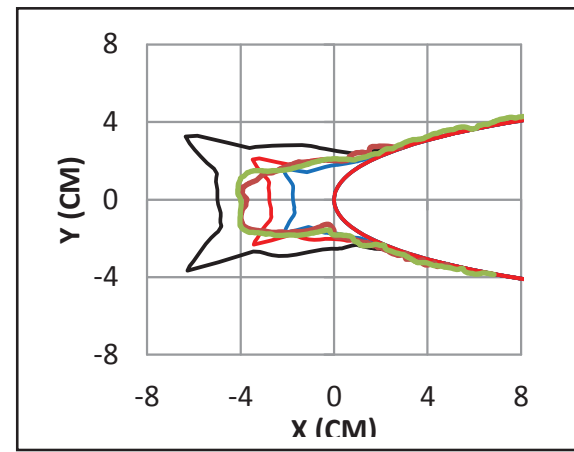

LEWICE3D (Void Density)

— LEWICE3D (Standard Density)

- LEWICE3D (Exp. Density)

- Experiment Station 1

Experiment Station 2
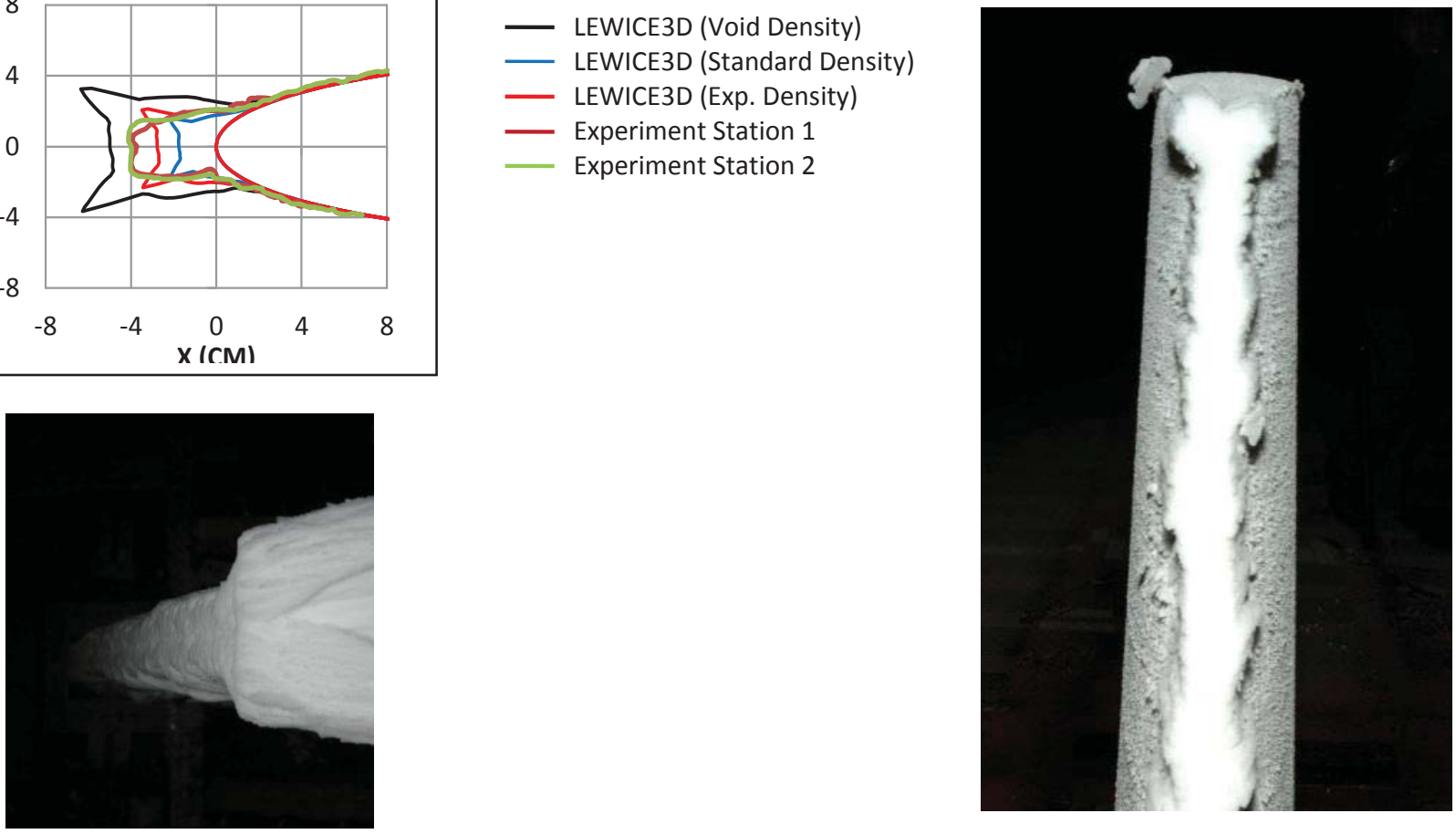

a) static temperature, $255 \mathrm{~K}$
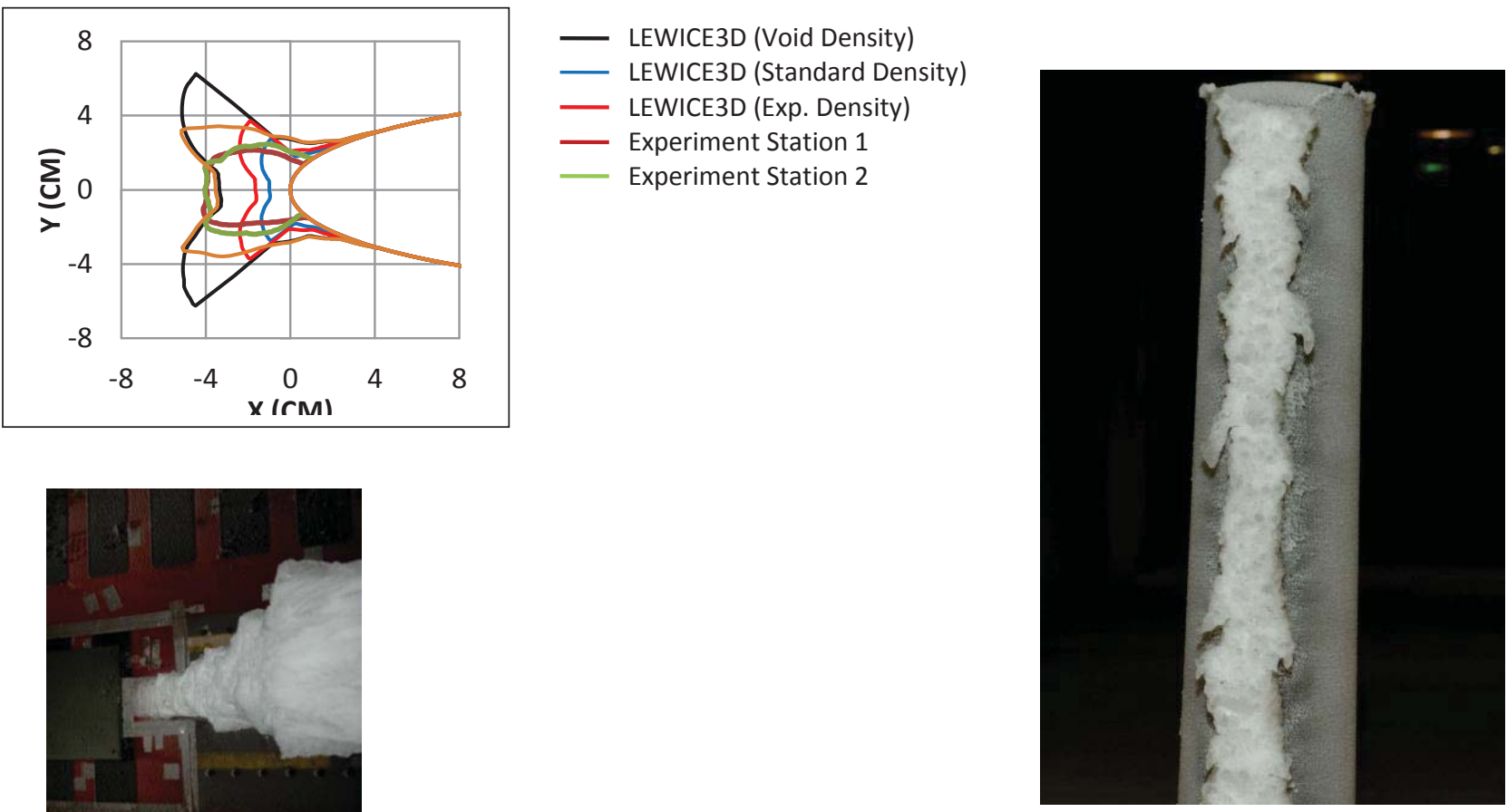

b) static temperature, $264 \mathrm{~K}$

Figure 14. Ice shape comparisons for $30^{\circ}$ swept wing. Icing conditions: airspeed $45 \mathrm{~m} / \mathrm{s}$; icing time 20 minutes; liquid water content, $1.5 \mathrm{~g} / \mathrm{m}^{3}$; static pressure, $97491 \mathrm{~Pa}$; MVD, $15 \mu \mathrm{m}$. 


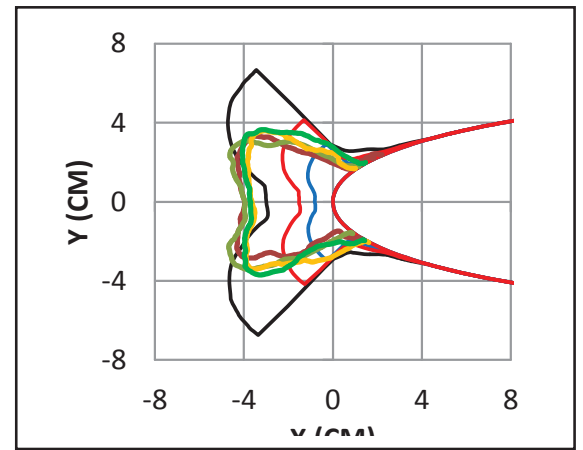

LEWICE3D (Void Density)

— LEWICE3D (Standard Density)

— LEWICE3D (Exp. Density)

- Experiment Station 1

- Experiment Station 2

- Experiment Repeat Station 1

— Experiment Repeat Station 2
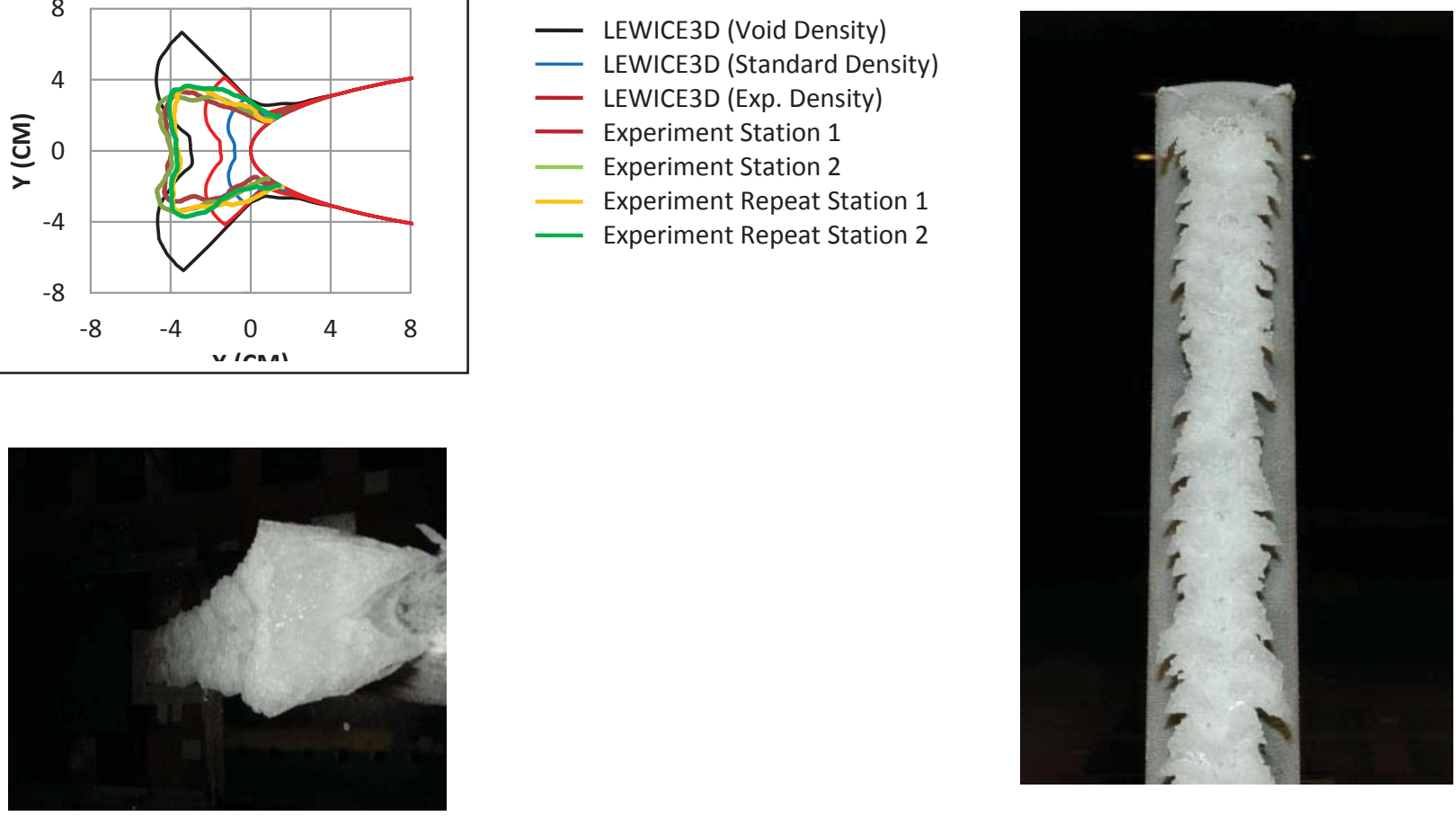

c) static temperature, $266 \mathrm{~K}$
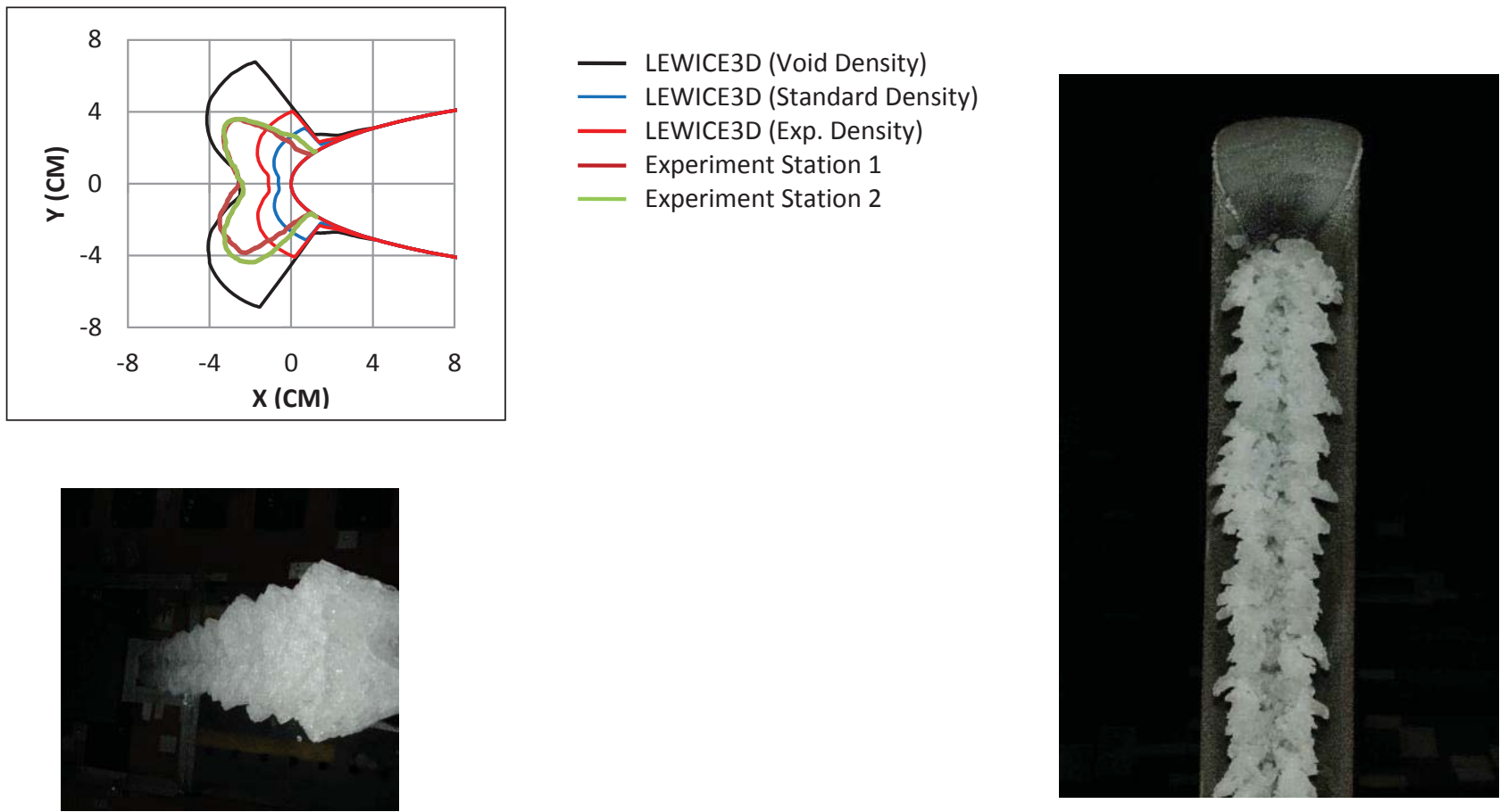

d) static temperature, $268 \mathrm{~K}$

Figure 14. - Concluded. Ice shape comparisons for $30^{\circ}$ swept wing. Icing conditions: airspeed $45 \mathrm{~m} / \mathrm{s}$; icing time 20 minutes; liquid water content, $1.5 \mathrm{~g} / \mathrm{m}^{3}$; static pressure, 97491 Pa; MVD, $15 \mu \mathrm{m}$. 

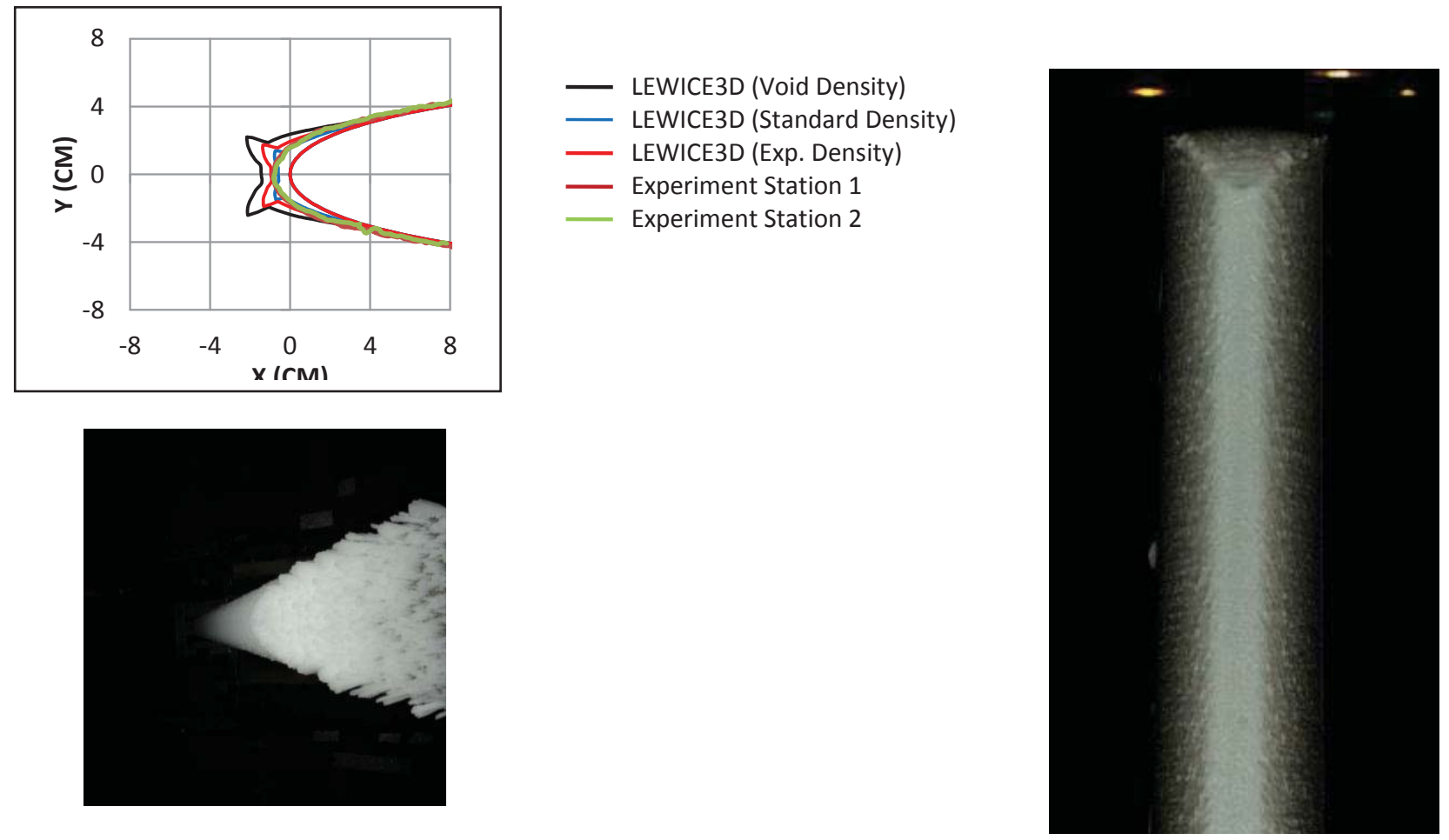

a) static temperature, $257 \mathrm{~K}$; icing time, 5 minutes
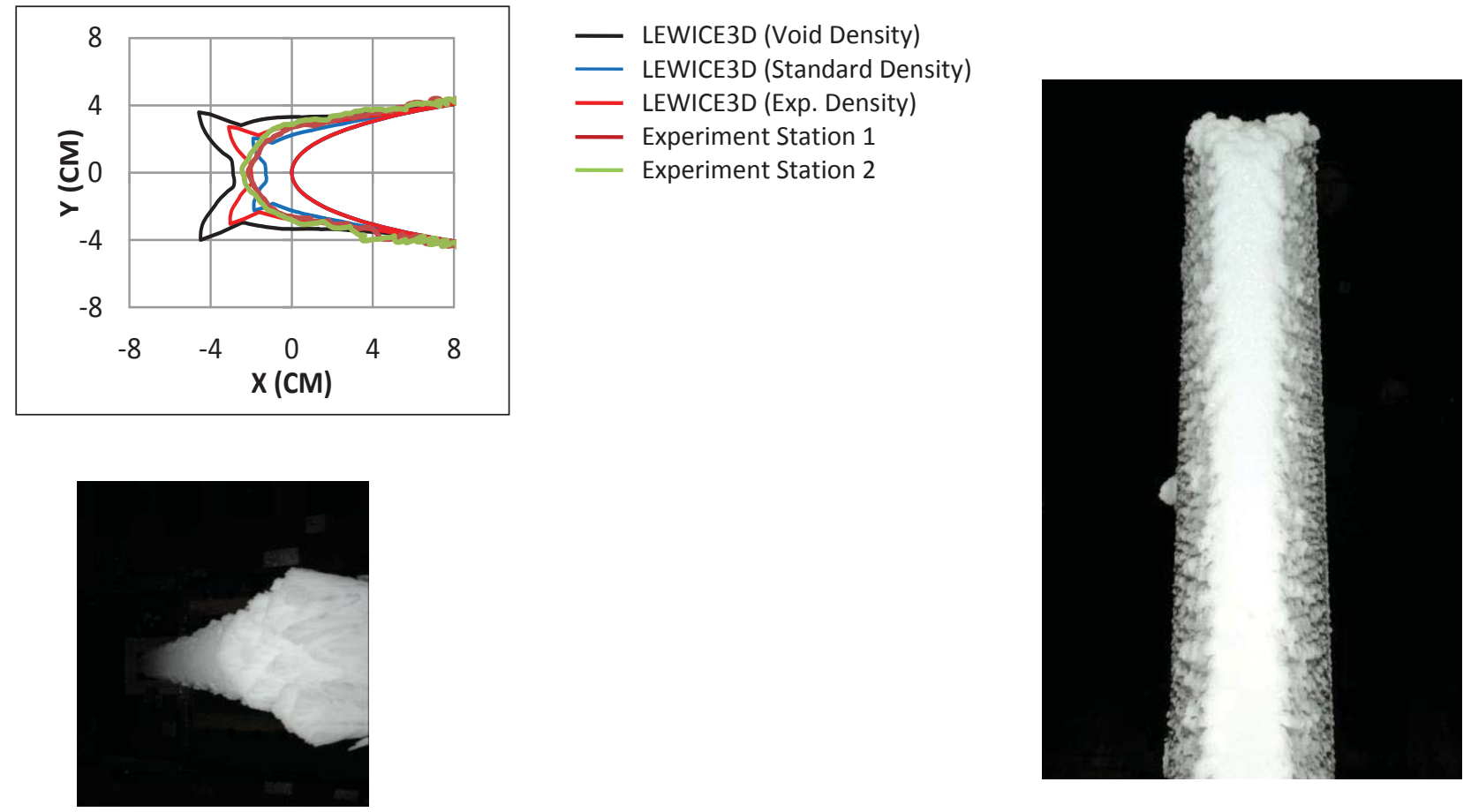

b) static temperature, $257 \mathrm{~K}$; icing time, 12 minutes

Figure 15. Ice shape comparisons for $30^{\circ}$ swept wing. Icing conditions: airspeed $103 \mathrm{~m} / \mathrm{s}$; liquid water content, $0.47 \mathrm{~g} / \mathrm{m}^{3}$; static pressure, $92321 \mathrm{~Pa}$; MVD, $32 \mu \mathrm{m}$. 

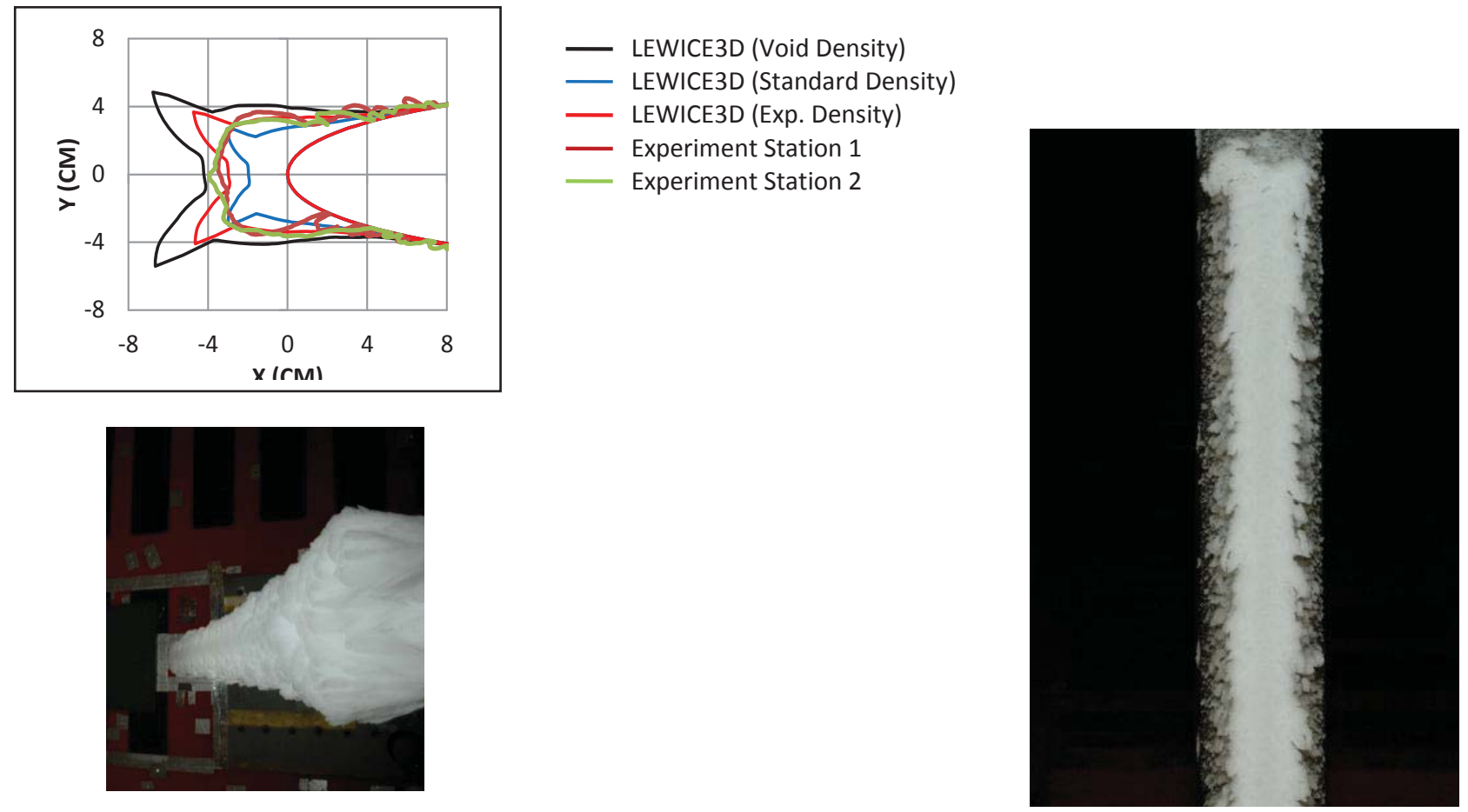

c) static temperature, $257 \mathrm{~K}$; icing time, 20 minutes
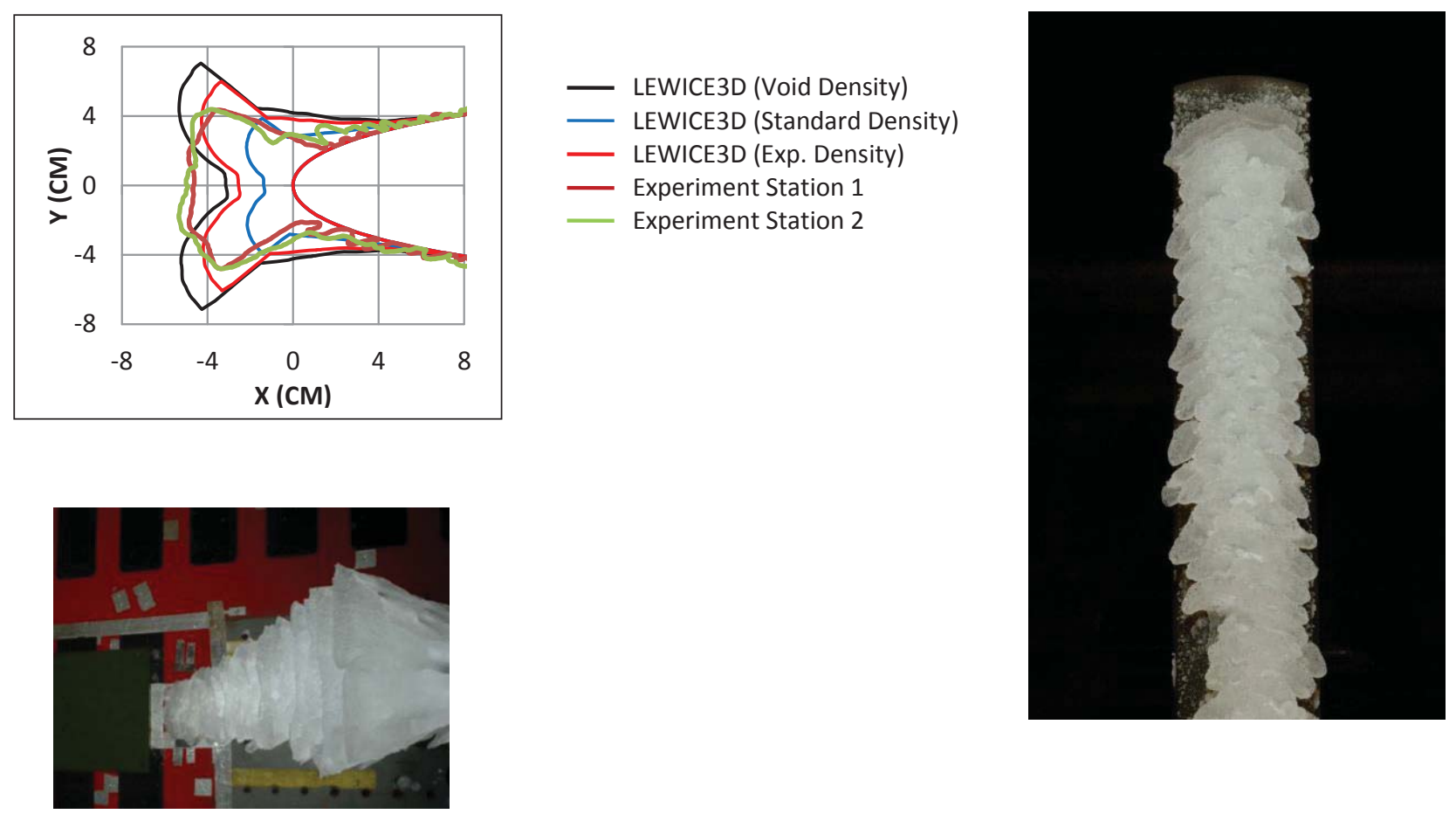

d) static temperature, $262 \mathrm{~K}$; icing time, 20 minutes

Figure 15. - Continued. Ice shape comparisons for $30^{\circ}$ swept wing. Icing conditions: airspeed $103 \mathrm{~m} / \mathrm{s}$; liquid water content, $0.47 \mathrm{~g} / \mathrm{m}^{3}$; static pressure, $92321 \mathrm{~Pa}$; MVD, $32 \mu \mathrm{m}$. 

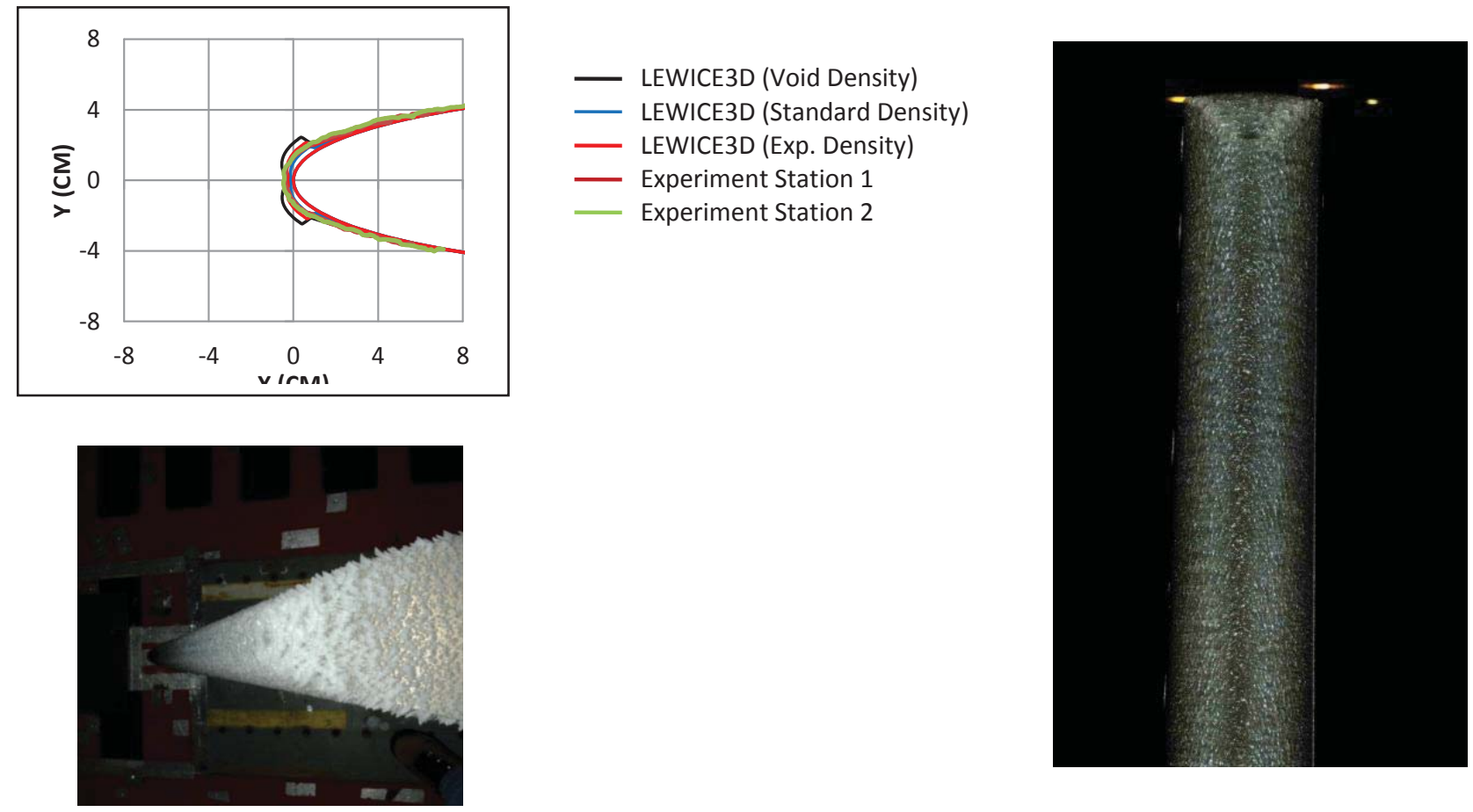

e) static temperature, $263 \mathrm{~K}$; icing time, 2 minutes
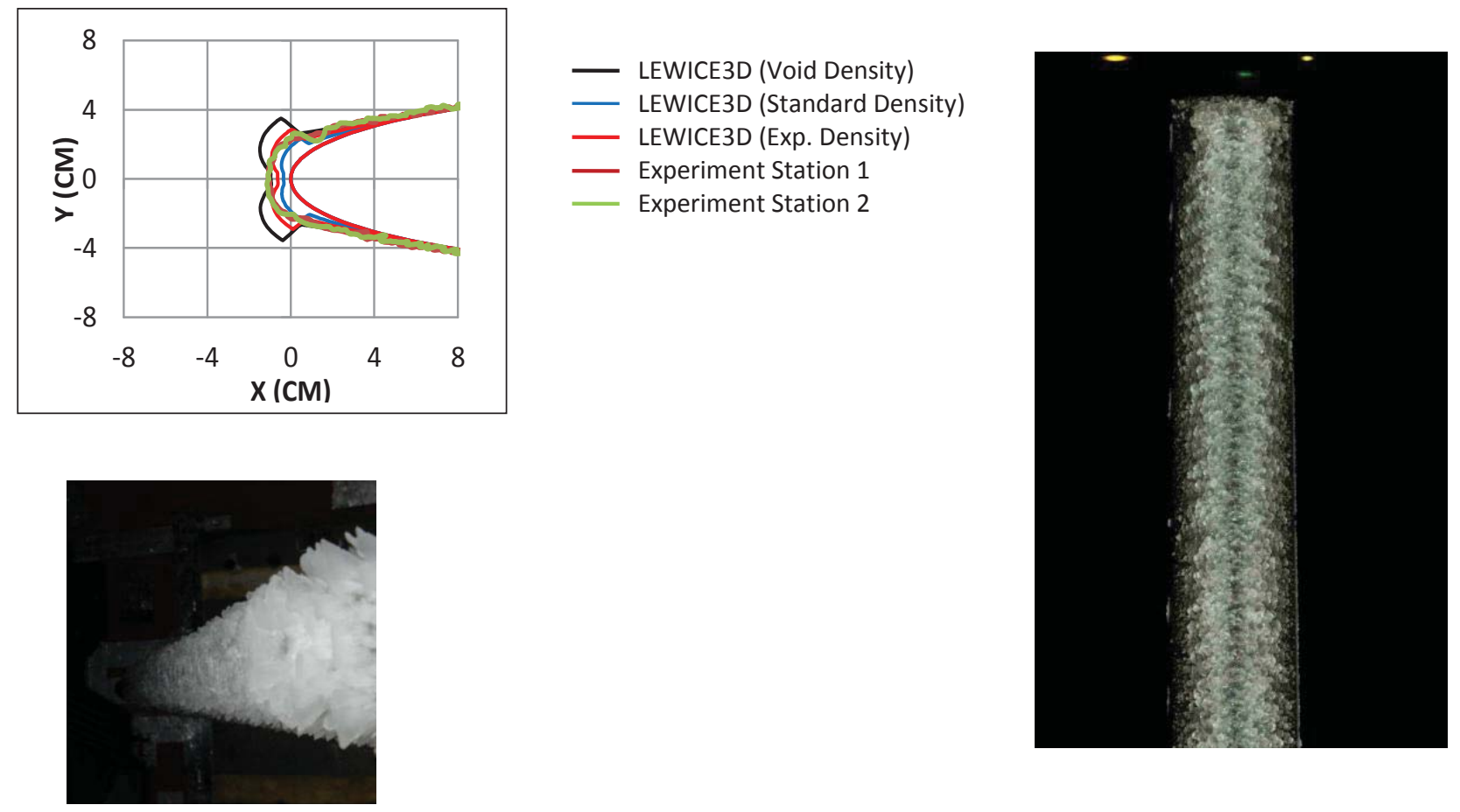

f) static temperature, $263 \mathrm{~K}$; icing time, 5 minutes

Figure 15. - Continued. Ice shape Comparisons for $30^{\circ}$ swept wing. Icing conditions: airspeed $103 \mathrm{~m} / \mathrm{s}$; liquid water content, $0.47 \mathrm{~g} / \mathrm{m}^{3}$; static pressure, $92321 \mathrm{~Pa}$; MVD, $32 \mu \mathrm{m}$. 

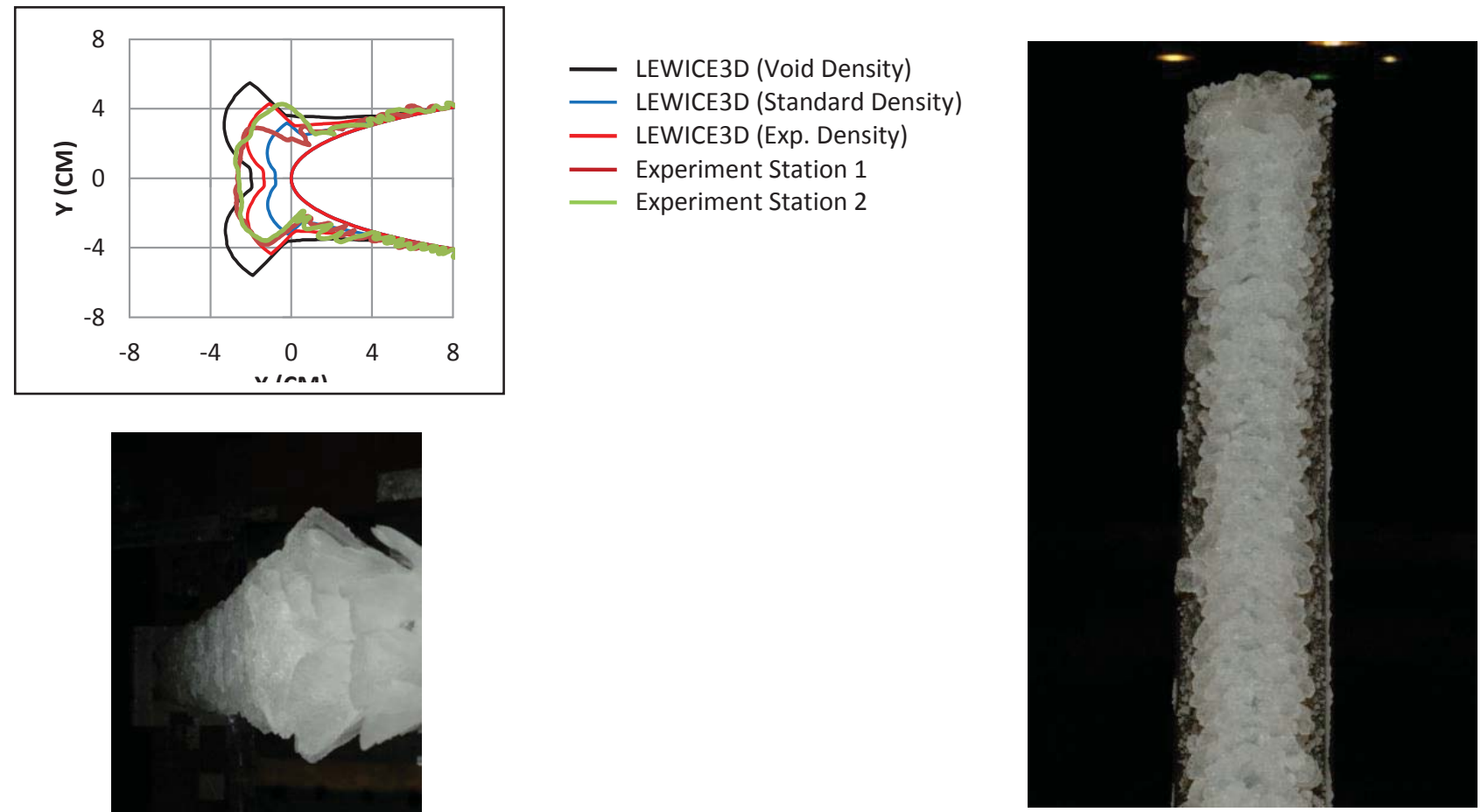

g) static temperature, $263 \mathrm{~K}$; icing time, 12 minutes
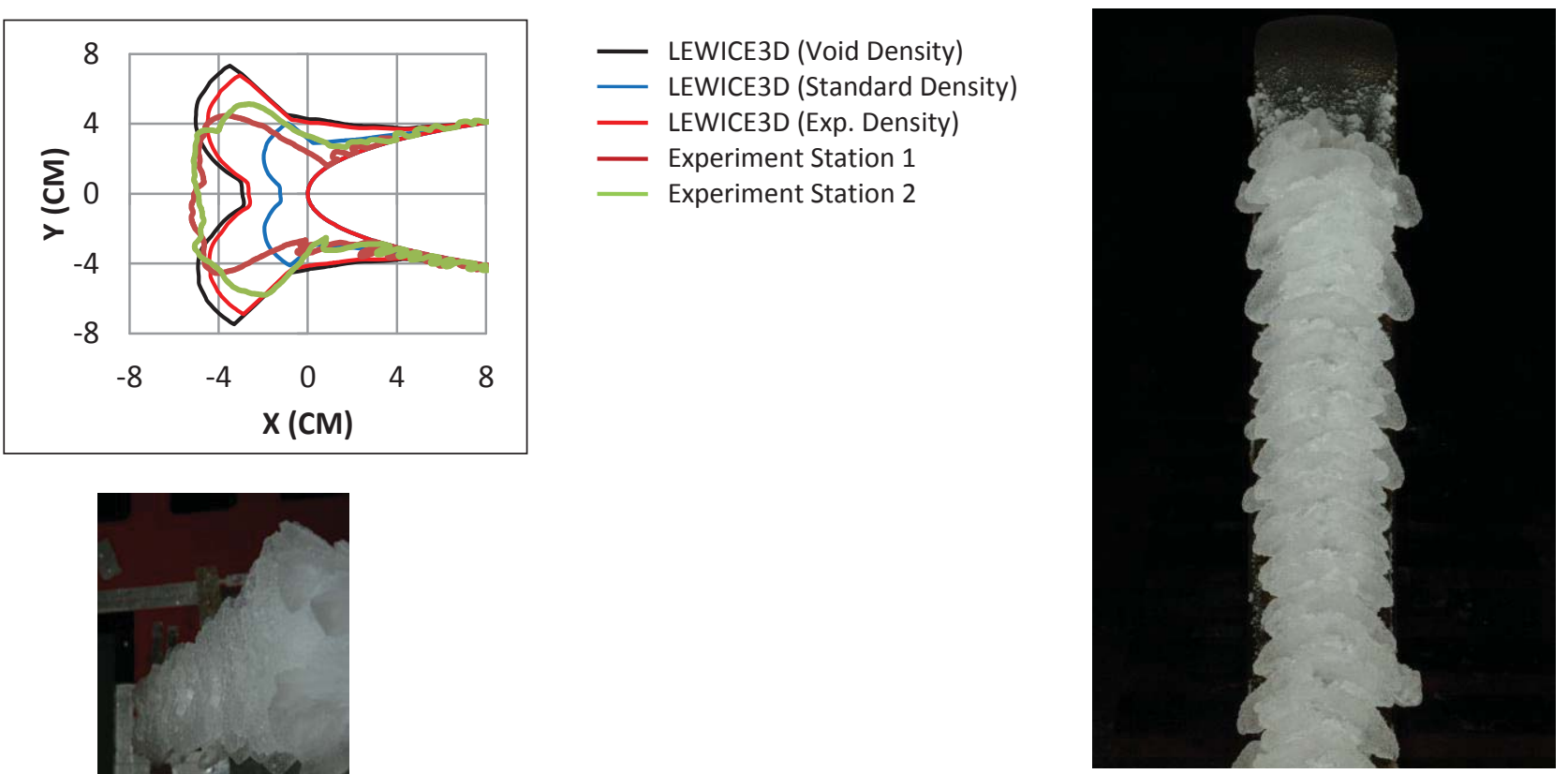

h) static temperature, $263 \mathrm{~K}$; icing time, 20 minutes

Figure 15. - Continued. Ice shape comparisons for $30^{\circ}$ swept wing. Icing conditions: airspeed $103 \mathrm{~m} / \mathrm{s}$; liquid water content, $0.47 \mathrm{~g} / \mathrm{m}^{3}$; static pressure, $92321 \mathrm{~Pa}$; MVD, $32 \mu \mathrm{m}$. 


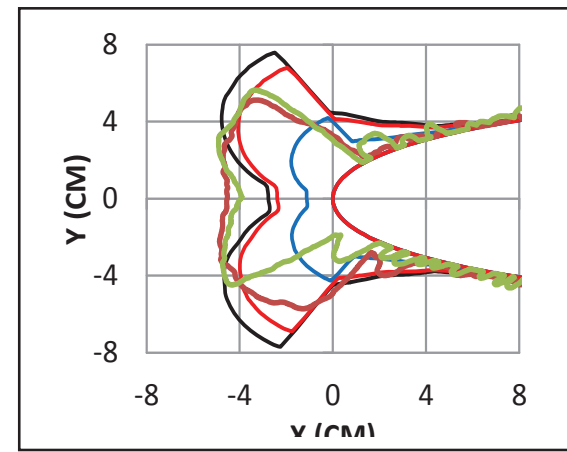

— LEWICE3D (Void Density)

— LEWICE3D (Standard Density)

— LEWICE3D (Exp. Density)

- Experiment Station 1

- Experiment Station 2
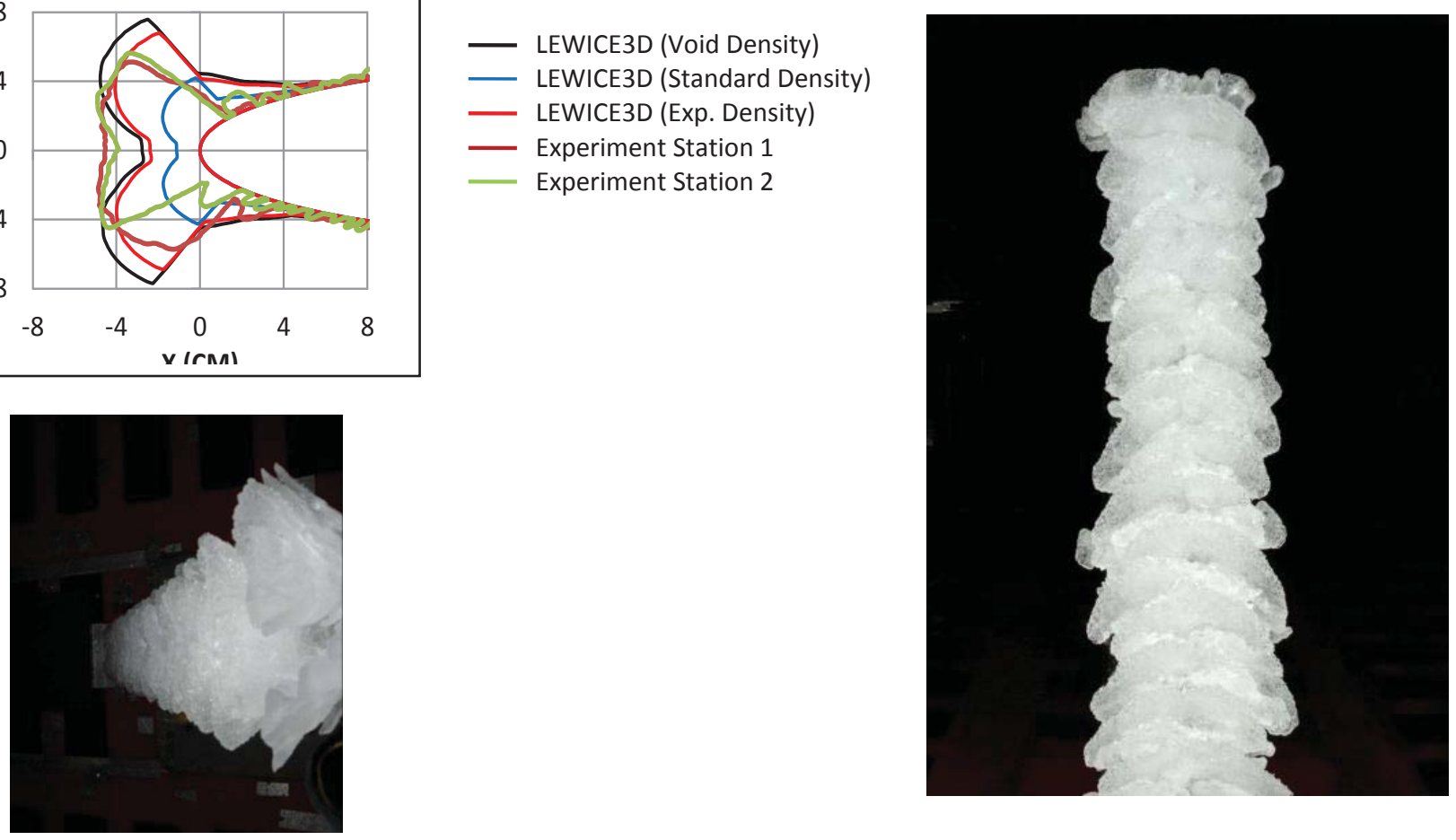

i) static temperature, $264 \mathrm{~K}$; icing time, 20 minutes
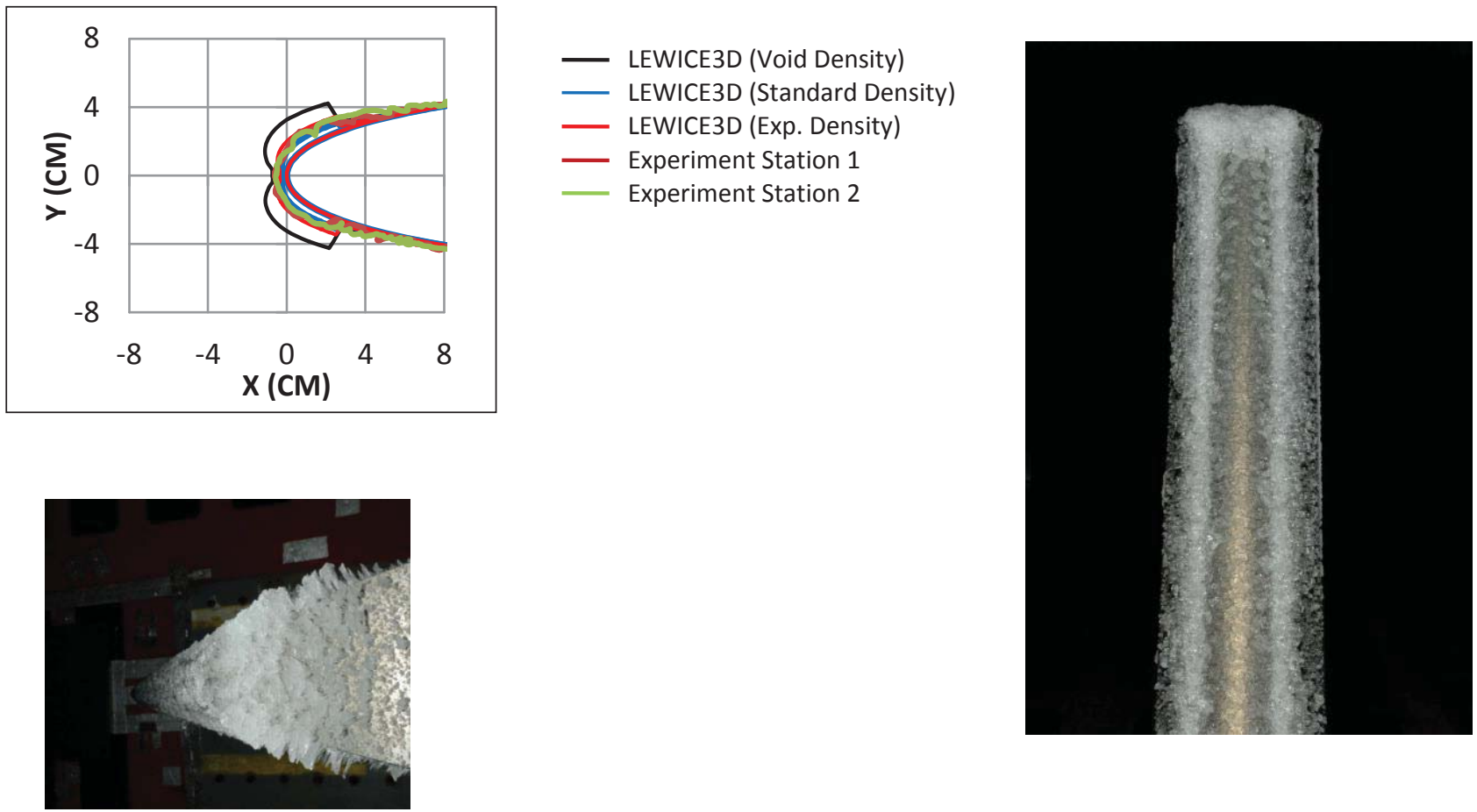

j) static temperature, $266 \mathrm{~K}$; icing time, 5 minutes

Figure 15. - Continued. Ice shape comparisons for $30^{\circ}$ swept wing. Icing conditions: airspeed $103 \mathrm{~m} / \mathrm{s}$; liquid water content, $0.47 \mathrm{~g} / \mathrm{m}^{3}$; static pressure, $92321 \mathrm{~Pa}$; MVD, $32 \mu \mathrm{m}$. 


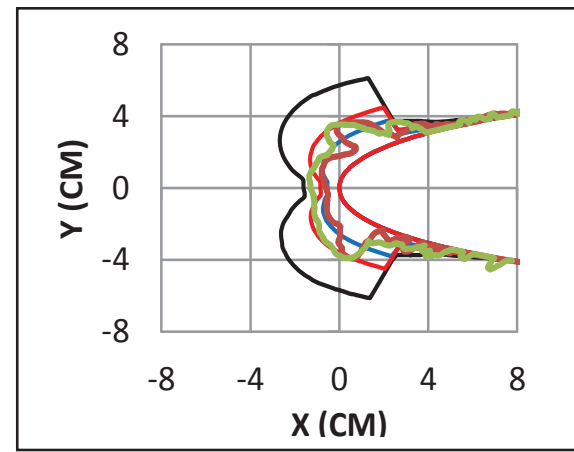

— LEWICE3D (Void Density)

— LEWICE3D (Standard Density)

— LEWICE3D (Exp. Density)

- Experiment Station 1

Experiment Station 2
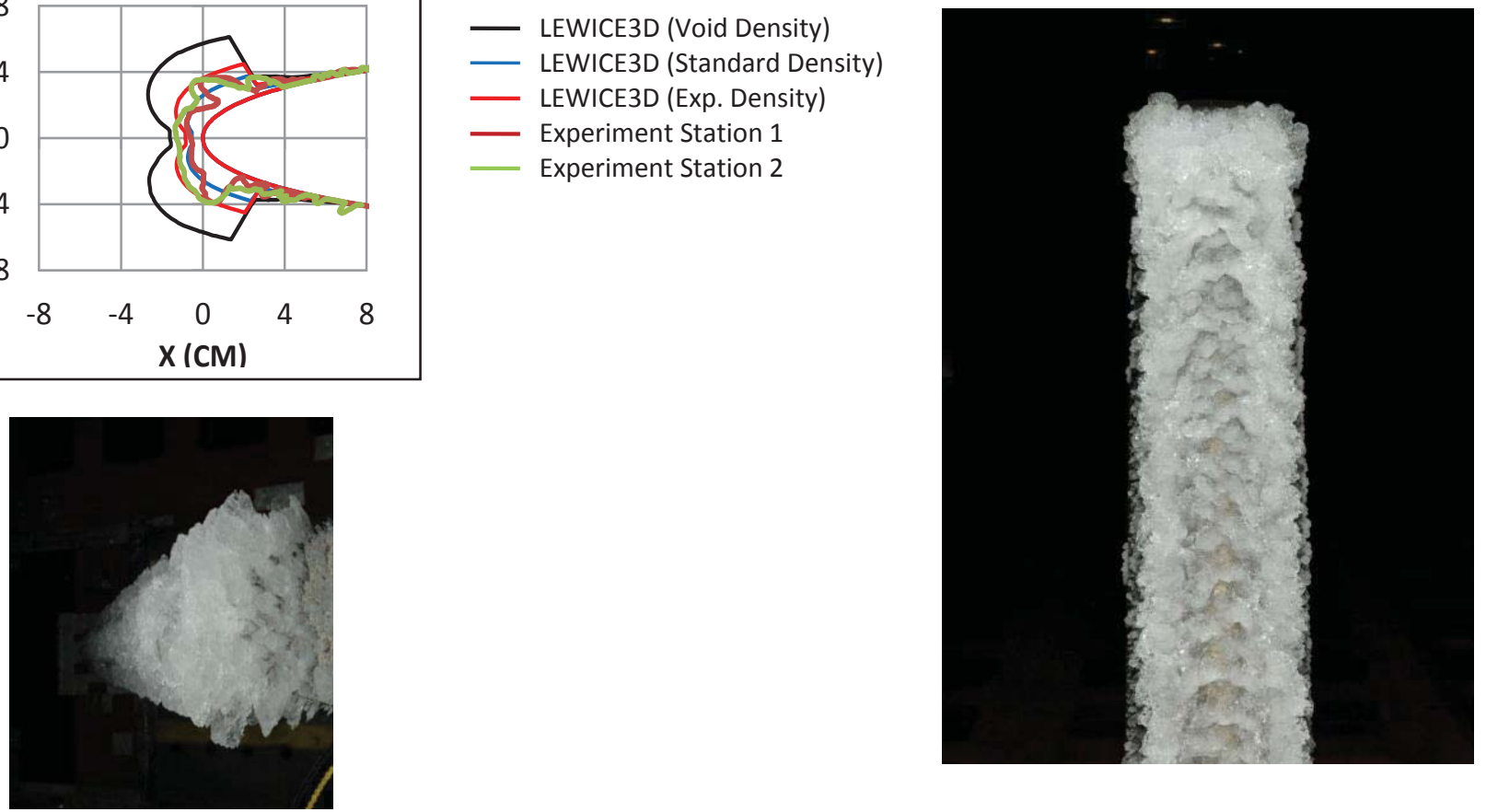

k) static temperature, $266 \mathrm{~K}$; icing time, 12 minutes
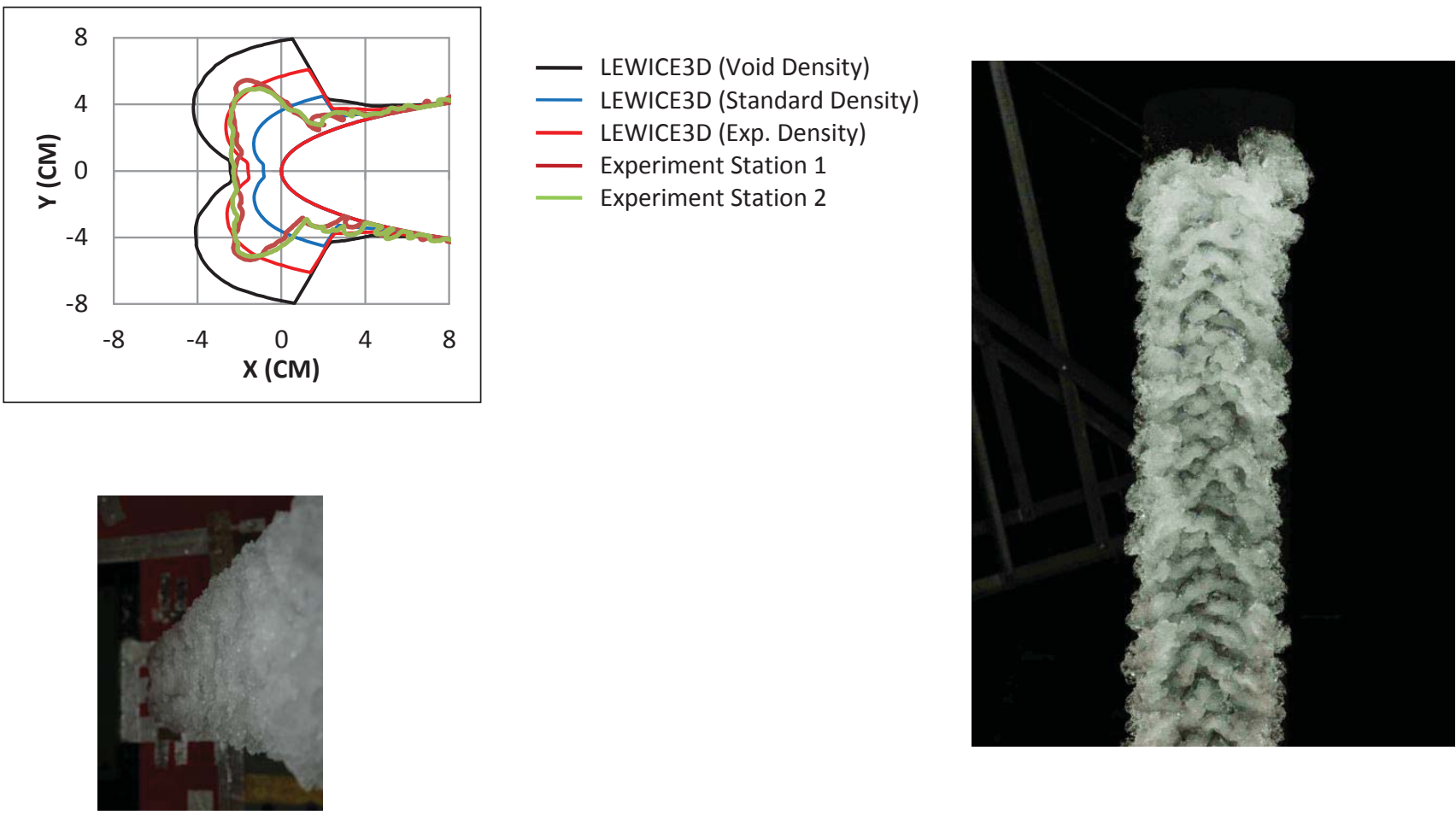

l) static temperature, $266 \mathrm{~K}$; icing time, 20 minutes

Figure 15. - Concluded. Ice shape comparisons for $30^{\circ}$ swept wing. Icing conditions: airspeed $103 \mathrm{~m} / \mathrm{s}$; liquid water content, $0.47 \mathrm{~g} / \mathrm{m}^{3}$; static pressure, $92321 \mathrm{~Pa}$; MVD, $32 \mu \mathrm{m}$. 


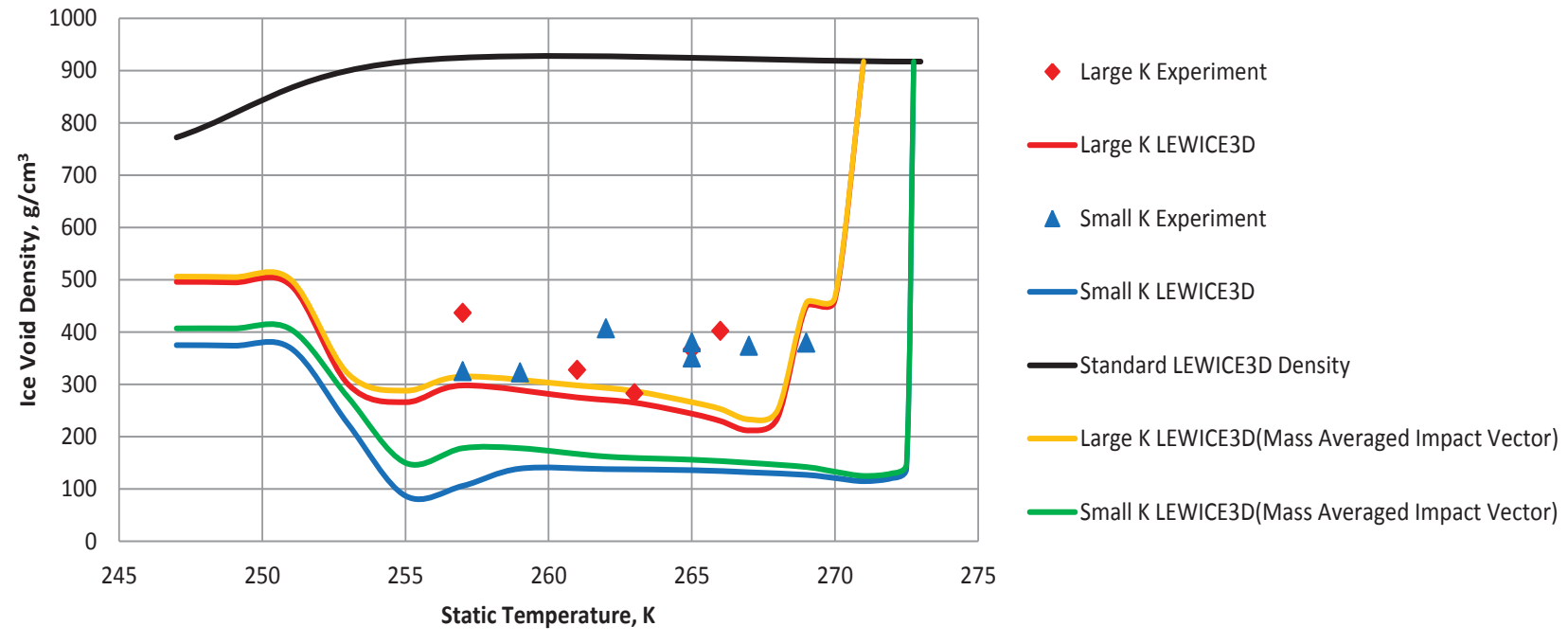

Figure 16. Ice shape void density comparisons for $45^{\circ}$ swept wing.

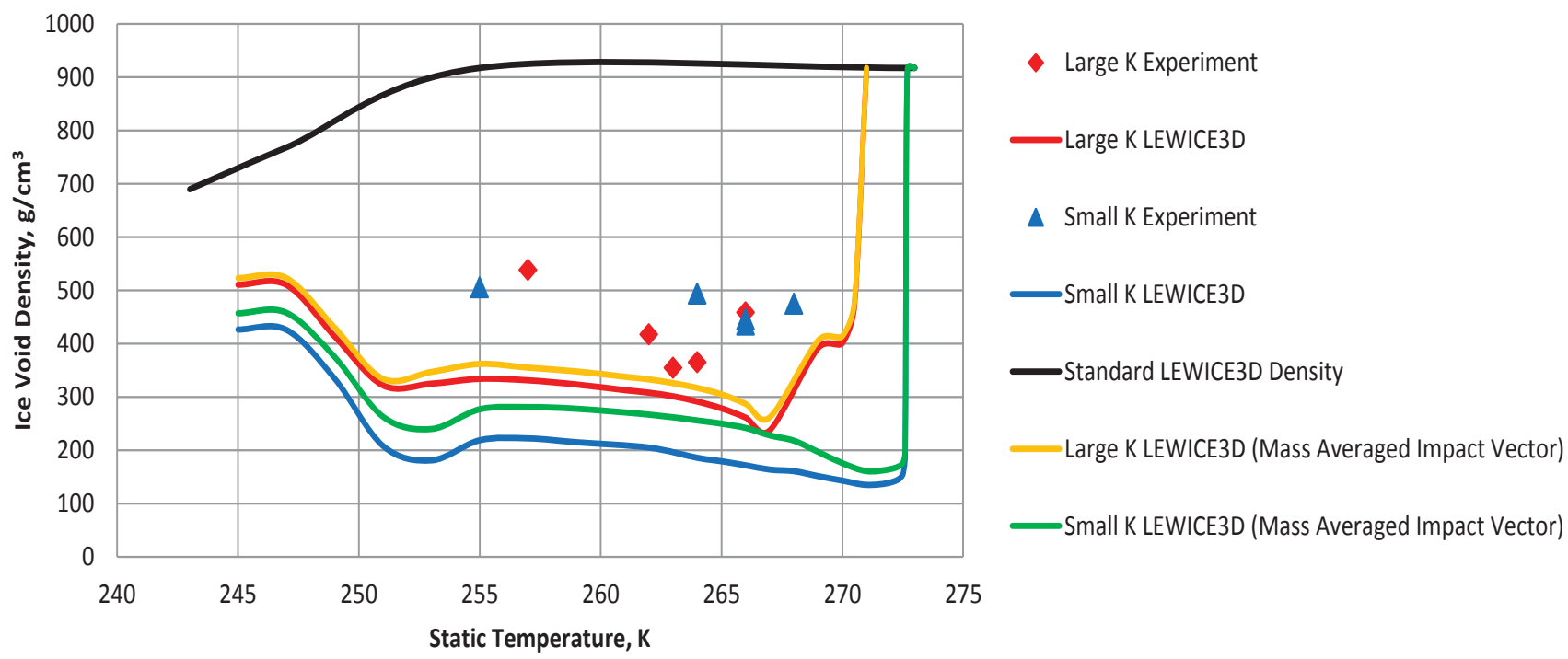

Figure 17. Ice shape void density comparisons for $30^{\circ}$ swept wing.

American Institute of Aeronautics and Astronautics 


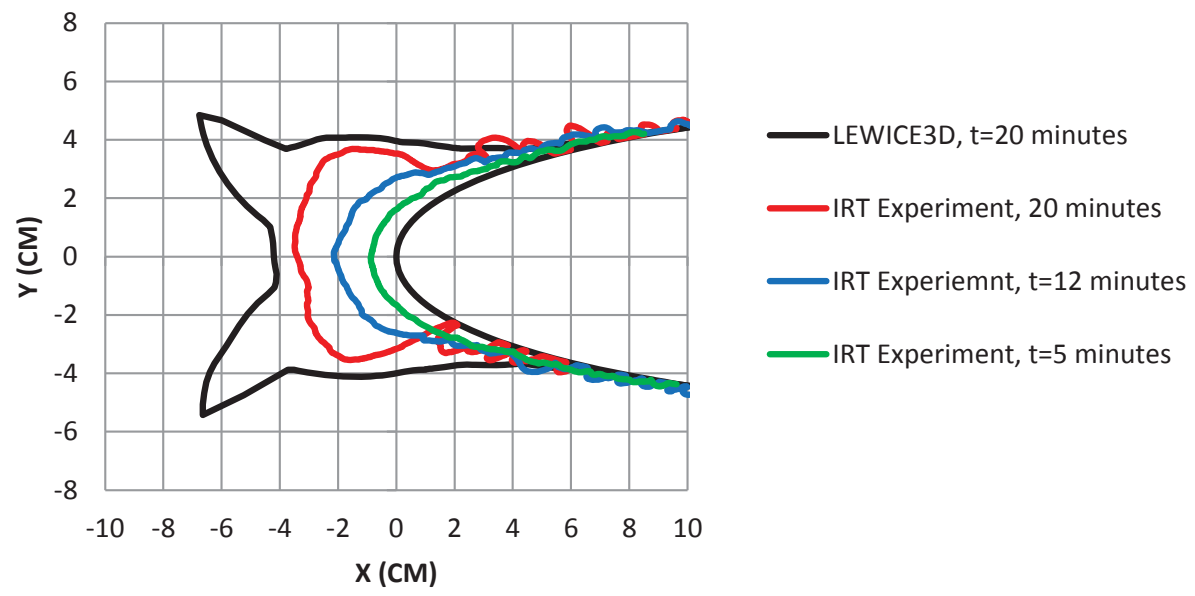

a) static temperature, $257 \mathrm{~K}$

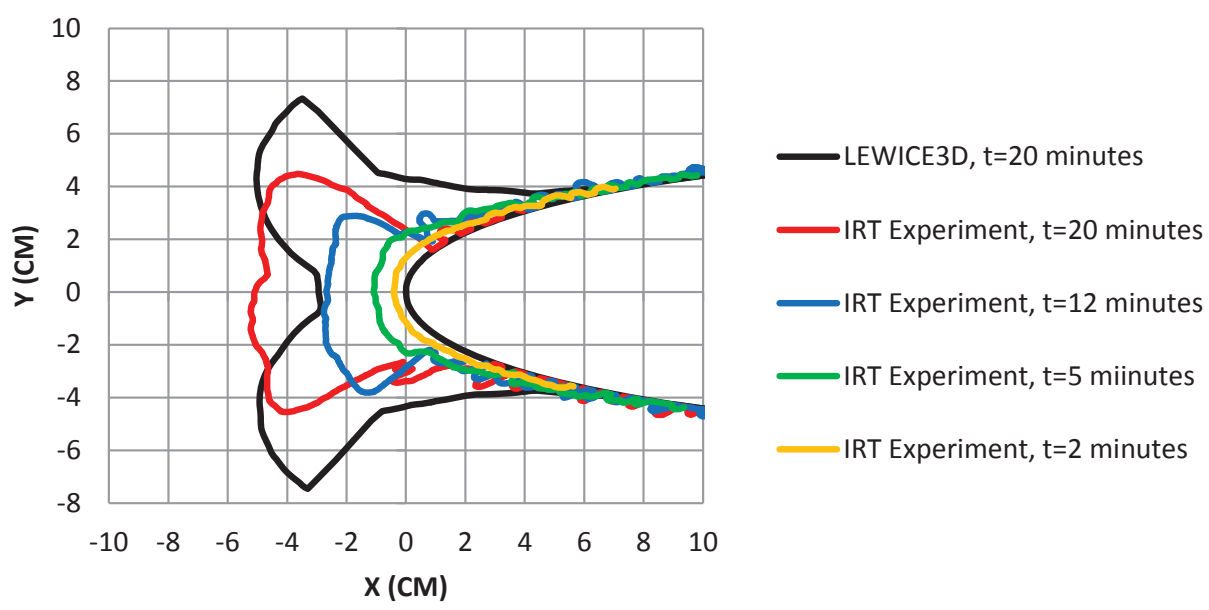

b) static temperature, $263 \mathrm{~K}$

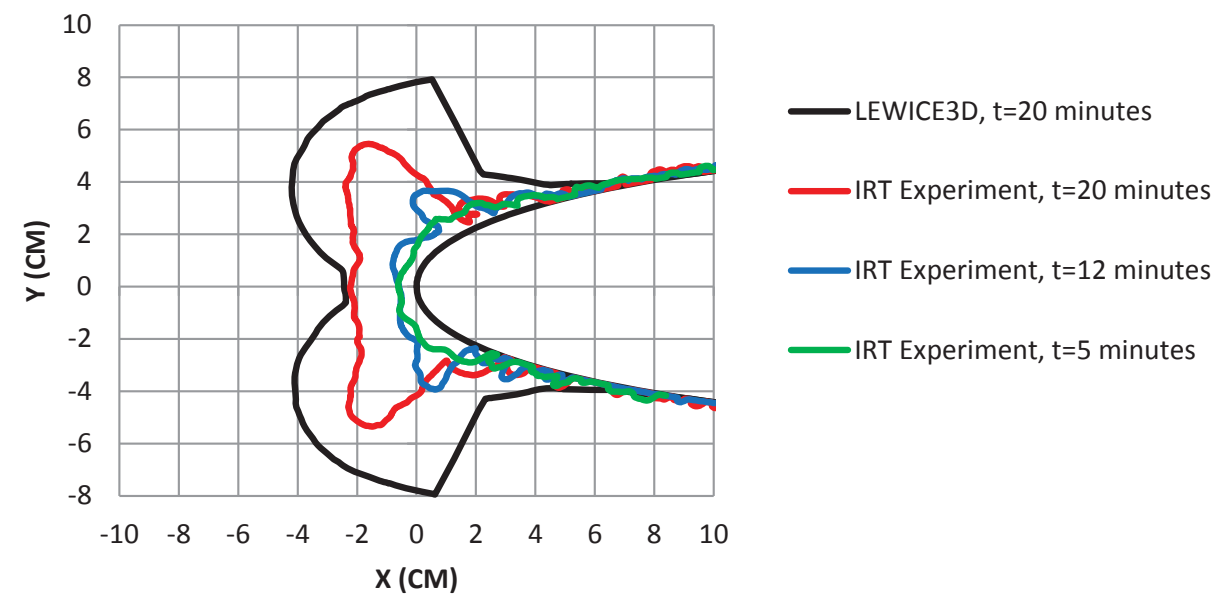

c) static temperature, $266 \mathrm{~K}$

Figure 18. Ice shape comparisons for $30^{\circ}$ swept wing. Icing conditions: airspeed $103 \mathrm{~m} / \mathrm{s}$; liquid water content, $0.47 \mathrm{~g} / \mathrm{m}^{3}$; static pressure, $92321 \mathrm{~Pa}$; MVD, $32 \mu \mathrm{m}$. 


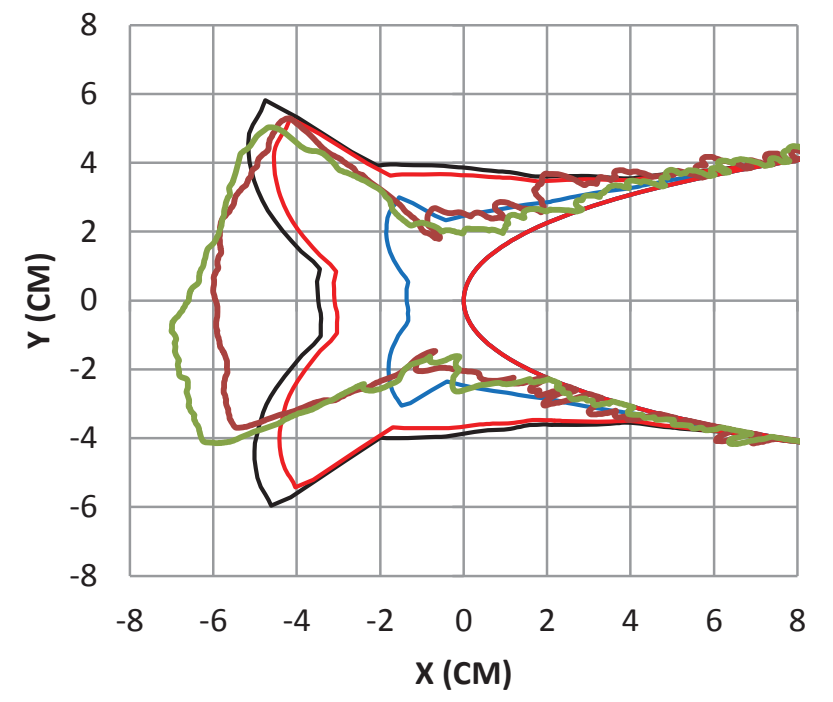

— LEWICE3D (Void Density)

— LEWICE3D (Standard Density)

— LEWICE3D (Exp. Density)

IIRT Experiment

IRT Experiment, CL-8
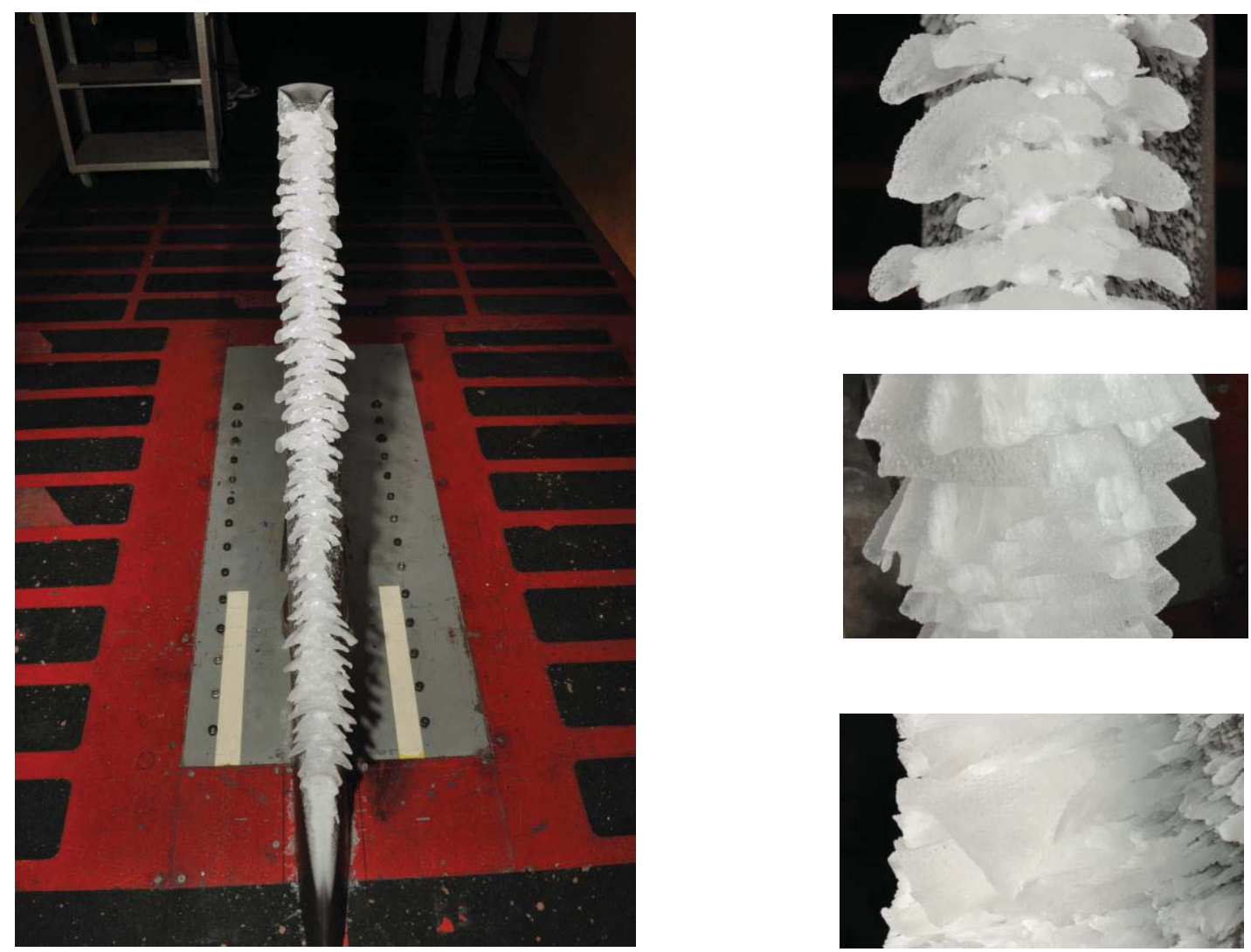

Figure 19. Ice shape for $45^{\circ}$ swept wing. Icing conditions: airspeed $103 \mathrm{~m} / \mathrm{s}$; icing time 20 minutes; liquid water content, $0.45 \mathrm{~g} / \mathrm{m}^{3}$; static temperature, $261 \mathrm{~K}$, static pressure, $94463 \mathrm{~Pa}$; MVD, $32 \mu \mathrm{m}$. 


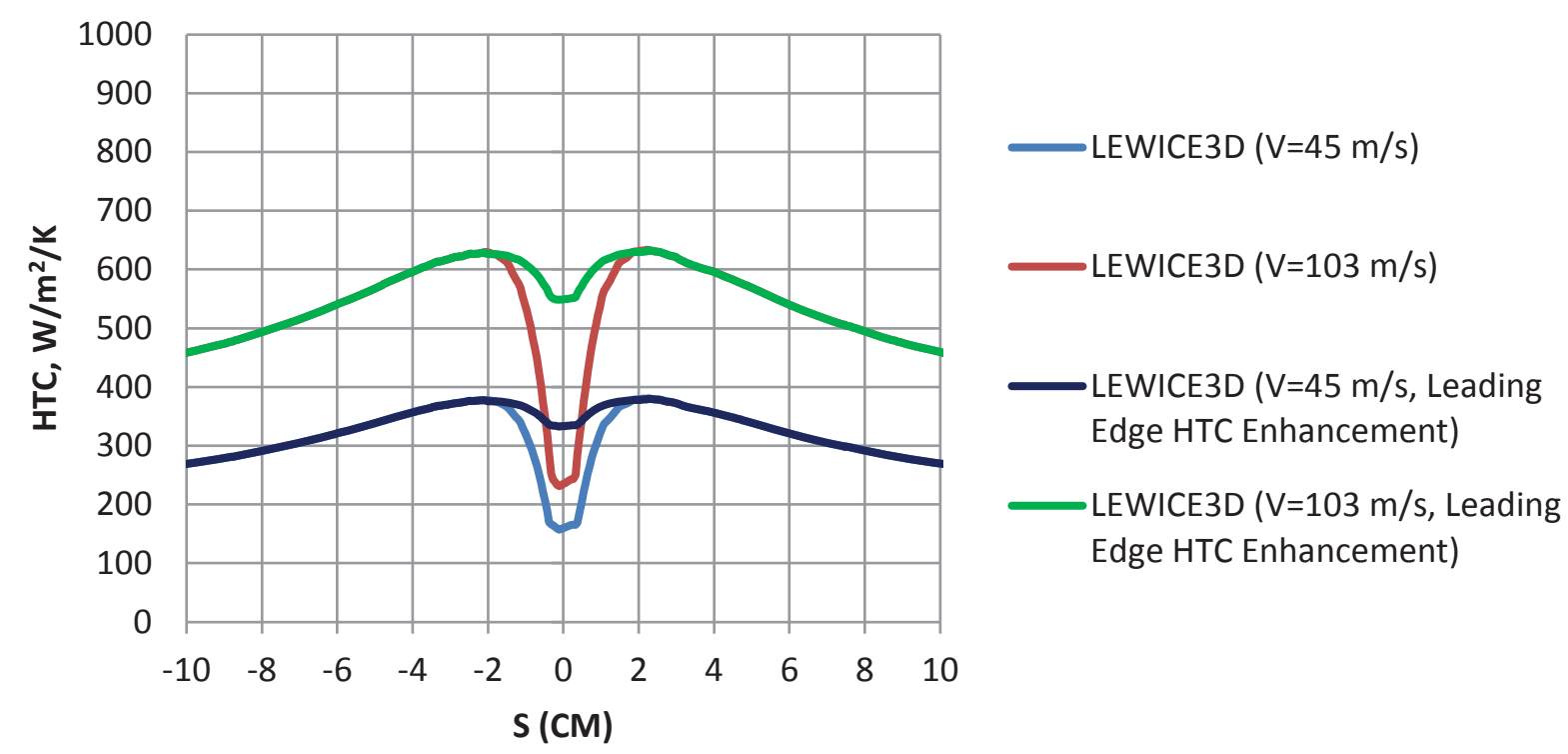

Figure 20. Heat transfer coefficient distributions for $45^{\circ}$ swept wing.

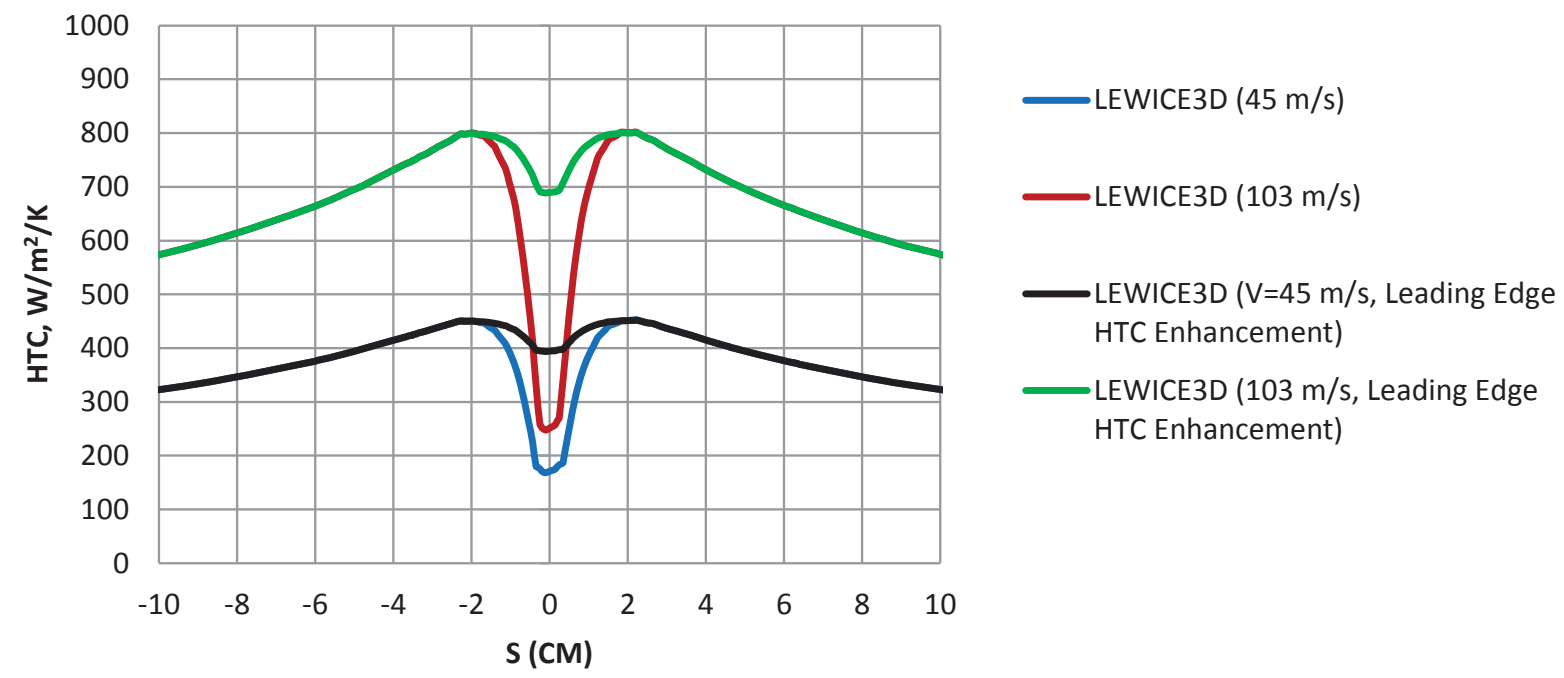

Figure 21. Heat transfer coefficient distributions for $30^{\circ}$ swept wing. 


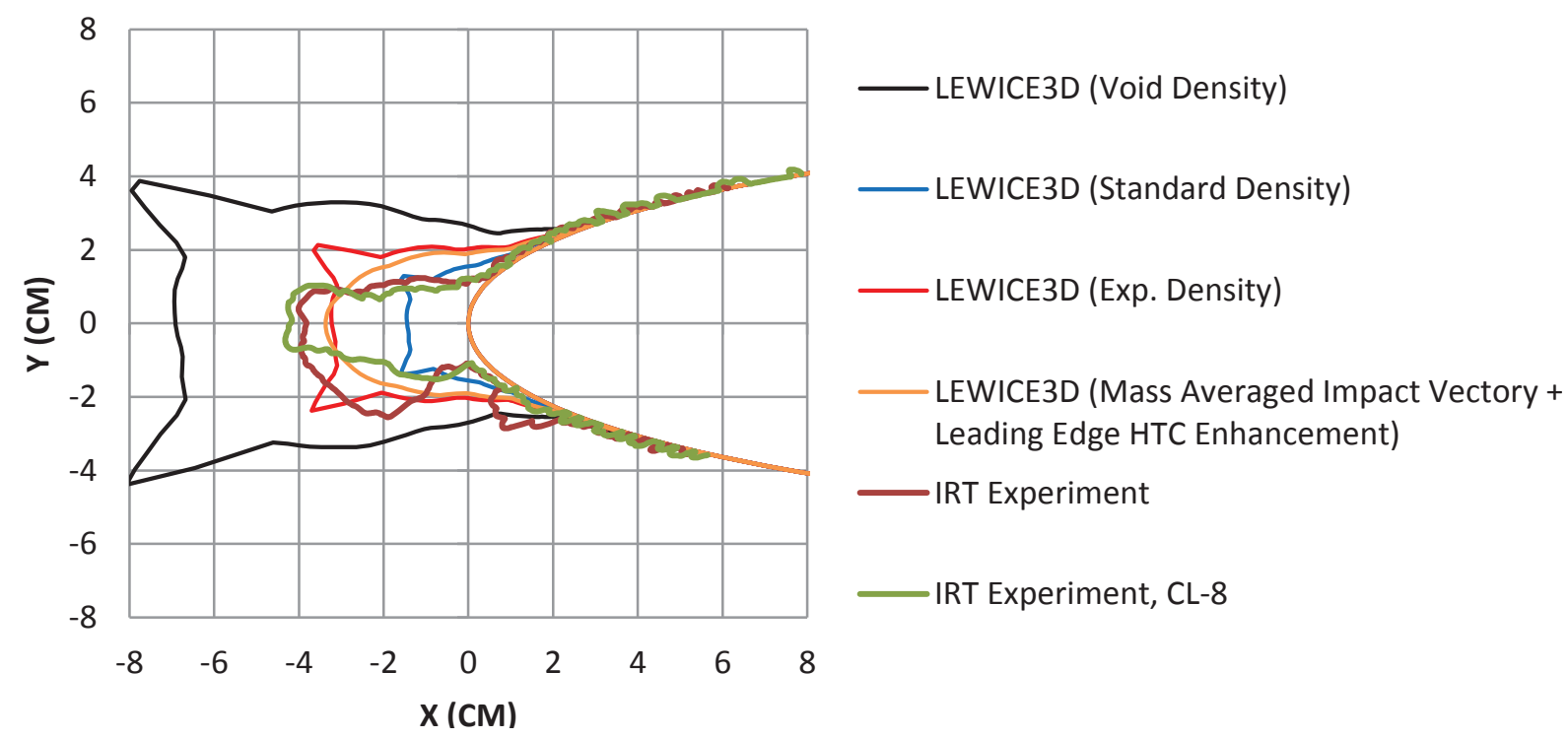

Figure 22. Ice shape comparisons for $45^{\circ}$ swept wing. Icing conditions: airspeed $45 \mathrm{~m} / \mathrm{s}$; icing time 20 minutes; liquid water content, $1.5 \mathrm{~g} / \mathrm{m}^{3}$; static temperature, $257 \mathrm{~K}$, static pressure, $99981 \mathrm{~Pa}$; MVD, $15 \mu \mathrm{m}$.

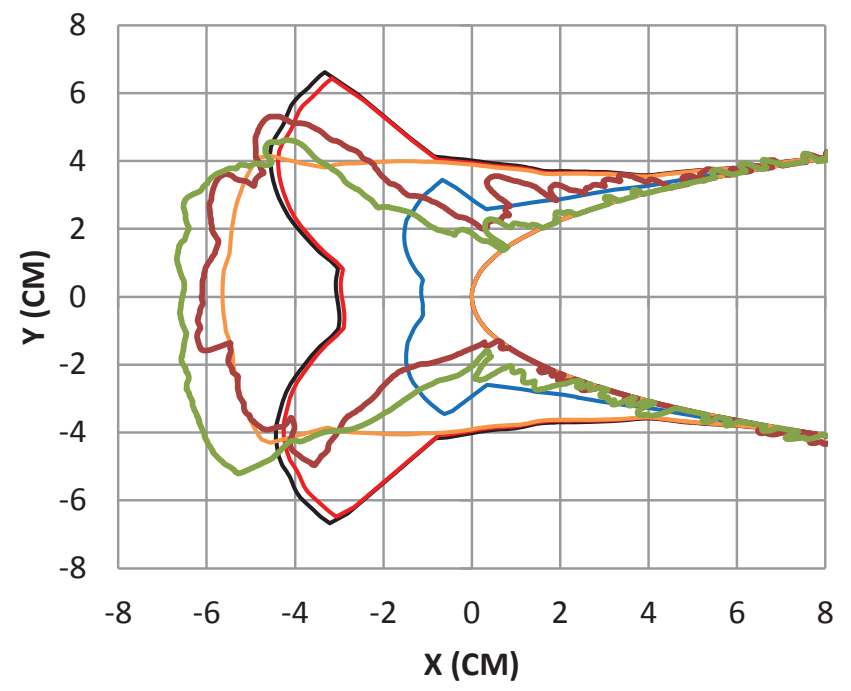

— LEWICE3D (Void Density)

— LEWICE3D (Standard Density)

— LEWICE3D (Exp. Density)

- LEWICE3D (Mass Averaged Impact Vector + Leading Edge HTC Enhancement)

—IRT Experiment

_IRT Experiment, CL-8

Figure 23. Ice shape comparisons for $45^{\circ}$ swept wing. Icing conditions: airspeed $103 \mathrm{~m} / \mathrm{s}$; icing time 20 minutes; liquid water content, $0.45 \mathrm{~g} / \mathrm{m}^{3}$; static temperature, $263 \mathrm{~K}$, static pressure, $94463 \mathrm{~Pa}$; MVD, $32 \mu \mathrm{m}$. 


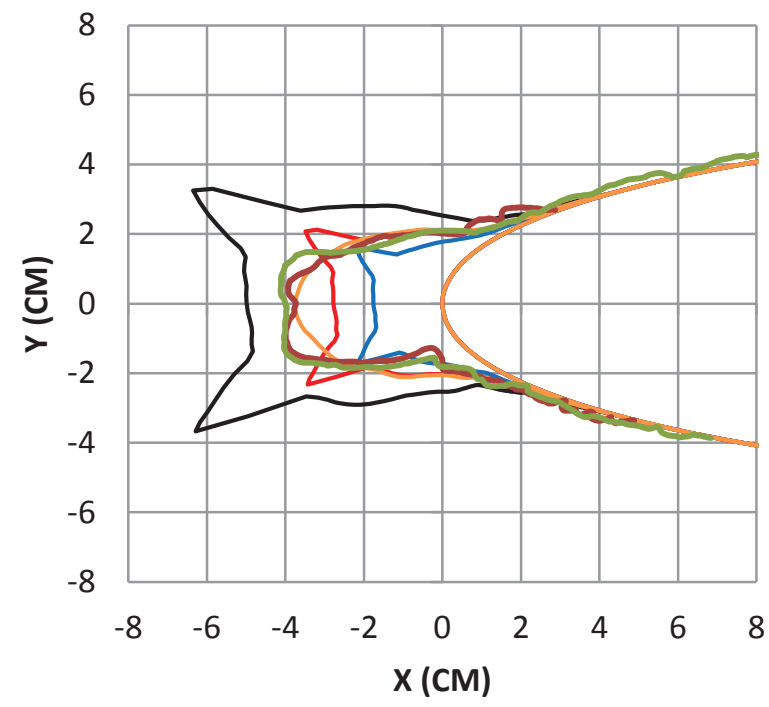

— LEWICE3D (Void Density)

_ LEWICE3D (Standard Density)

LEWICE3D (Exp. Density)

- LEWICE3D (Mass Averaged Impact Vector + Leading Edge HTC Enhancement)

IRT Experiment

IRT Experiment, $\mathrm{CL}-8$

Figure 24. Ice shape comparisons for $30^{\circ}$ swept wing. Icing conditions: airspeed 45 m/s; icing time 20 minutes; liquid water content, $1.5 \mathrm{~g} / \mathrm{m}^{3}$; static temperature, $255 \mathrm{~K}$, static pressure, $97491 \mathrm{~Pa}$; MVD, $15 \mu \mathrm{m}$.

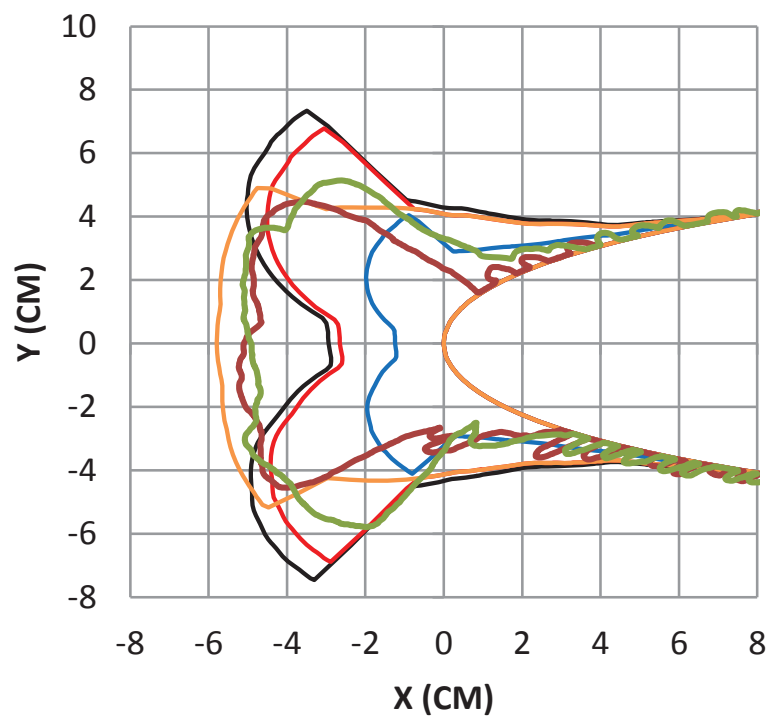

— LEWICE3D (Void Density)

— LEWICE3D (Standard Density)

— LEWICE3D (Exp. Density)

- LEWICE3D (Mass Averaged Impact Vector + Leading Edge HTC Enhancement)

IRT Experiment

IRT Experiment, $\mathrm{CL}-8$

Figure 25. Ice shape comparisons for $30^{\circ}$ swept wing. Icing conditions: airspeed $103 \mathrm{~m} / \mathrm{s}$; icing time 20 minutes; liquid water content, $0.47 \mathrm{~g} / \mathrm{m}^{3}$; static temperature, $263 \mathrm{~K}$, static pressure, $94463 \mathrm{~Pa}$; MVD, $32 \mu \mathrm{m}$. 


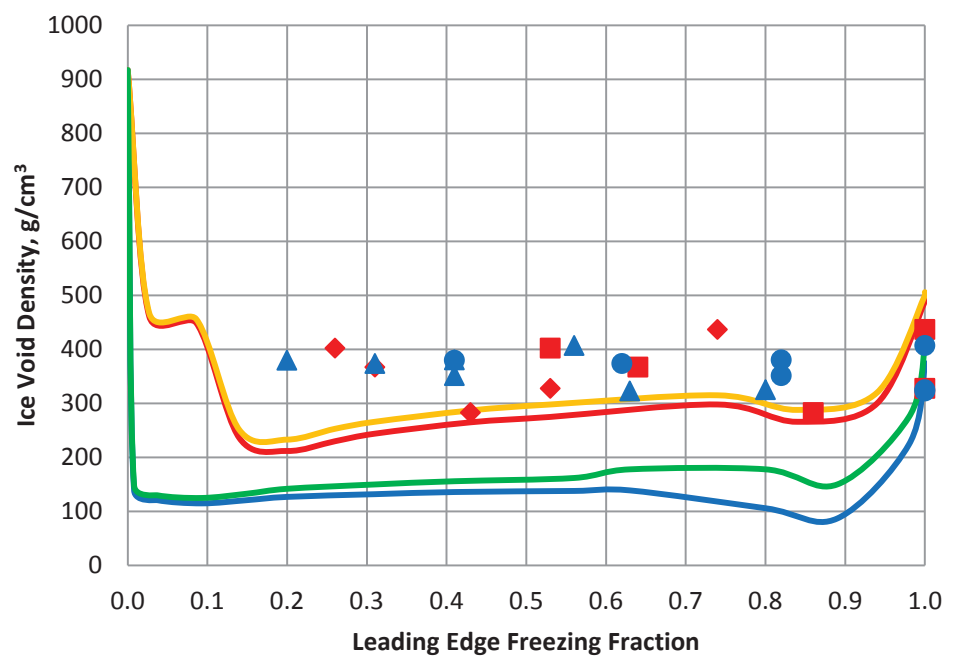

- Large K Experiment

Large K LEWICE3D

Small K Experiment

Small K LEWICE3D

Large K LEWICE3D(Mass Averaged Impact Vector)

Small K LEWICE3D(Mass Averaged Impact Vector)

- Large K Experiment (Leading Edge Freezing Fraction Based on Leading Edge HTC Enhancement)

- Small K Experiment (Leading Edge Freezing Fraction Based on Leading Edge HTC Enhancement)

Figure 26. Ice shape void density comparisons for $45^{\circ}$ swept wing.

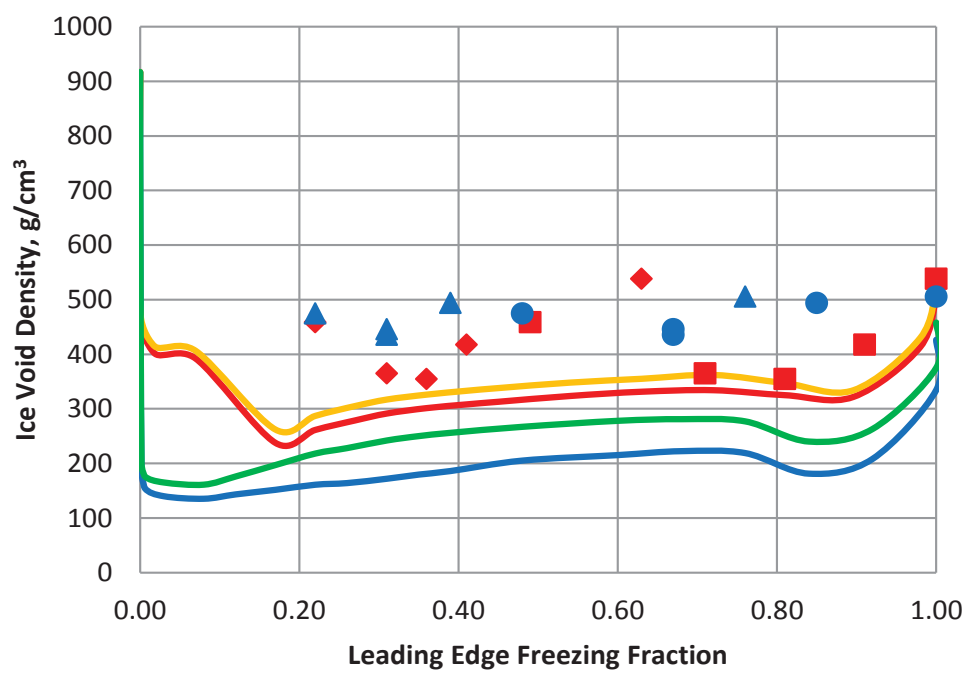

- Large K Experiment Large K LEWICE3D

$\Delta$ Small K Experiment

- Small K LEWICE3D

Large K LEWICE3D (Mass Averaged Impact Vector)

Small K LEWICE3D (Mass Averaged Impact Vector)

- Large K Experiment (Leading Edge Freezing Fraction Based on Leading Edge HTC Enhancement)

- Small K (Leading Edge Freezing Fraction Based on Leading Edge HTC Enhancement)

Figure 27. Ice shape void density comparisons for $30^{\circ}$ swept wing.

American Institute of Aeronautics and Astronautics 